\title{
Chord Language:Chord Painting Legend
}

\author{
ISBN: 9780463058800
}

Li Xiaohong

Smashwords Edition, License Notes

Thank you for downloading this ebook. This book remains the copyrighted property of the author, and may not be redistributed to others for commercial or non-commercial purposes.If you enjoyed this book, please encourage your friends to download their own copy from their favorite authorized retailer.Thank you for your support.

The text and chord paintings in this article were created by Li Xiaohong and have full copyright.

About the author: Li Xiaohong (1956-), male, Chinese, Sichuan, lecturer of Yibin Normal School, lecturer of Yibin Cultural Center, engaged in chord language, chord painting, chord time and space research, artistic creation. He has written books such as "chord language - chord time and space and chord painting". He has read related papers at the 24th World Philosophy Conference (2018, Beijing): "Chord time-space", "spiritual chords".

ORCID: https://orcid.org/0000-0001-6461-1239 


\section{Foreword}

Music, painting is the chord language phenomenon, and also the main observation basis of chord language. Understanding chord language is the premise of understanding music and painting.

This book is a chord language-chord painting visual experiment legend, including: Diationic Scale, jazz scale, tonality, atonality, transposition, etc., is the original experimental data, graphic data of chord language, chord painting, chord space, can Completely present the overall framework and structure of the chord space language. For chord language, chord painting learning, researchers have reference, auxiliary value.

For the theoretical part of grammar, semantics, and constitutive rules for chord painting, see the book Chord Language (ISBN: 9871370273348).

The observation of chord language is a long-term process, and we will continue to update the legend as the observation progresses.

The visual experiment legend of this book is made by mixed media. The tools used are: colored pencils, watercolors, oil paintings, computers, etc.

\section{Review, chord language and theory of everything}

Chord language is the natural (physical, mathematical) coding language of time-space and life. In chord language, music, painting, life, physics and other disciplines are interdependent and cannot be cut. They can be expressed in chord mathematics, which is like the theory of all things.

Chord language is often expressed in the disciplines of music, painting, and meridian (the theory of oriental ancient medicine), which produce semantic expressions such as time, space, life, and spirit. The basic features are: quantized discrete spectrum, chord geometric semantics (open string, closed string, membrane string), which is a time-space, life coding language with physical and mathematical forms. Here is a question that cannot be avoided: quantum, string theory in music, painting?

Music and painting are the most common chord language phenomena. In chord mathematics, the two are reverse-mirror relations, respectively expressing: time and space. Can directly present the nature and relationship of time-space.

Chord language is not only a spiritual phenomenon (music, painting), but also a physical phenomenon (discrete spectrum, string), observing chord language events, such as: music, painting, etc. - also observing physical events, it has spiritual-natural isomorphism, This is its philosophical significance.

The chord language is an ancient knowledge system, and its mathematical model can be traced back to the Pythagorean law of ancient Greece, gradually perfected by musicians of all ages. The chord geometry can be observed in chord painting: open string, closed string, Membrane string, which is predicted by string theory. Meridian (Oriental Ancient Medicine) observes the positive-negative (yin-yang) coding rules of chord language: they form the basis for observation and verification of chord language. 


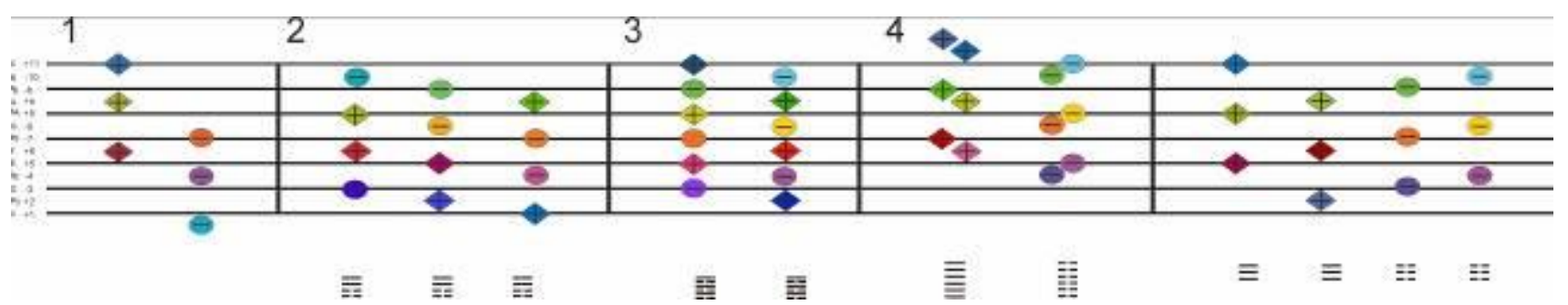

Common chord spectrum: 1-1, major triad(closed string), 1-2, minor triad(open string), 2-5, Membrane string: 2, diminished seventh chord, 3 , whole tone chord, 4 , atonal chord 5, augmented triad

The basic value formula of chord language:

$\mathrm{S}=\mathrm{HV},(\mathrm{S}=$ semitone, $\mathrm{H}=$ Equal Temperament constant, $\mathrm{V}=$ frequency), minimum discrete value.

$\mathrm{I}=\mathrm{H}^{\wedge} \mathrm{n} . \mathrm{V}(\mathrm{I}=$ interval, $\mathrm{n}=$ interval value $)$, allowing discrete values.

$\mathrm{C}=\mathrm{H}^{\wedge} \mathrm{n} 1, \mathrm{n} 2, \mathrm{n} 3, \mathrm{n}^{*} . \mathrm{V}(\mathrm{C}=$ chord $)$, discrete spectrum.

Obviously with quantized features

Observations and experiments in this paper show that: time-empty, life is composed of quantum discrete frequency coding.

Key words: chord language, quantum language,chord space-time, chord life, theory of everything, music, painting, meridian, string theory

\section{Two Languages And A World View}

Humans have two sets of language systems: chord language and symbolic language, the former is the physical language, the latter is the artificial language, involving different spiritual principles, and even different worldviews. Understanding the two languages and the principle of action, the compilation process is a must for human beings to understand themselves and nature.

The two linguistic systems involve two kinds of chord organization, which are tonal and atonal. In the tonal state, they exhibit chord semantics. In the atonal state, they do not express chord semantics, but can express the symbolic semantics established by conditioned reflection. To some extent, the difference in human worldview is the difference between chord language and symbolic language, or: tonality, asymmetry difference.

In symbolic languages, named symbols and named objects produce a difference between spiritual and natural, subjective and objective.

The chord language is the form of the spirit (music, painting), and also the physical form (quantization, string geometry), with spiritual-physical isomorphism, equivalence, without subjective-objective distinction, which brings philosophical The problem.

Most of the human knowledge systems are based on atonalistic symbols and conceptual thinking, and chord semantics are shielded. This is the biggest obstacle for human beings to understand the world.

See: 14, Spiritual Chords 


\section{Two Views Of Life}

The chord life is based on the chord coding language. The basic features are: quantized discrete spectrum, chord geometric semantics (open string, closed string, membrane string), related subjects are meridian (Chinese ancient medicine), chakra (Indian yoga).

Chord language, chords, and mode are expressed as meridians and acupoints (chakras), which are used for the expression and control of life, and are related to the cause, purpose, and process of life. Among them: Yin-Yang (positive-negative) is an important attribute of chord language, which determines the grammar, semantics, mathematics, and geometric rules of chord language.

Chord life and modern life science are different views of life (worldview). The natural principle is the tonal-tonic form of chords. The chords express chord semantics in tonal forms, and do not express chord semantics in atonal forms. Chord life (eg, meridian, etc.) is based on chord life semantics. Life science has nothing to do with chord life semantics. Understanding the principles of two life views is the key to understanding life correctly.

See also: 13, the chord of life

\section{Two Views Of Time And Space}

Humans have two sets of spatiotemporal expressions: reference space-time and chord space-time. Simply put: the reference space-time comes from the external metric reference system such as clock, ruler, etc. The chord space-time comes from the quantized discrete spectrum, string (open string, closed string, Membrane string), usually, science and physics use the reference system of time and space, music and painting use chord time and space.

The quantized discrete spectrum, chord (open string, closed string, non-string string) is the different expression of chord space-time, the former expresses the coding rule, the latter expresses the geometric rule, the effect of the two produces space, which can be directly in the chord painting Observed.

Chord space-time is the semantic expression of chord language, music expression time, painting expression space, both of which have quantized discrete spectrum forms: chords, modal, etc., mathematically reverse-mirror mirrors, which can directly represent time-space physics, mathematics relationship.

In chord painting (chord geometry), specific chords have specific spatial-geometric semantics: open chords (minor chord), closed strings (major chord), Membrane strings (Discord), which produce all spatial states and spatial interactions, which are fundamental features of chord space (geometry) and are easy to observe and validate in chord painting This should be good news for string-M theory.

Again: science, physics, the use of reference system space-time, music, painting, etc. use chord space-time, the following are added:

Reference system space-time: From the external reference system: ruler, clock, assigned background reference system, etc. to generate position, shape, motion description, space-time is a measure from the external reference system.

Chord space-time: is the form of energy and information: the quantized chord spectrum, the chord geometry 
(open string, closed string, membrane string), and thus the spatiotemporal state, interaction and motion, independent of the clock, ruler and other external metrics reference system.

Reference frame space-time will block chord space-time (quantum space-time), for example:

Using clock, ruler and other external measurement reference system to measure chord space-time system;For example, the works of Beethoven, Mozart, van gogh and monet can establish a theoretical model of space-time from the measured values, but there is no chord spectrum and its energy and information functions in the space-time model based on the external reference system.

The two sets of space-time expressions are two kinds of space-time views (world view). The natural principle is the tonality and atonality of chords. The chord system expresses chord semantics in tonal form, and the chord semantics are not expressed in atonal form. Reference frame time and space is an atonal system without chord semantics.

Time and space expression is the intersection of physics and music-painting, and it is also the common center, but they are different ways of expressing space and time, and they are different views of time and space. The two time and space views include complete time and space.

See also: 15 , chord time and space

\section{Other}

The chord language is a powerful and wonderful coding system. I don't know who designed this system. For the time being: God code.

Chord language is a common human blind spot for two reasons:

1. Differences between the principles and methods of the two languages: The chord language usually occurs in the background and bottom layer of the symbol language, and does not depend on the symbolic language system. It is not easy to be noticed by the symbolic language and rationality.

2, the basis of chord language observation is: music, painting, meridian and other chord language phenomenon, due to education reasons, many people are not familiar with this field.

Added knowledge points: chord language, chord time and space, chord painting, chord math, chord life. Involved in existing knowledge points: music theory, music mathematics, color theory, physics, life, meridian, all things theory. 


\section{Catalogue}

Foreword

1、Diationic Scale-Tonality

2、Diationic Scale-Atonal

3、 Jazz scale Tonality

4、 Jazz scale-Atonality

5、 Next-related key group

6、Parallel key group

References

Afterword 


\section{1、 Diationic Scale-Tonality}

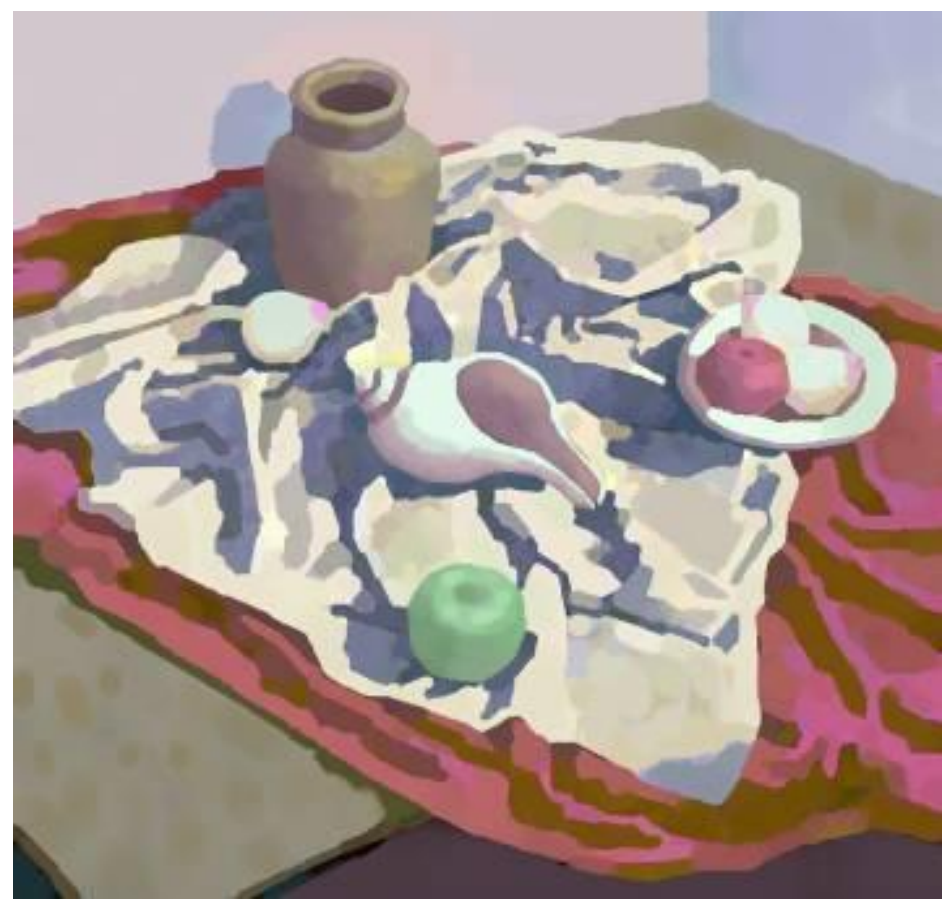

Still life, diationic scale, C major,\#f minor

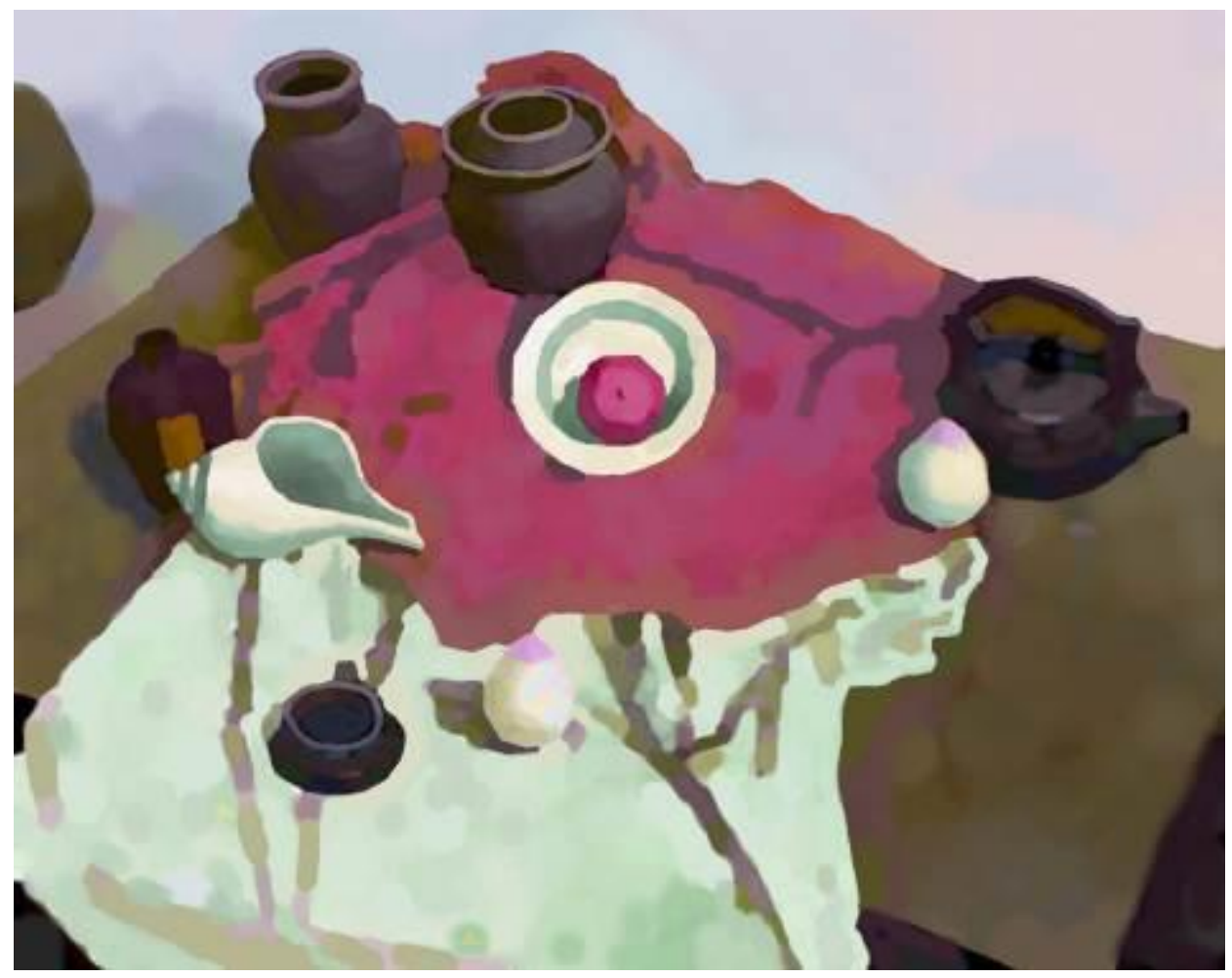

Still life, diationic scale, C major, A major 


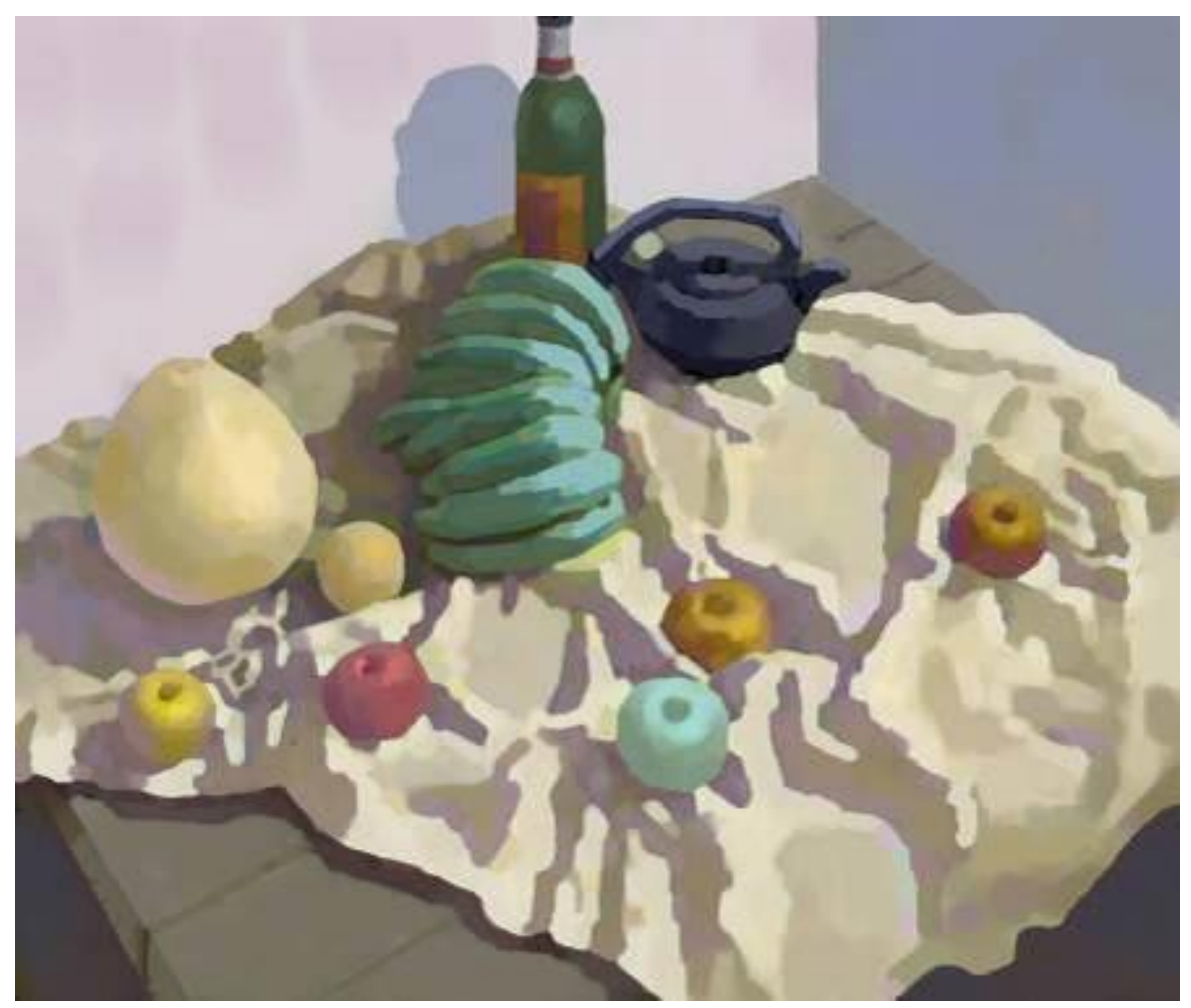

Still life, Pentatonic scale, C major, \#f minor

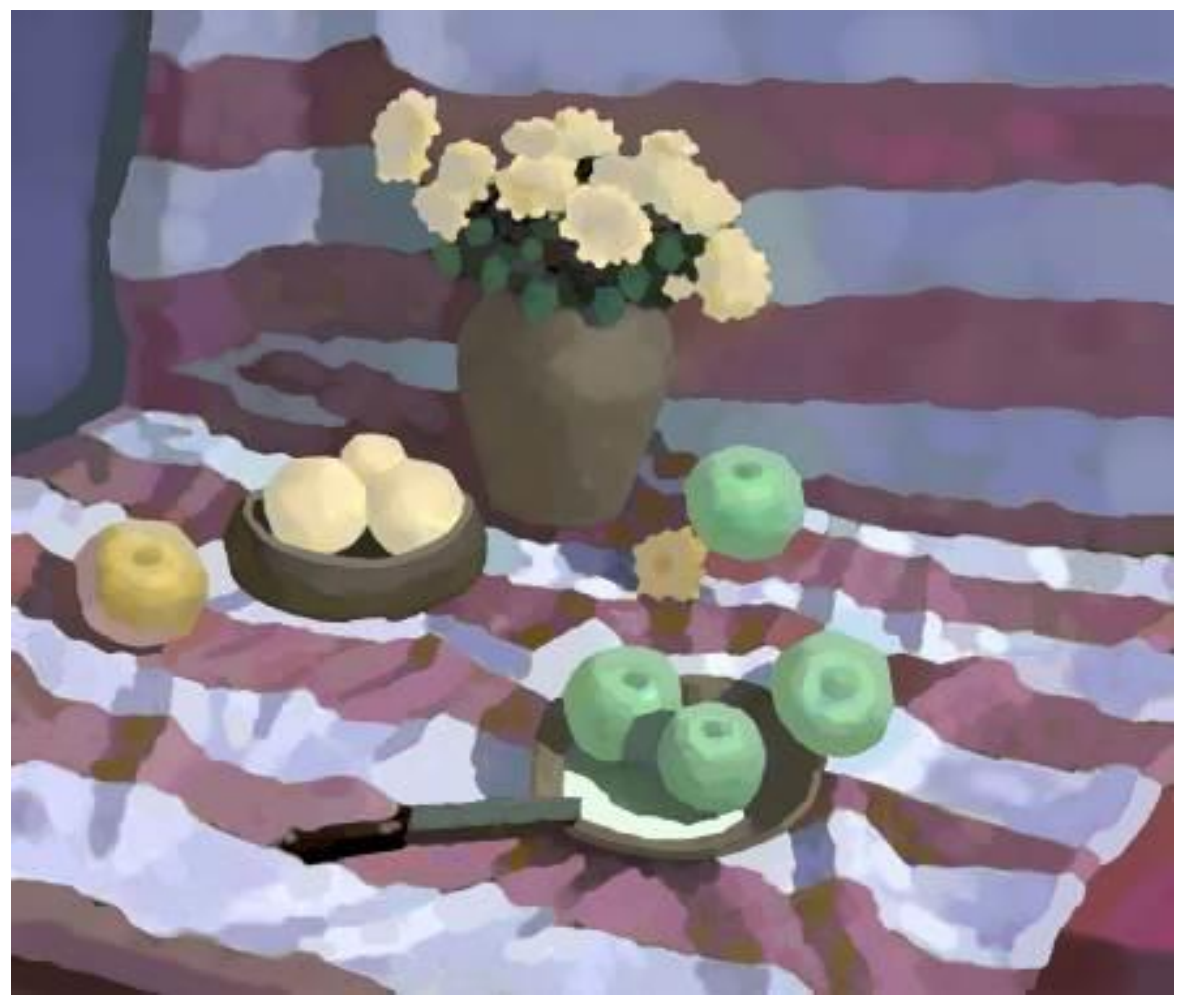

Still life, diationic scale C major, A major 


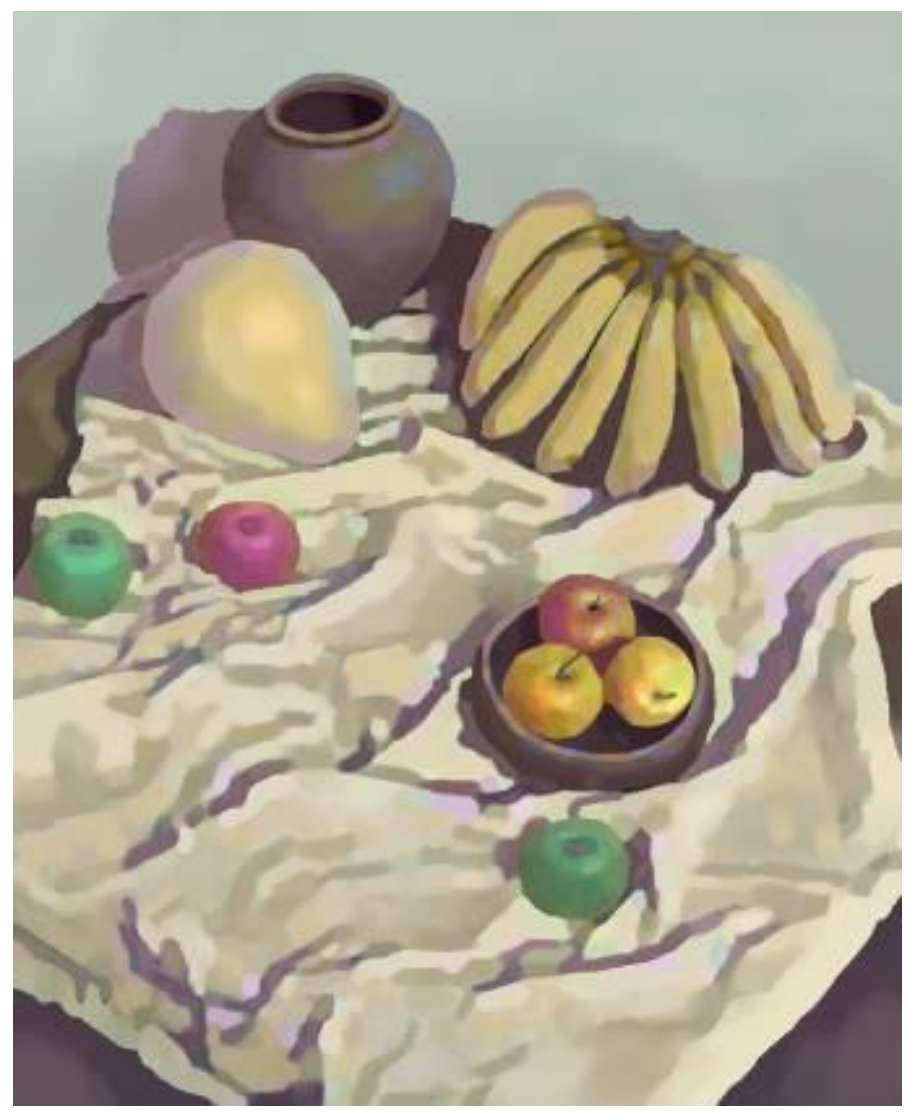

Still life, Pentatonic scale, C major, \#f minor

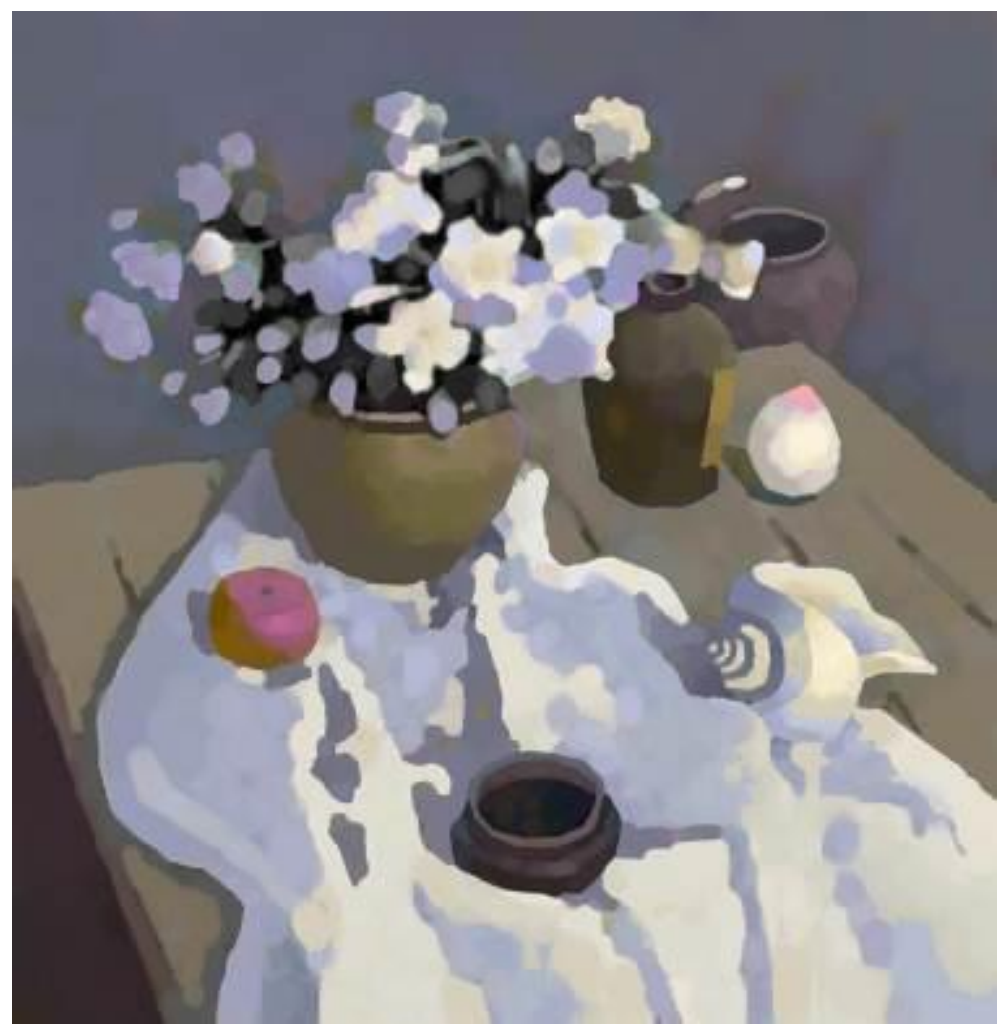

Still life, diationic scale C major, A major 


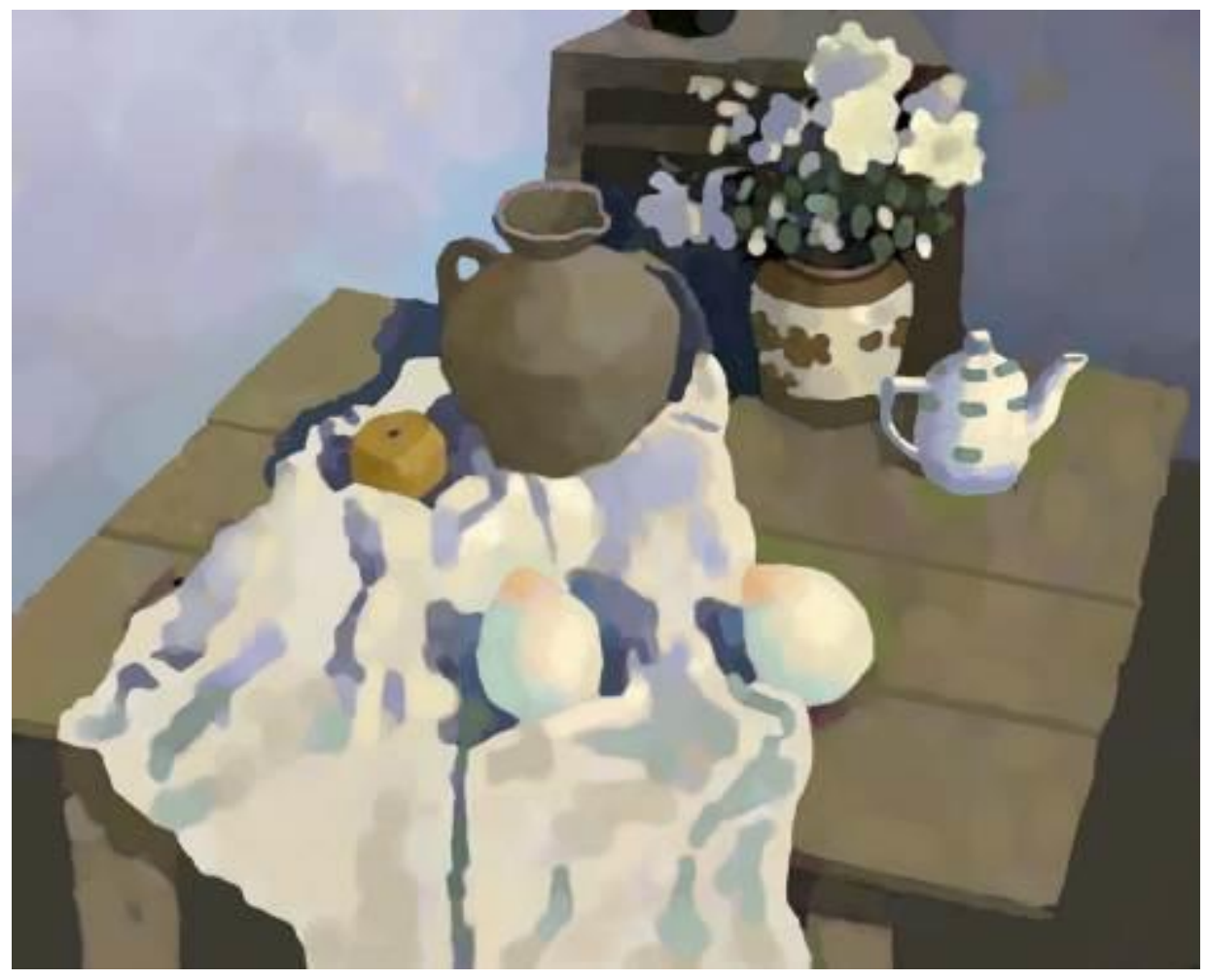

Still life, diationic scale C major, \#f minor, A major

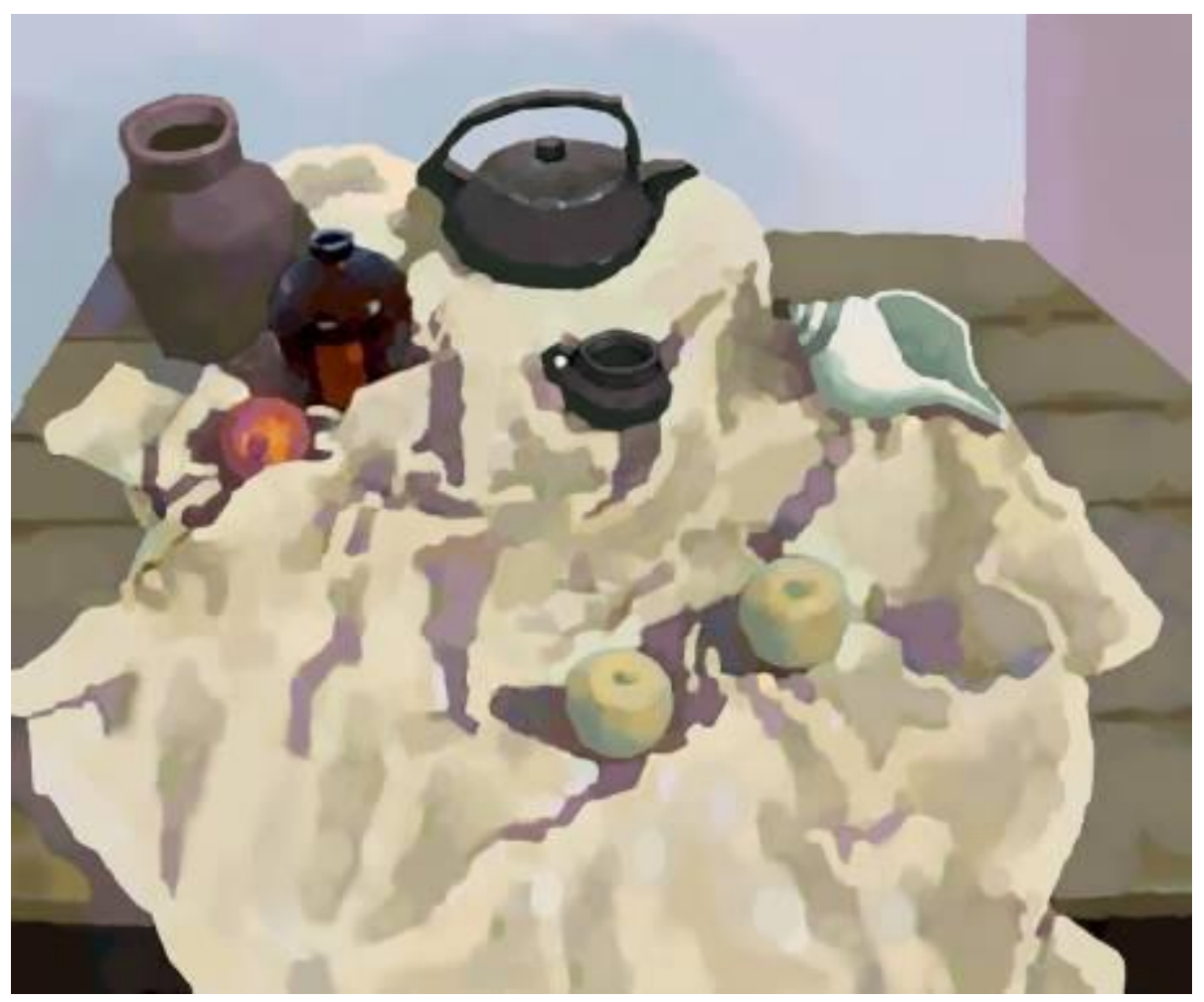

Still life, diationic scale, bE minor,A major 


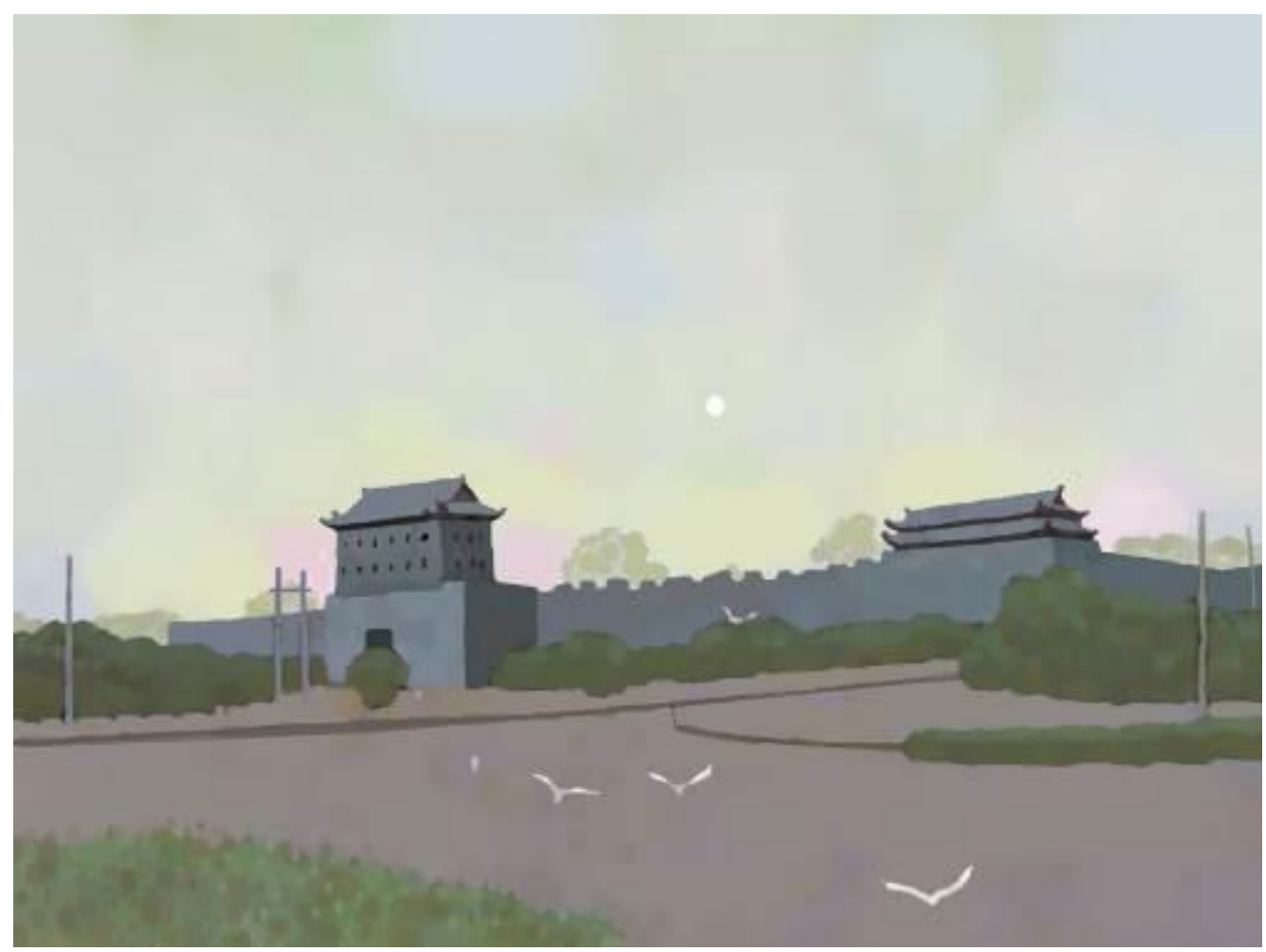

Landscape, diationic scale diminished triad form

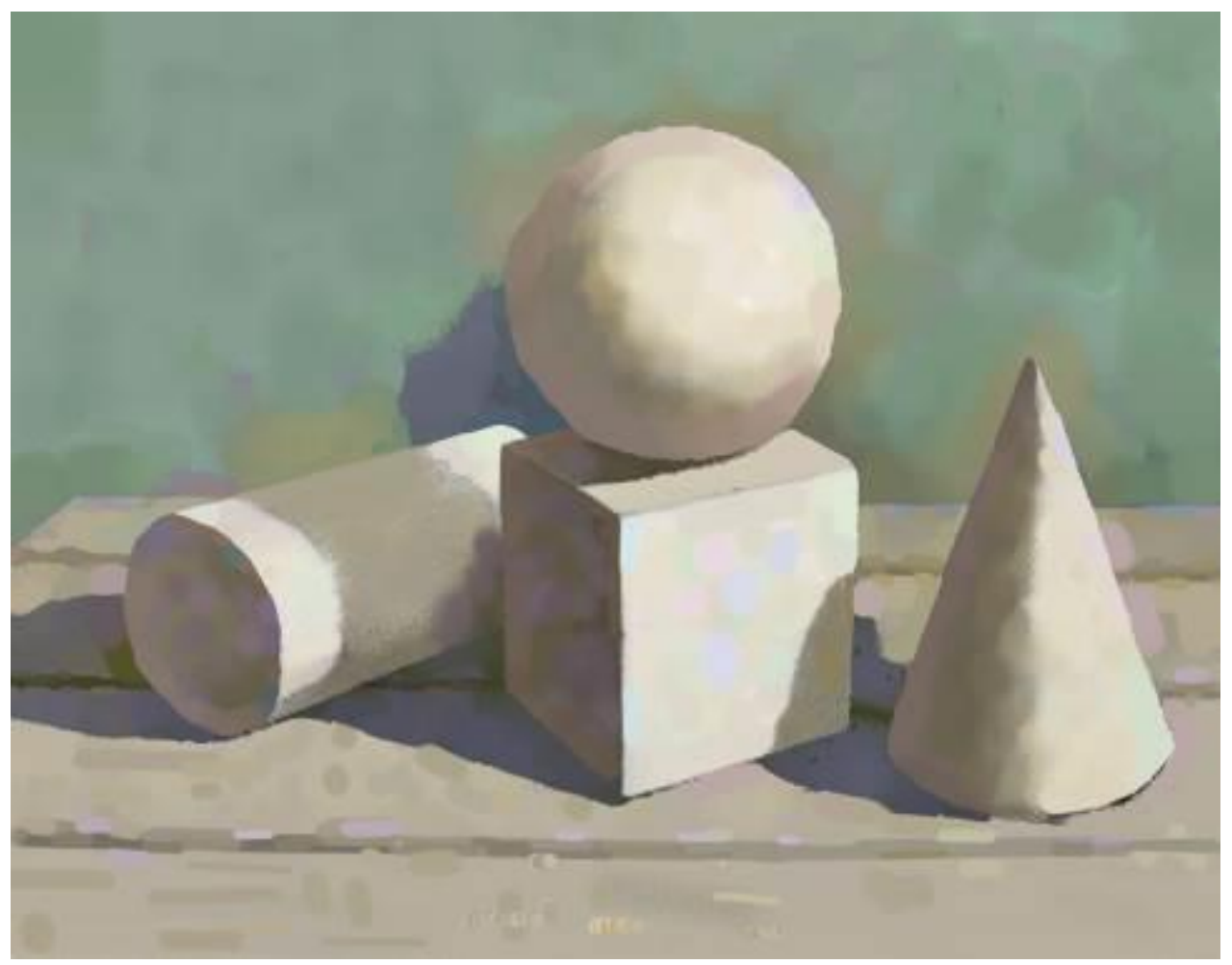

Laster model, diationic scale, C major, \#f minor 


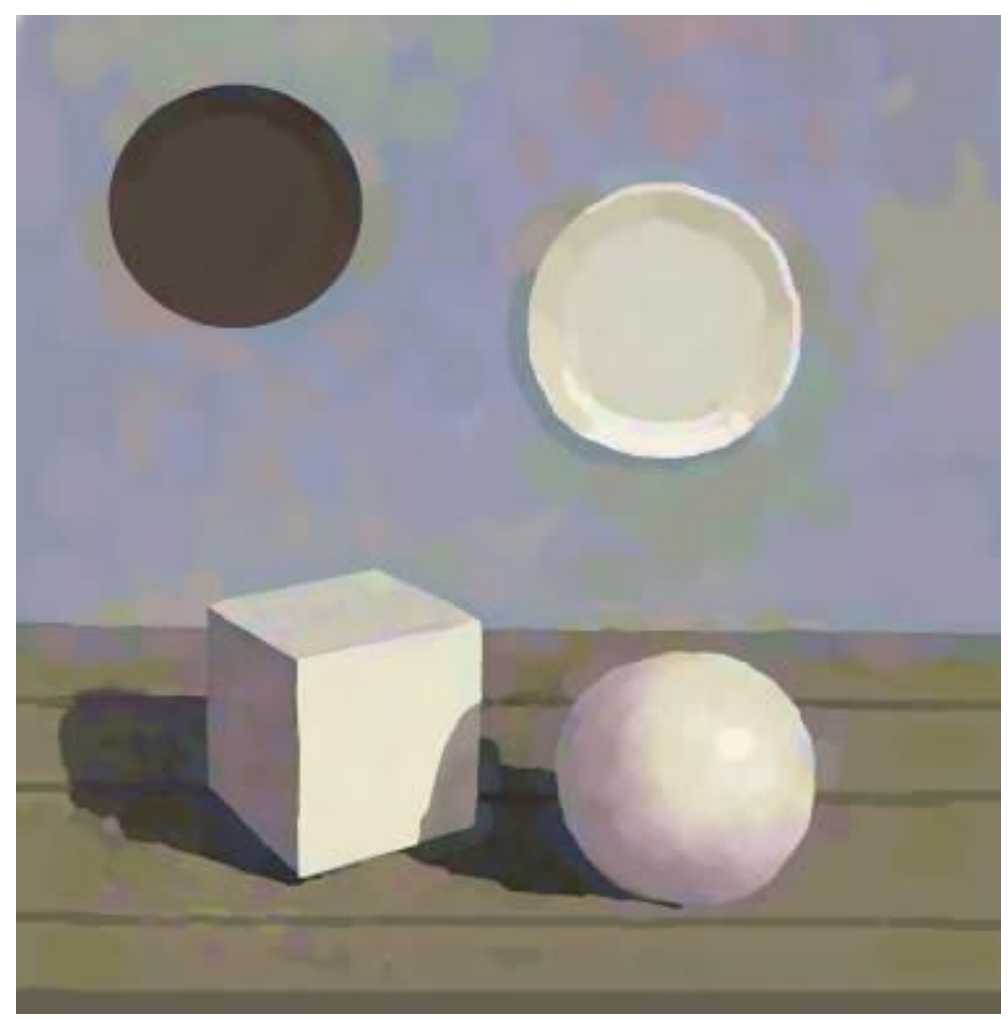

Laster model, Still life, diationic scale, C major, \#f minor

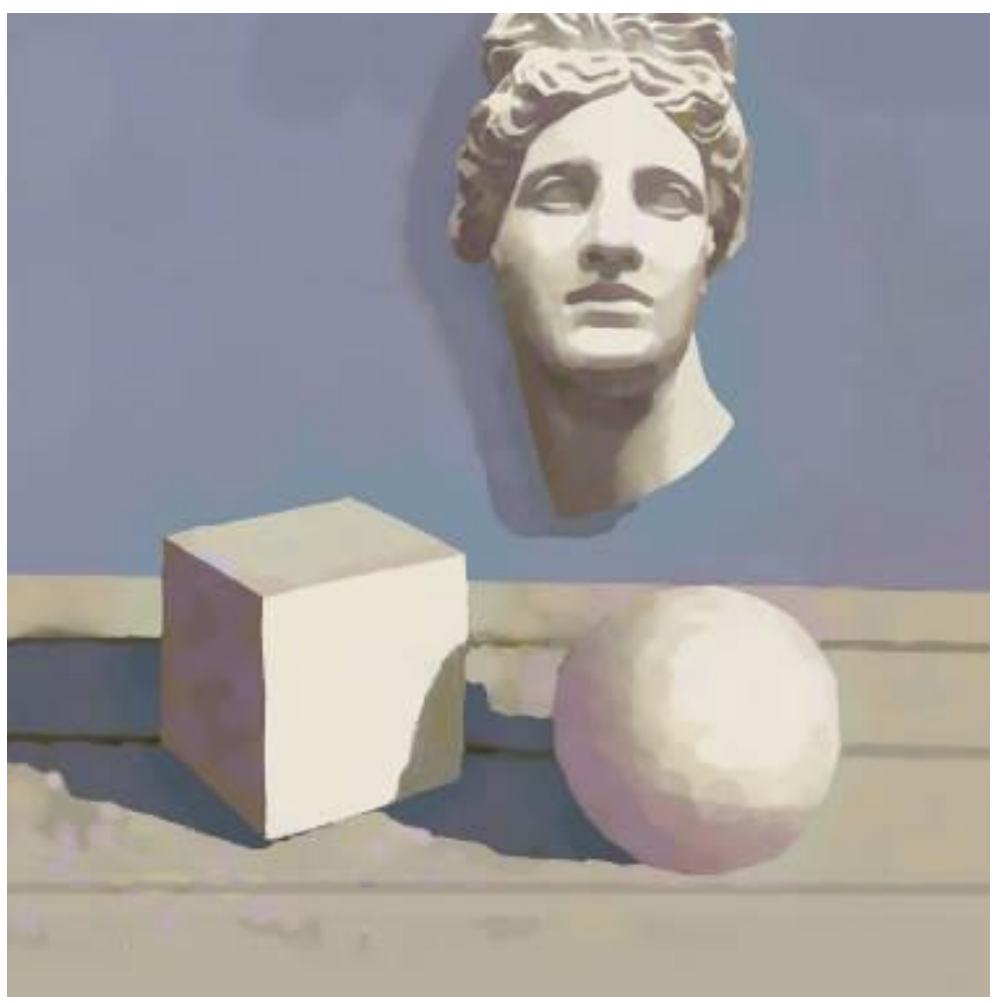

Laster model, Pentatonic scale, C major, \#f minor 


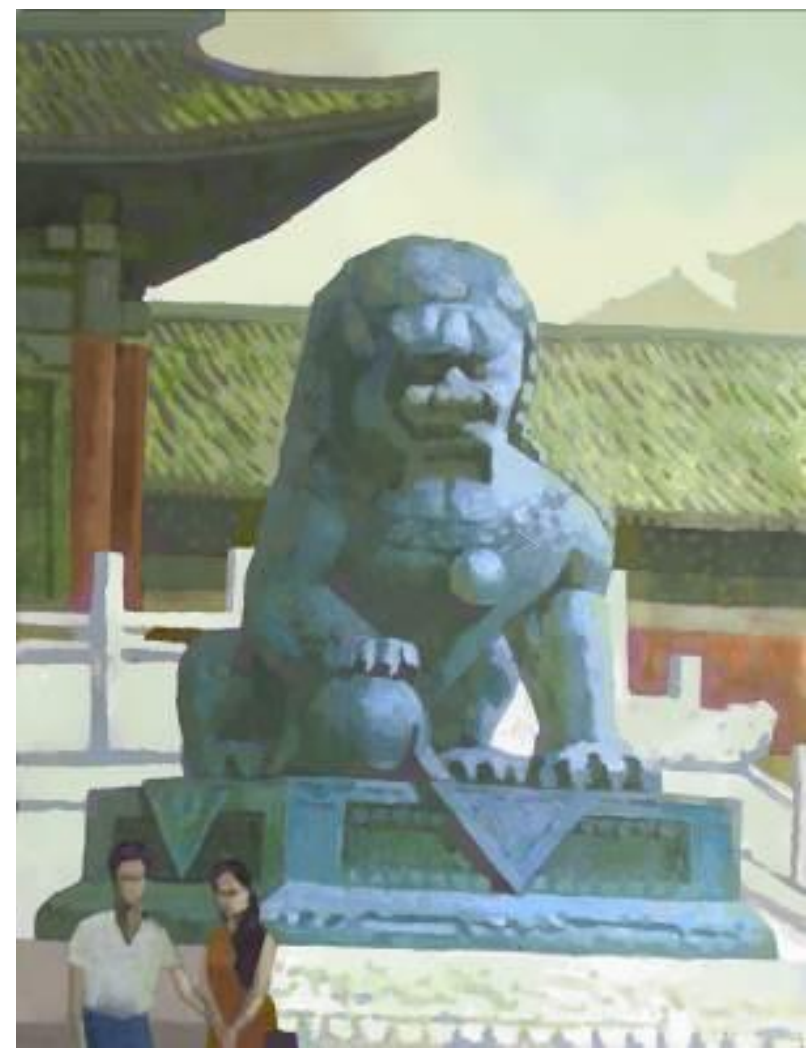

Tourists in the Forbidden City, diationic scale ${ }^{\mathrm{b}} \mathrm{A}$ major, $\mathrm{d}$ minor

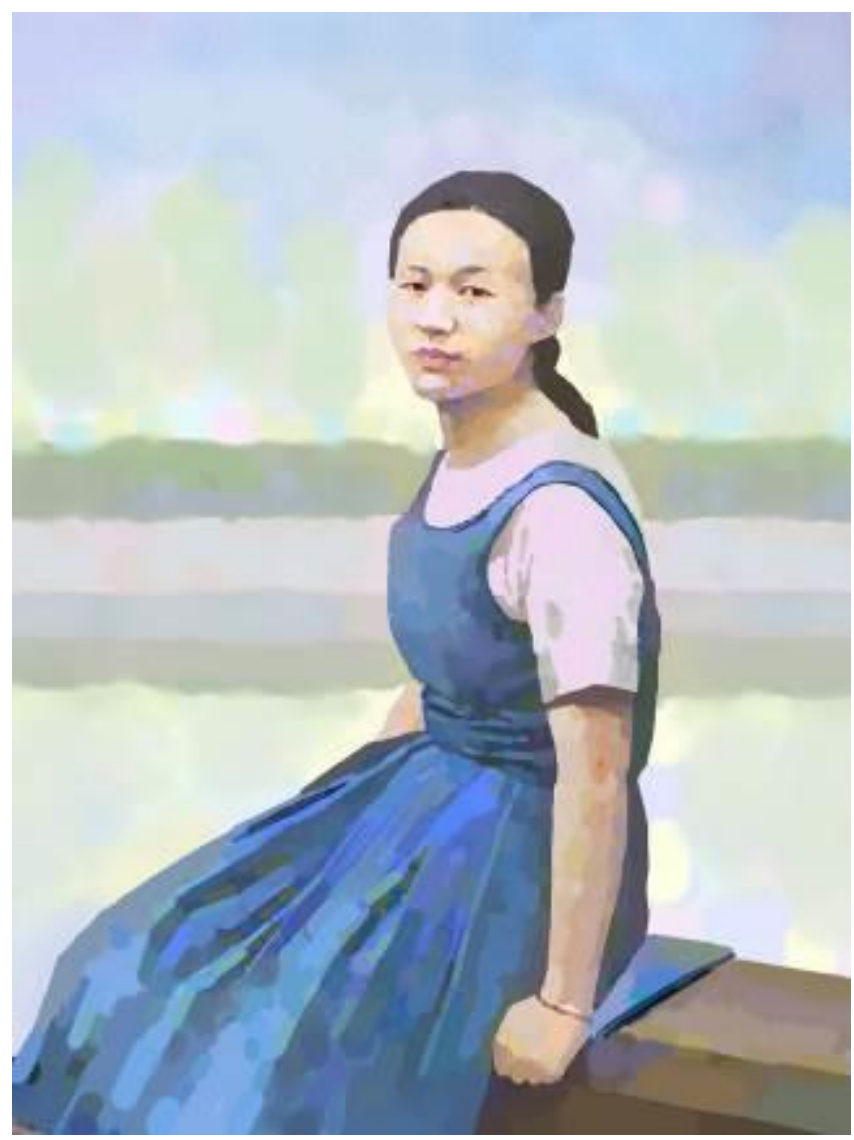

Lady of the lake, diationic scale ${ }^{\mathrm{b}} \mathrm{A}$ major, $\mathrm{d}$ minor 


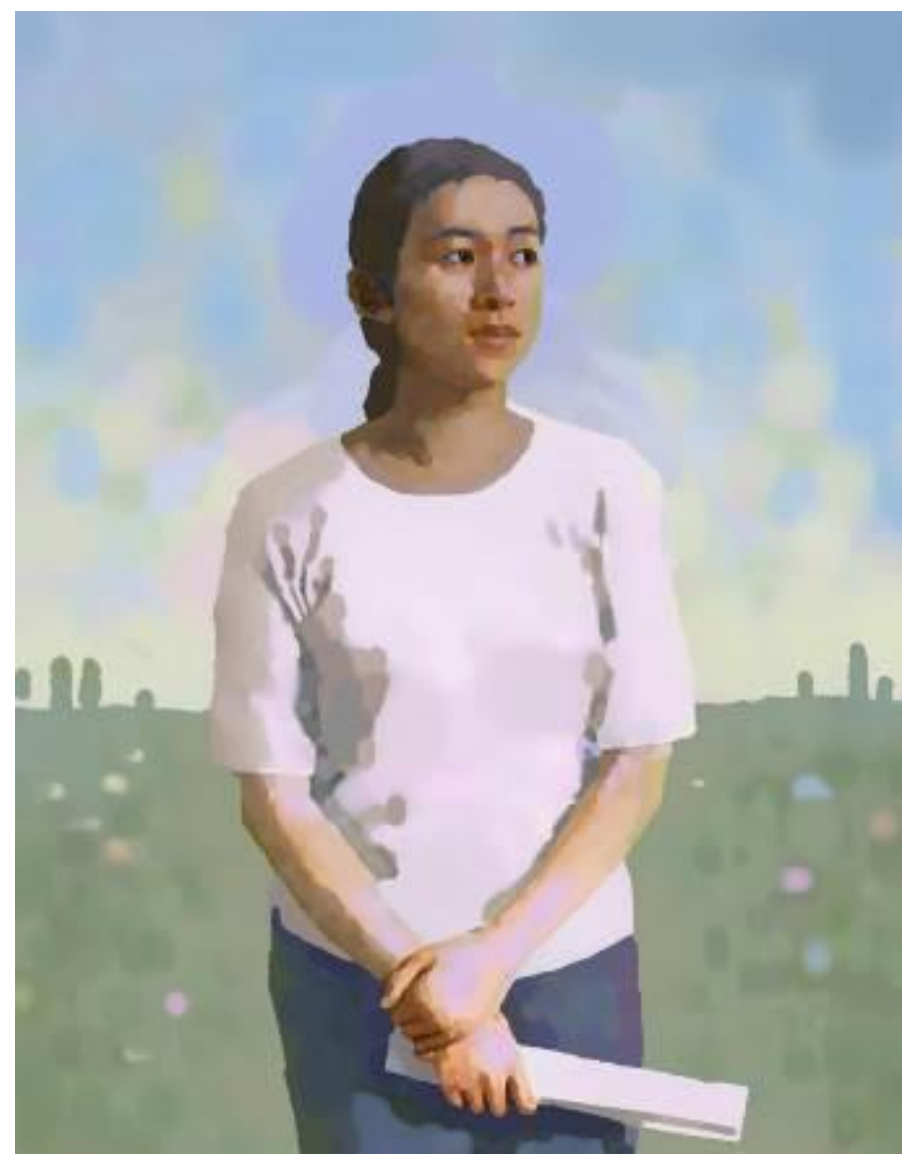

Prairie:diationic scale ${ }^{b} \mathrm{~A}$ major, $\mathrm{d}$ minor

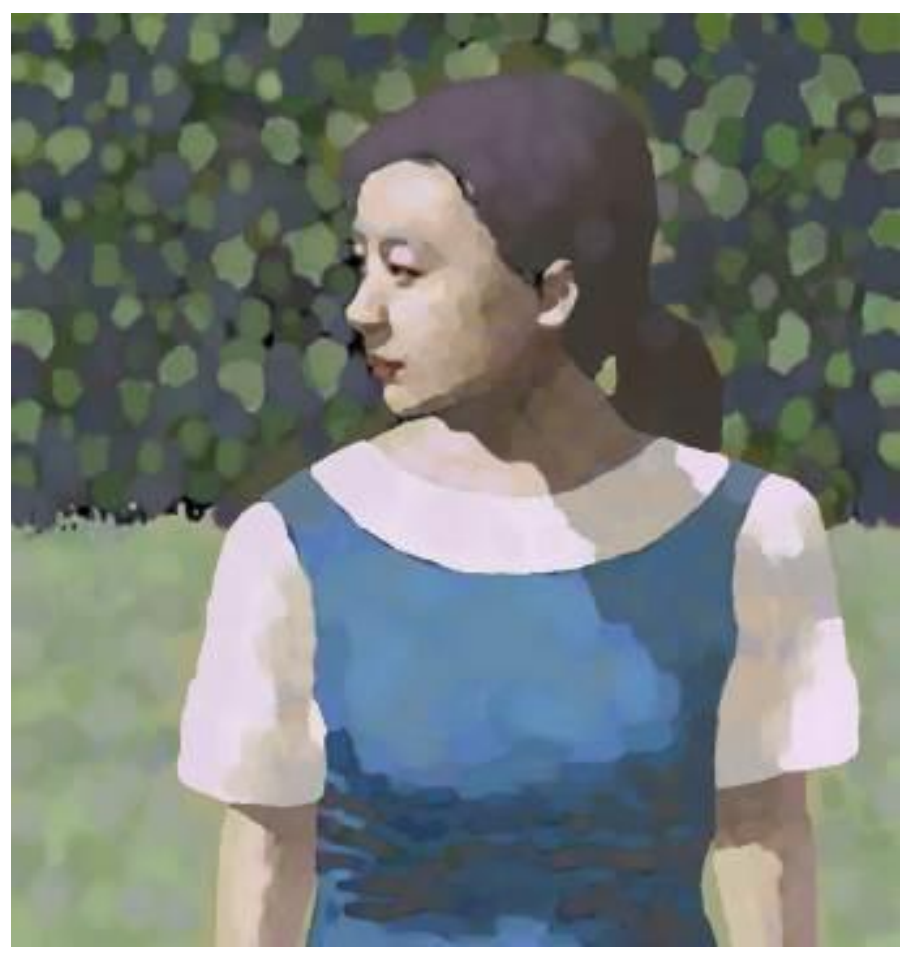

The yard,diationic scale A flat major, $\mathrm{d}$ minor 


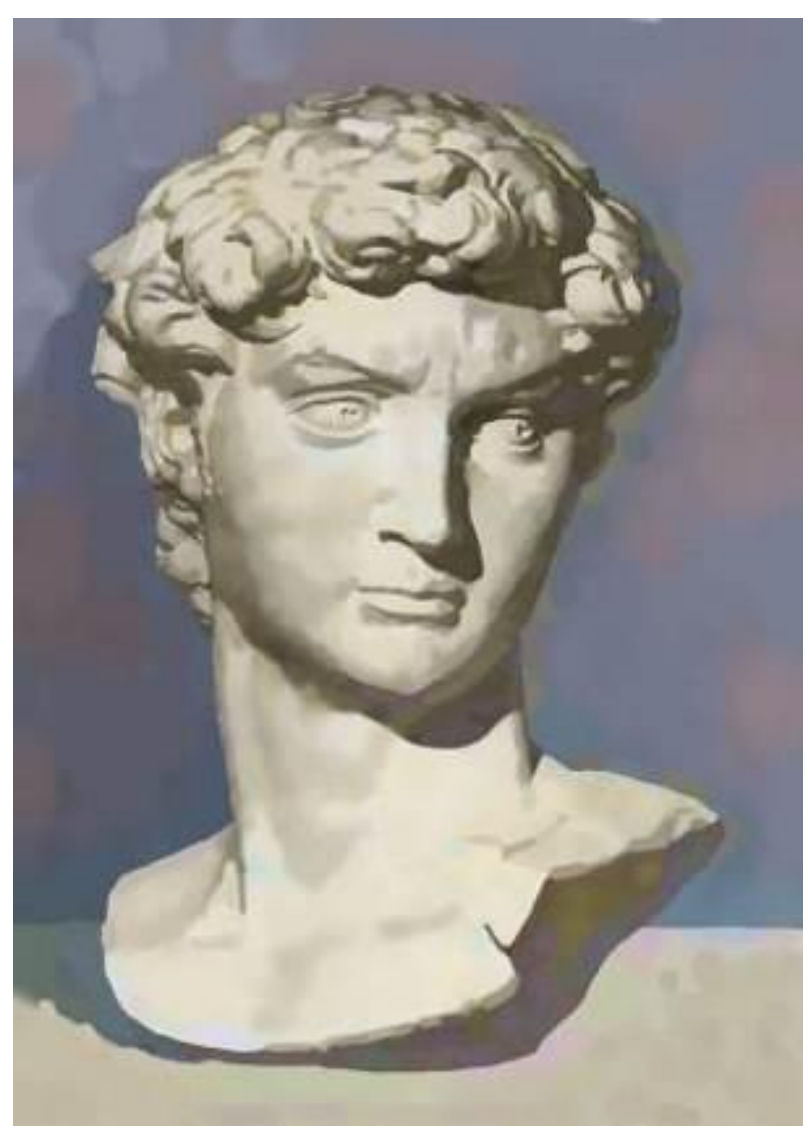

\section{David,diationic scale, C major,\#f minor}

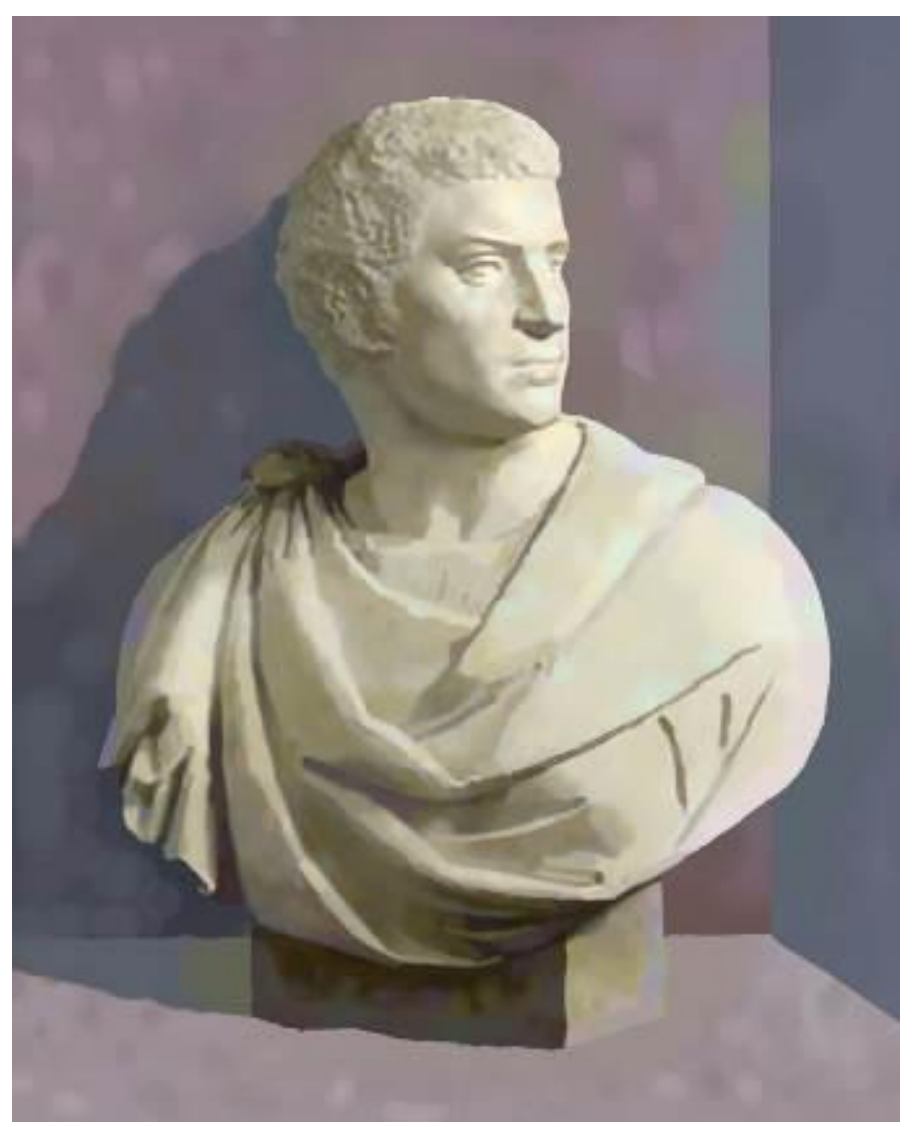

Brud,diationic scale, C major, \#f minor 


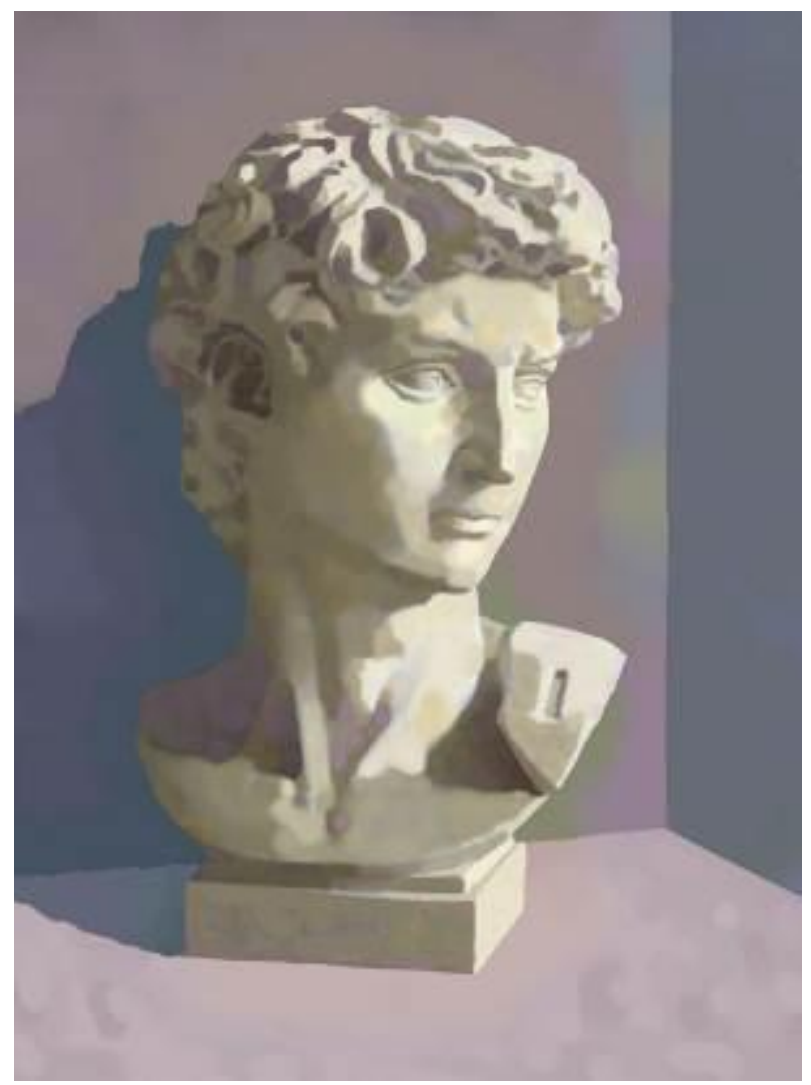

David,diationic scale, C major, \#f minor

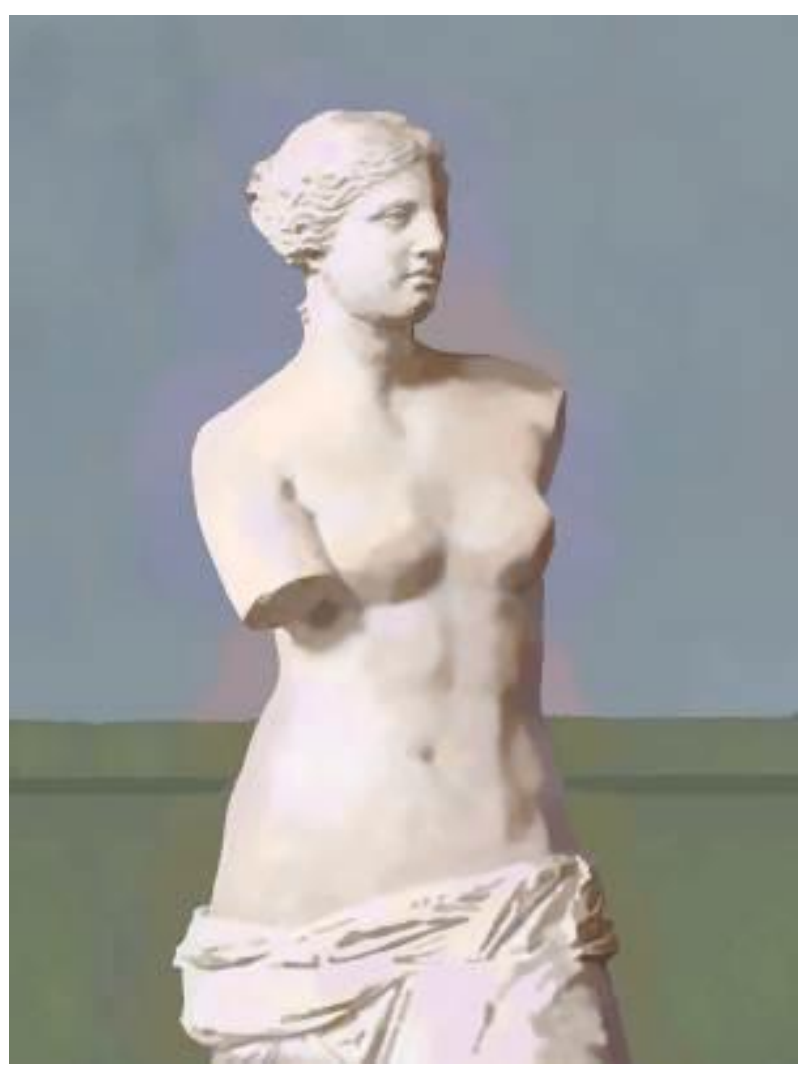

Venus, diationic scale bA major, $\mathrm{d}$ minor 


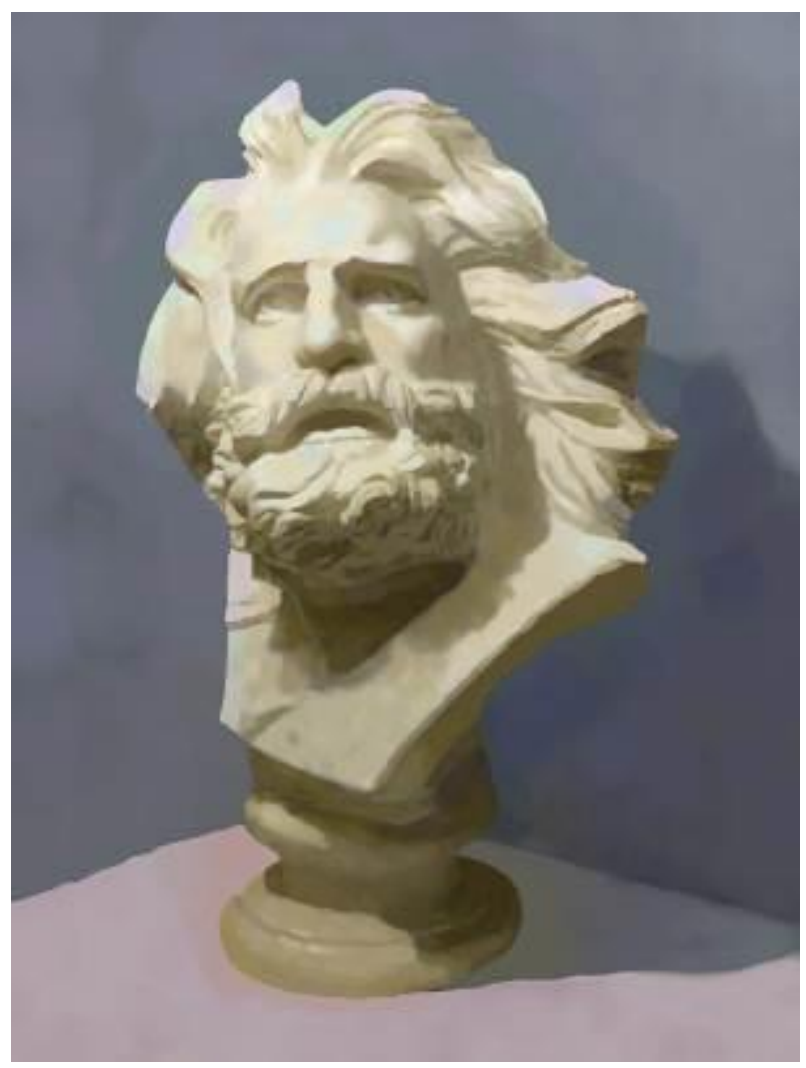

David,diationic scale, C major, \#f minor

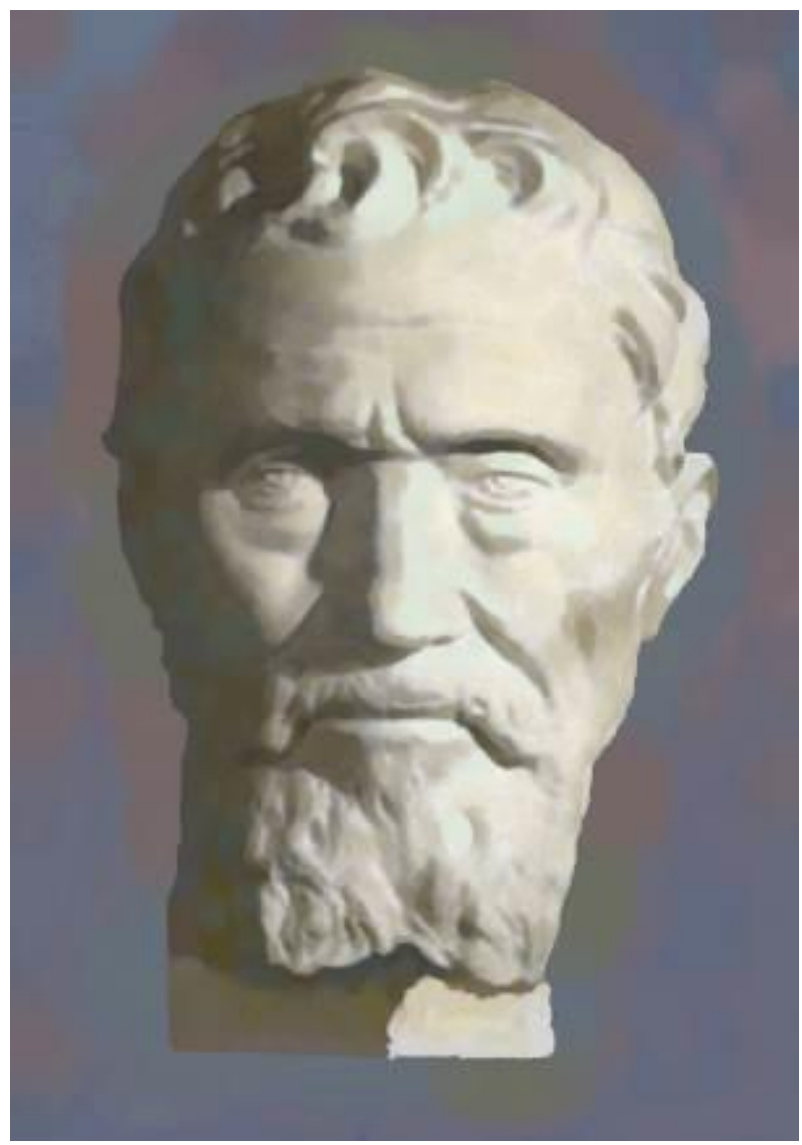

Gypsum image,diationic scale 


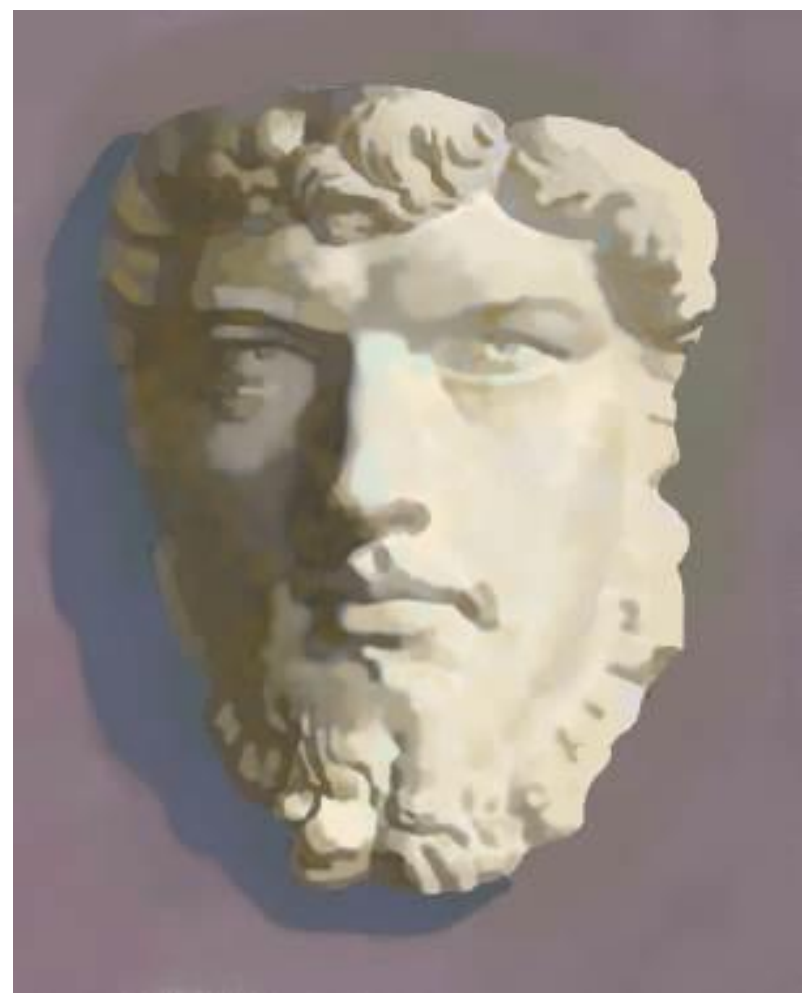

Gypsum image,diationic scale 


\section{2、Diationic Scale-Atonal}

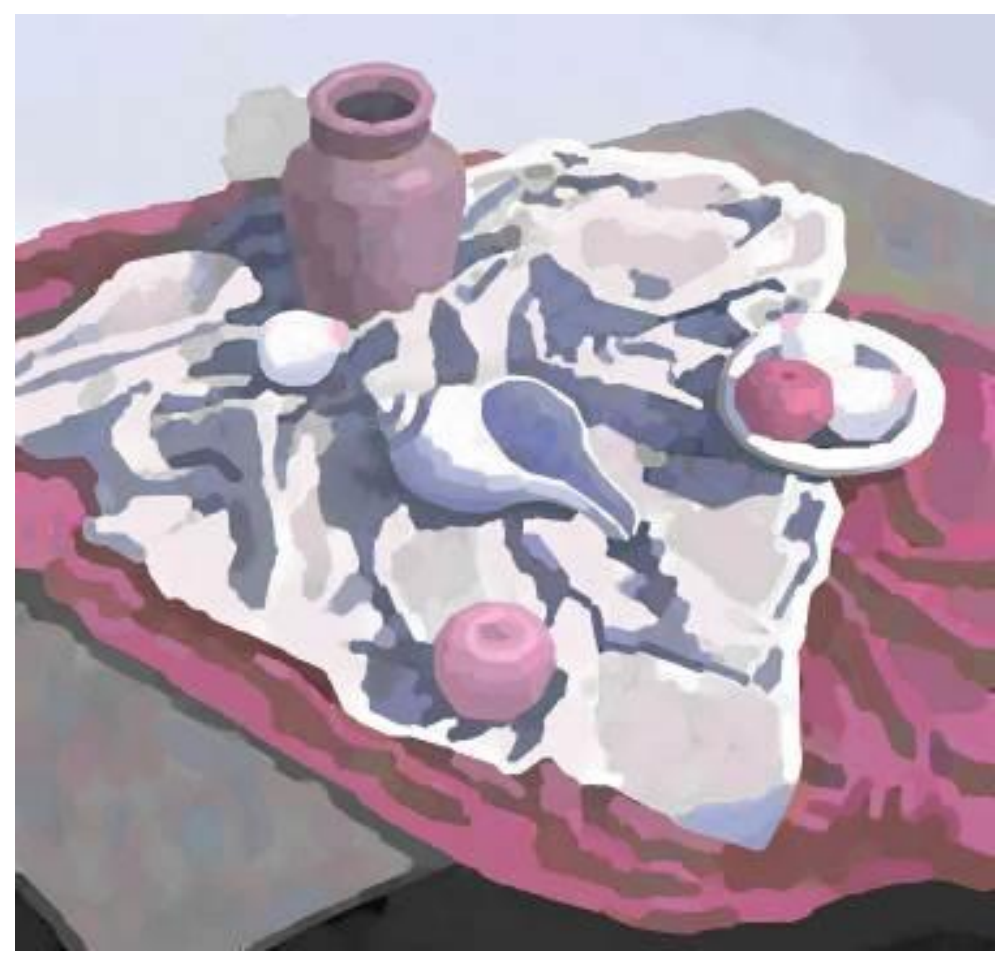

Still life, diationic scale Atonal form

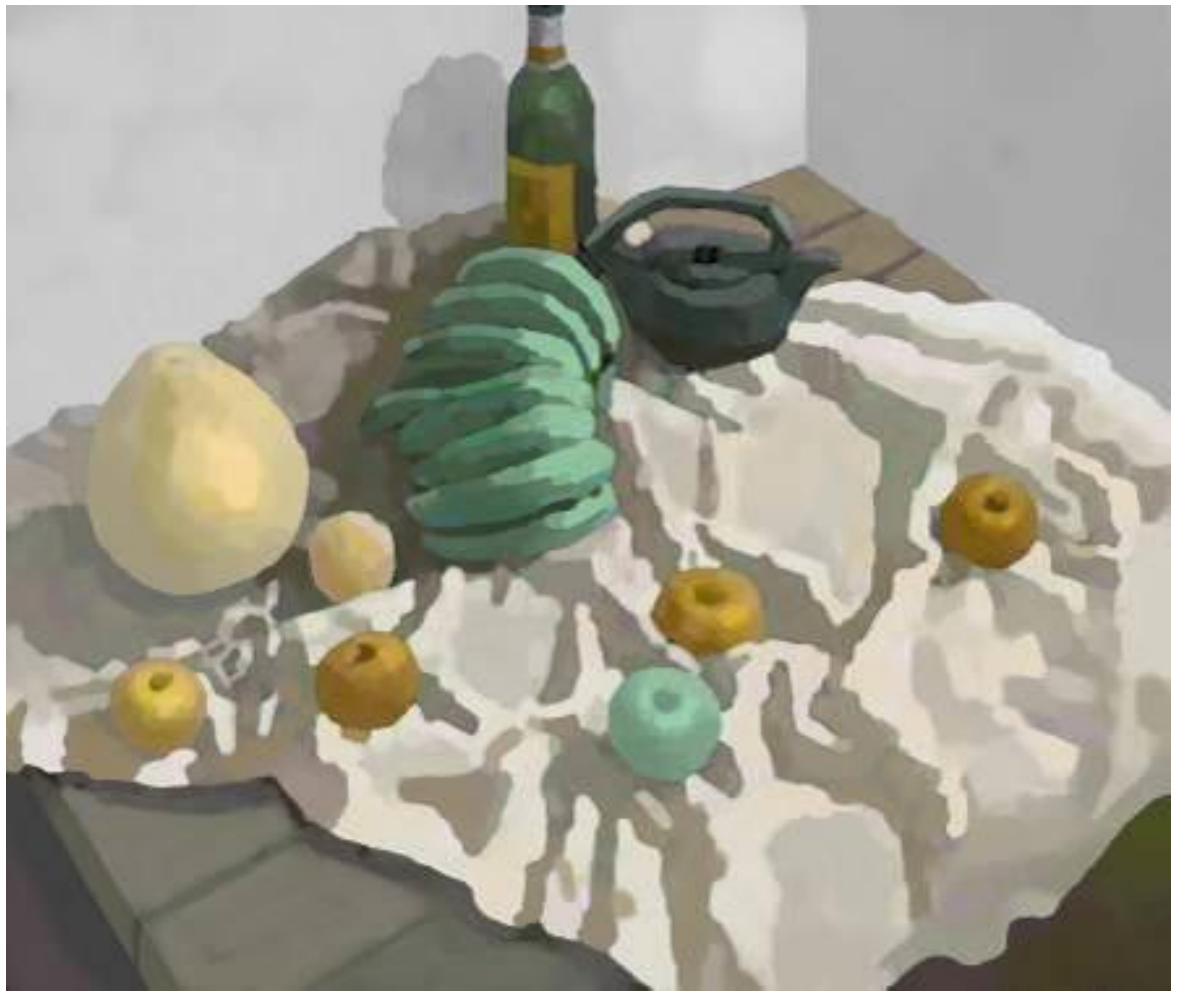

Still life, diationic scale Atonal form 


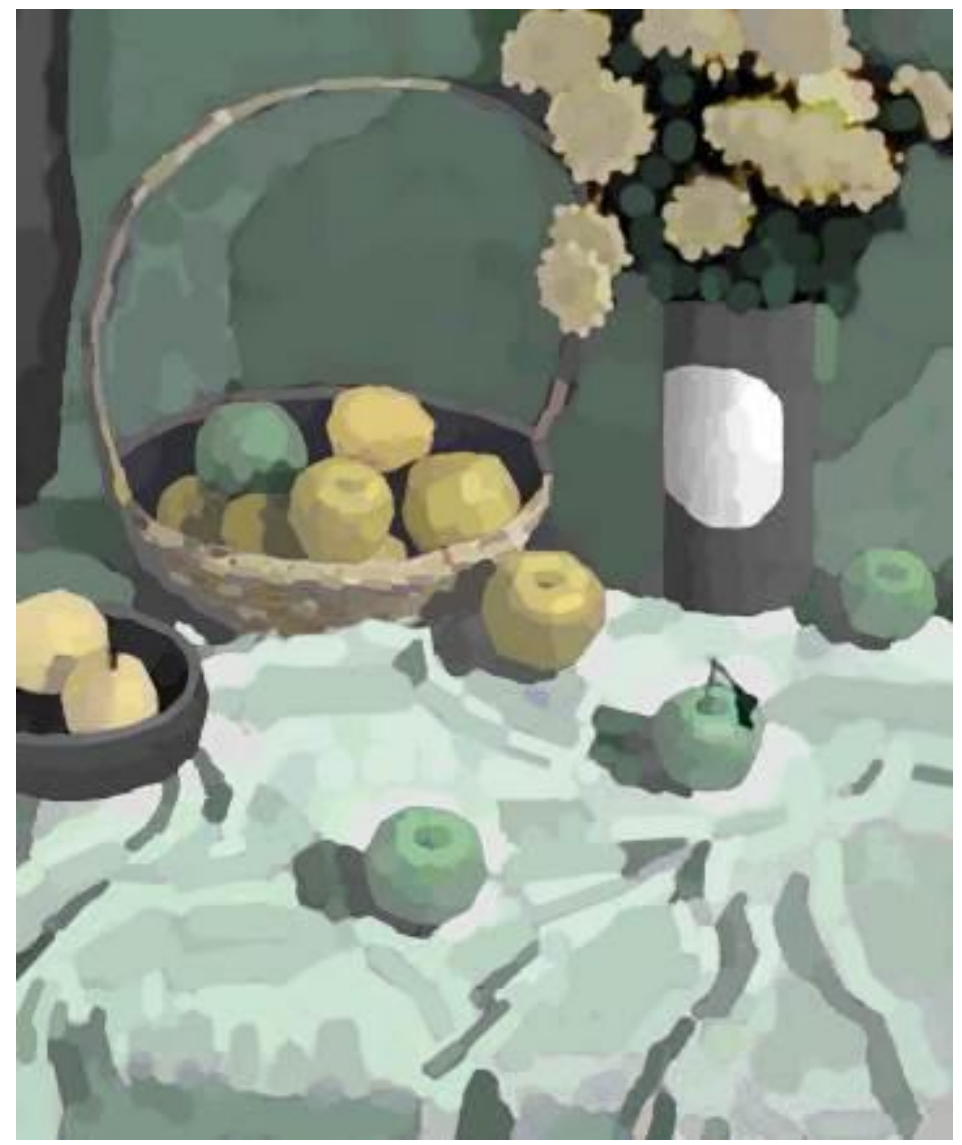

Still life, diationic scale Atonal form

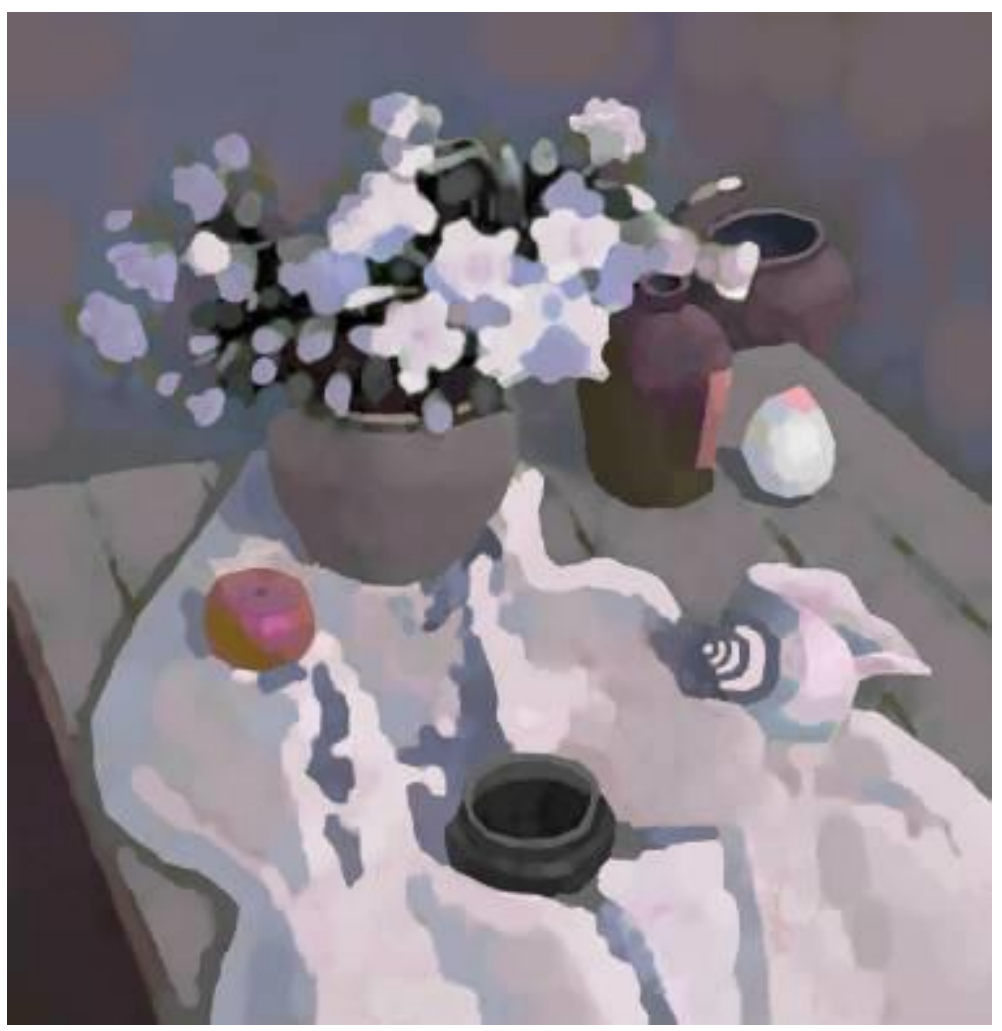

Still life, diationic scale Atonal form 


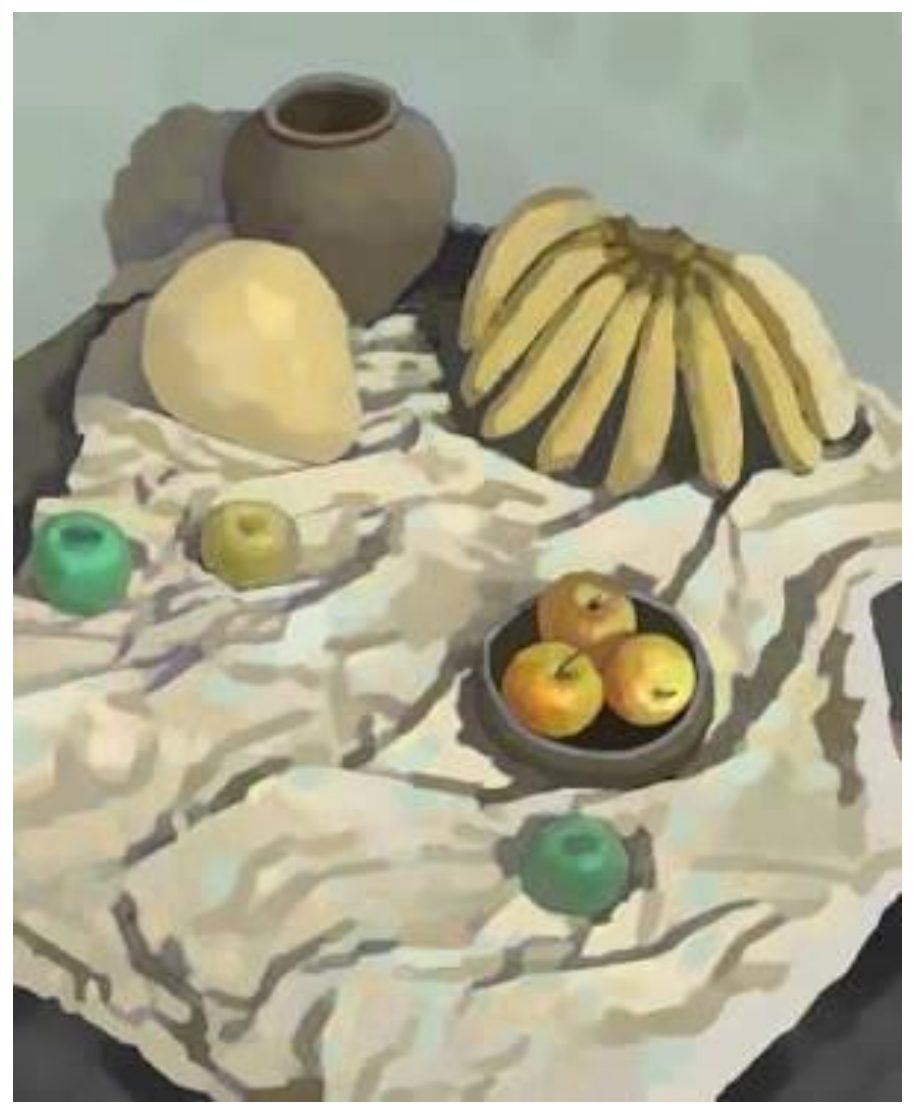

Still life, diationic scale Atonal form

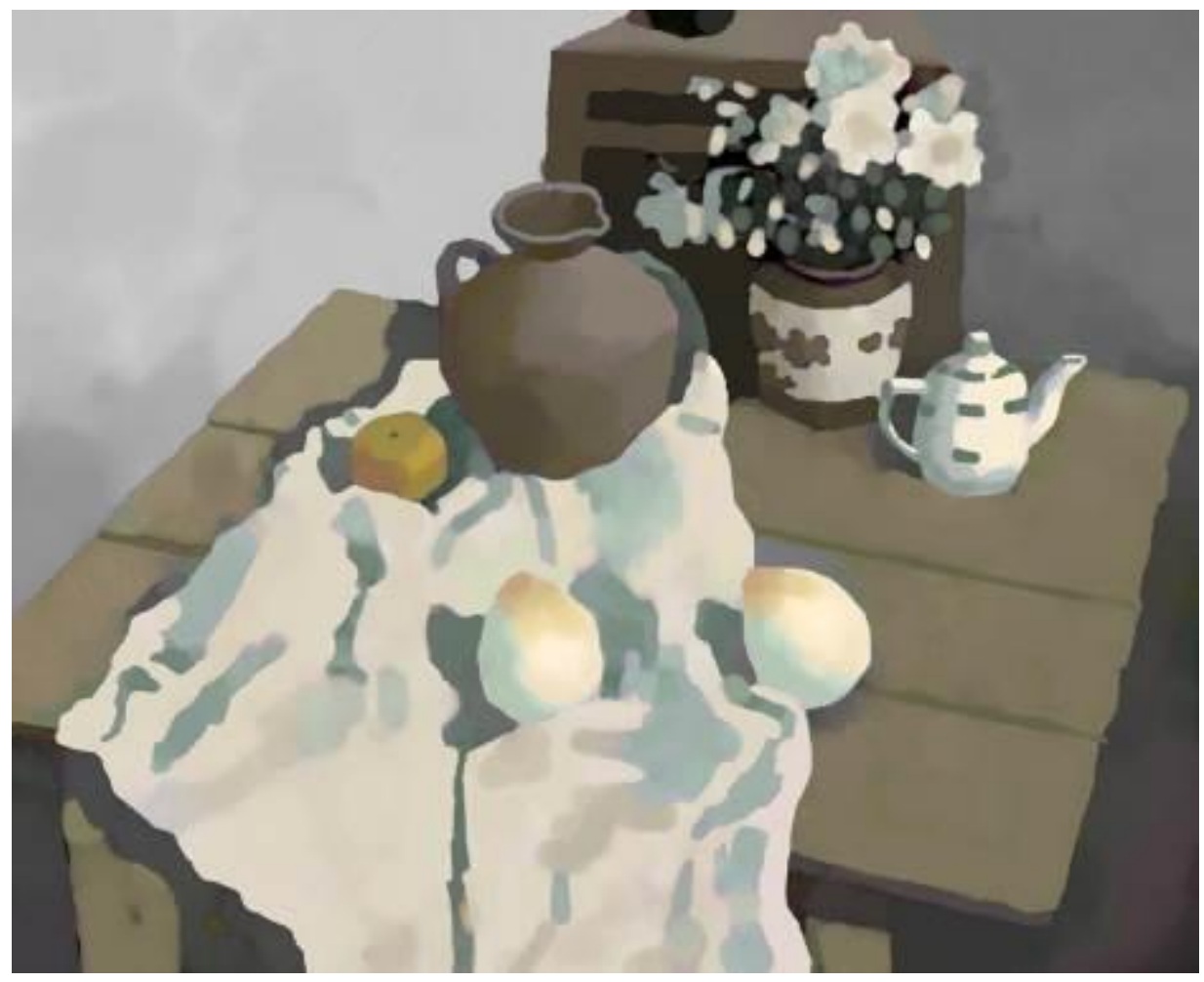

Still life, diationic scale Atonal form 


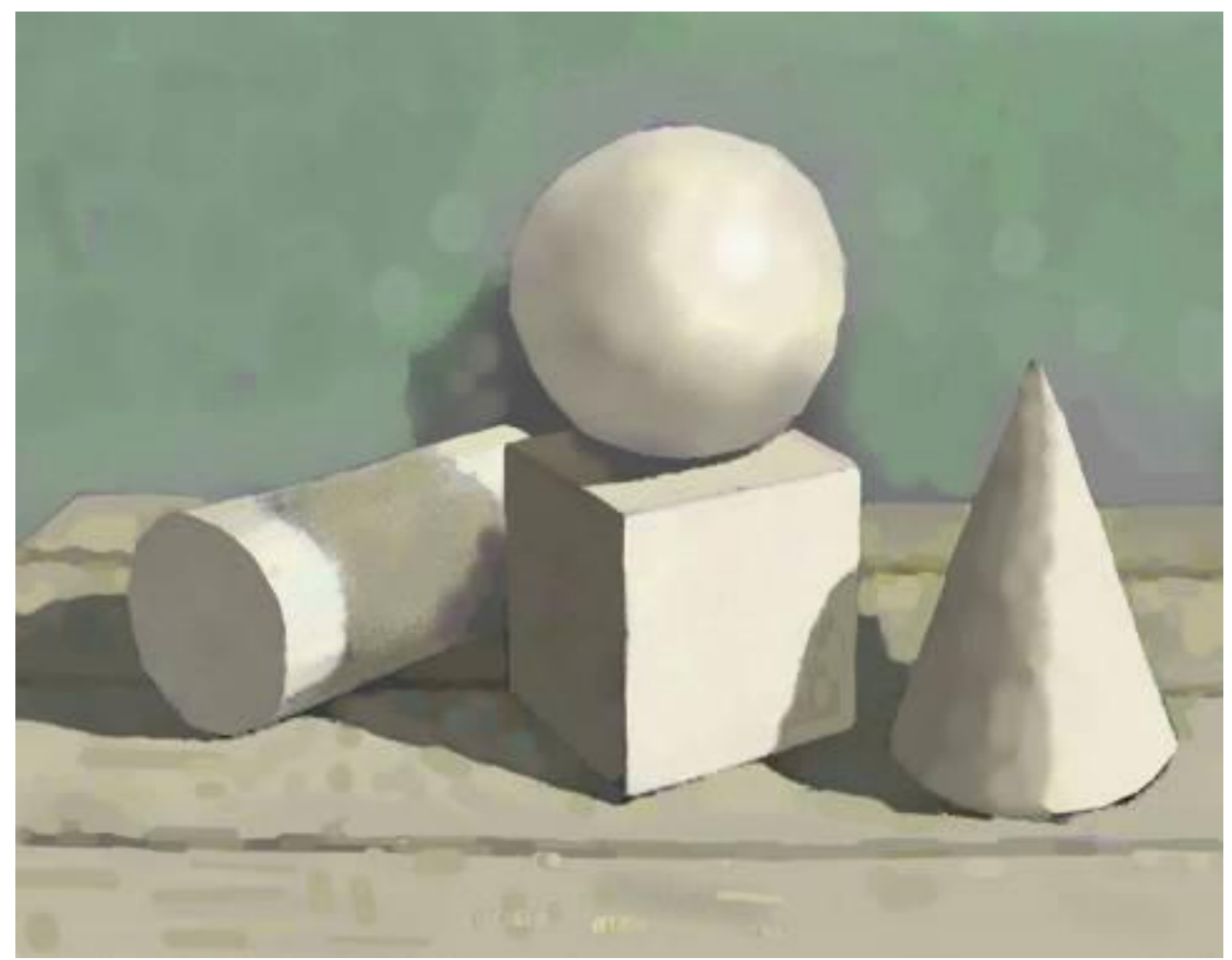

Gypsum graphics, diationic scale atonal form

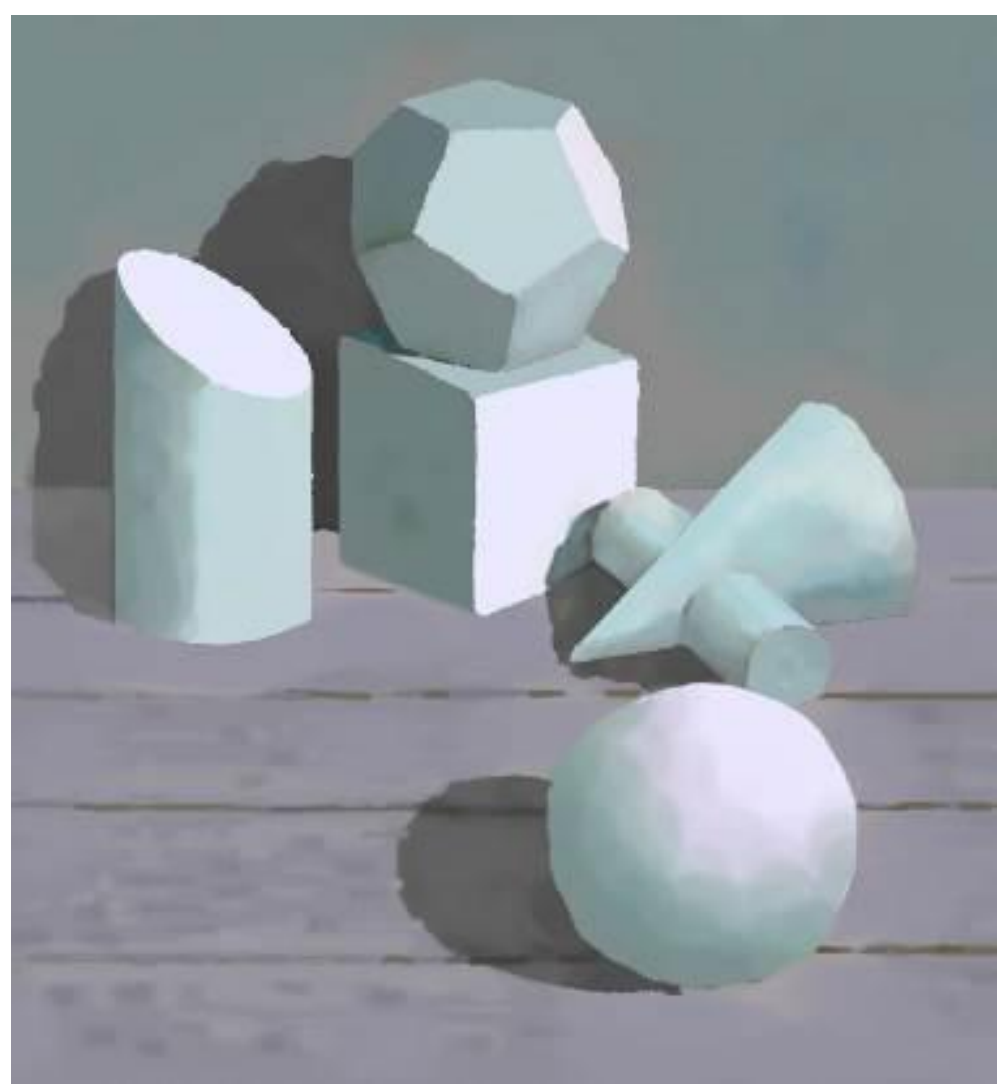

Gypsum graphics, diationic scale atonal form 


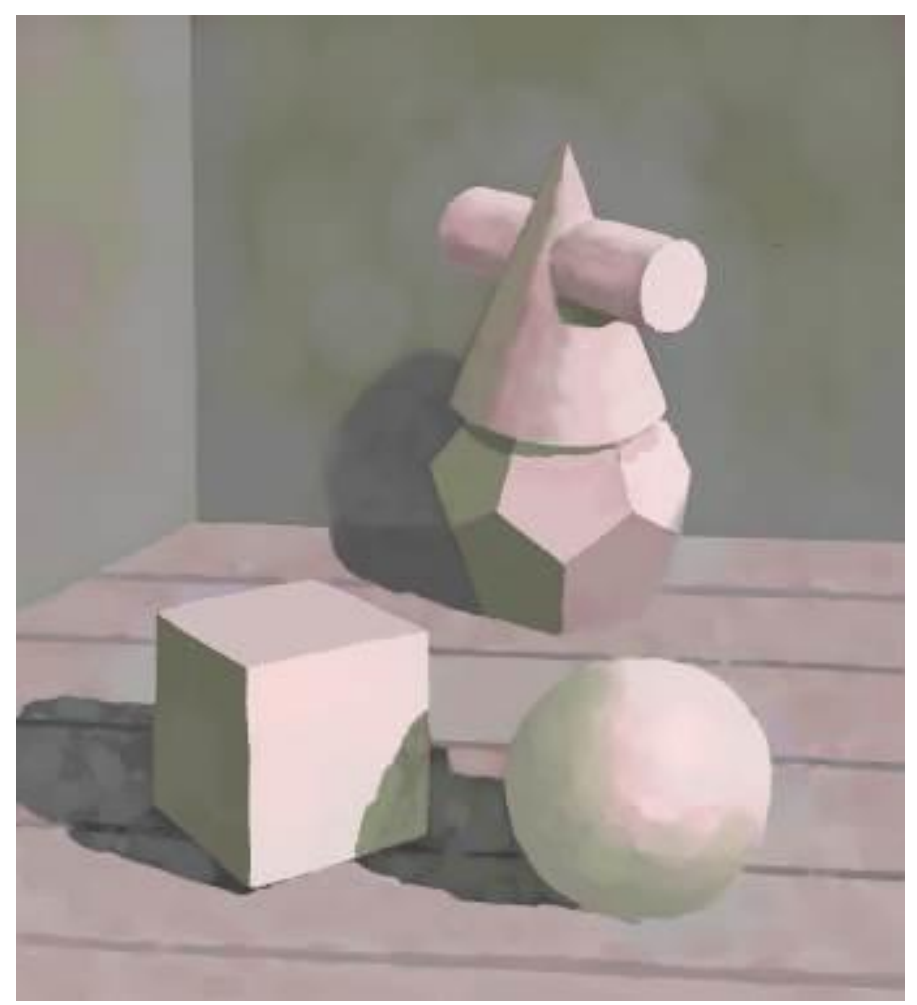

Gypsum graphics, diationic scale atonal form

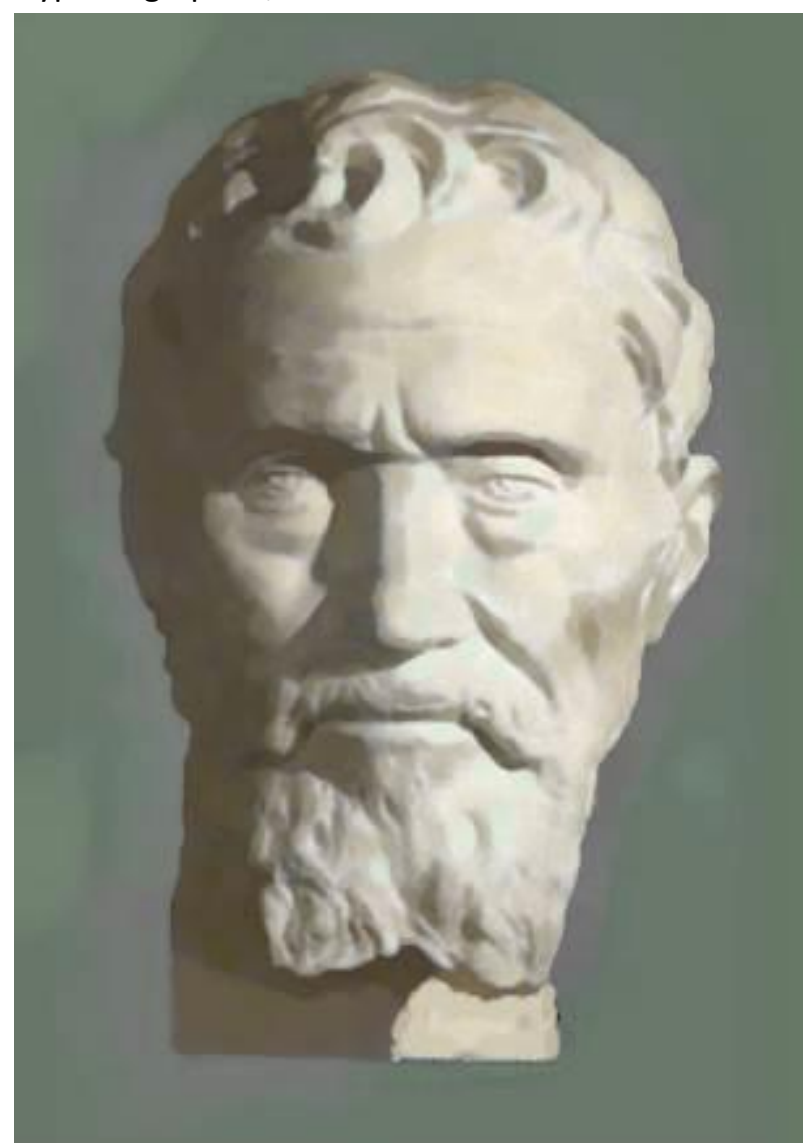

Gypsum graphics, diationic scale atonal form 


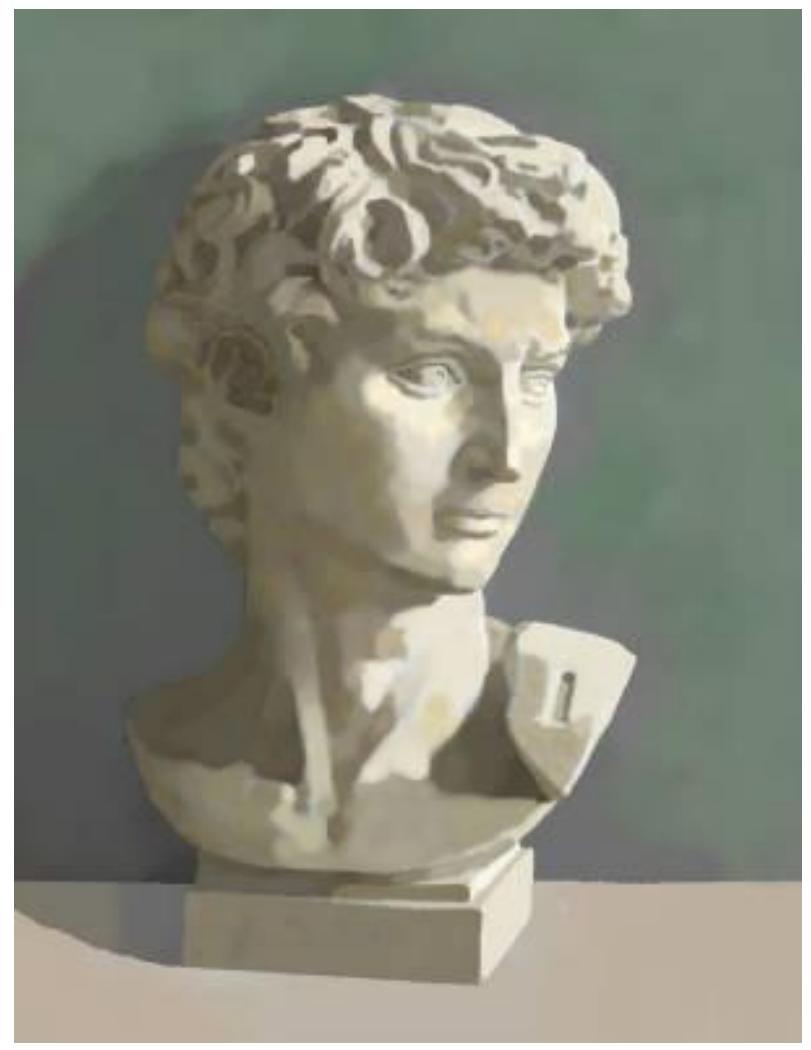

Gypsum graphics, diationic scale atonal form

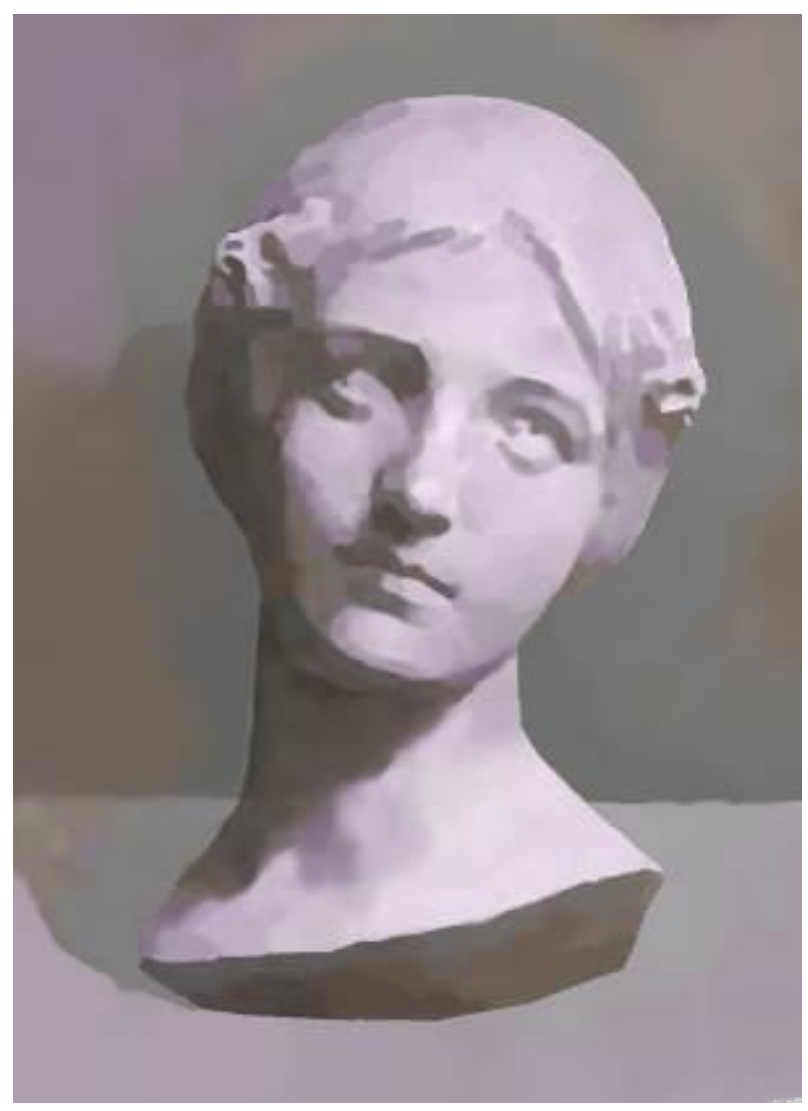

Gypsum graphics, diationic scale atonal form 


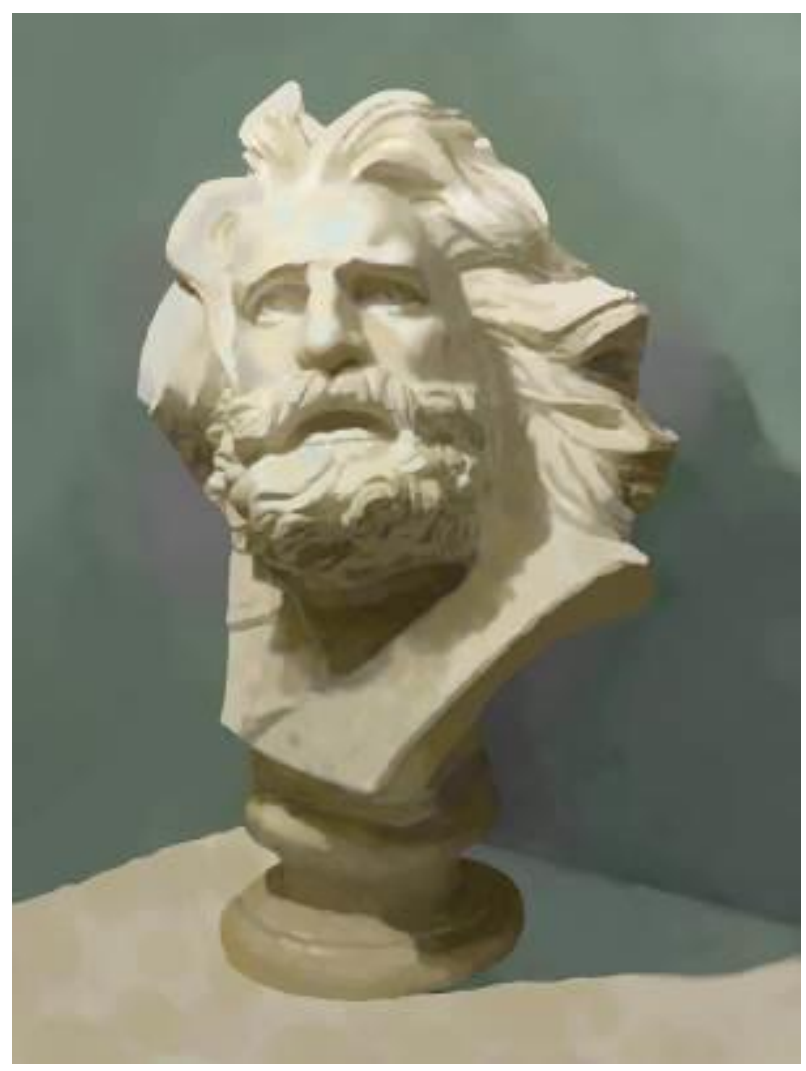

Gypsum graphics, diationic scale atonal form

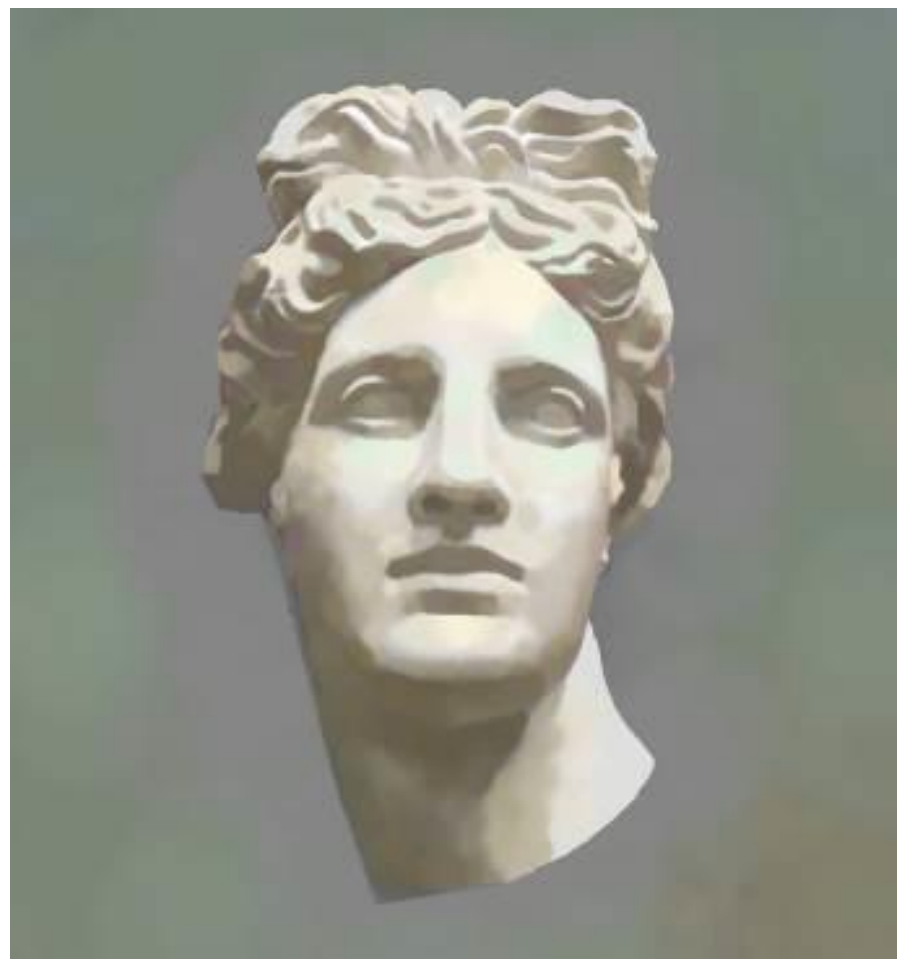

Gypsum graphics,diationic scale atonal form 
3、 Jazz Scale- Tonality

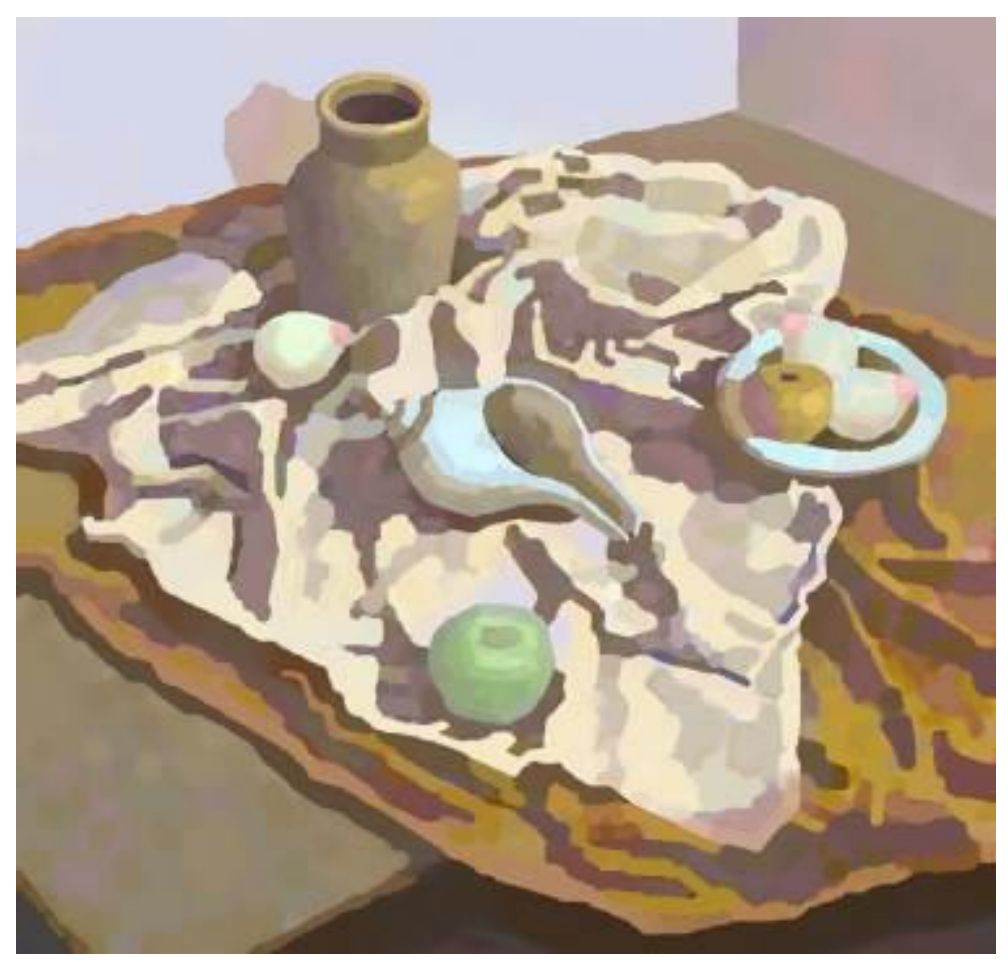

Still life,Jazz scale \#f minor

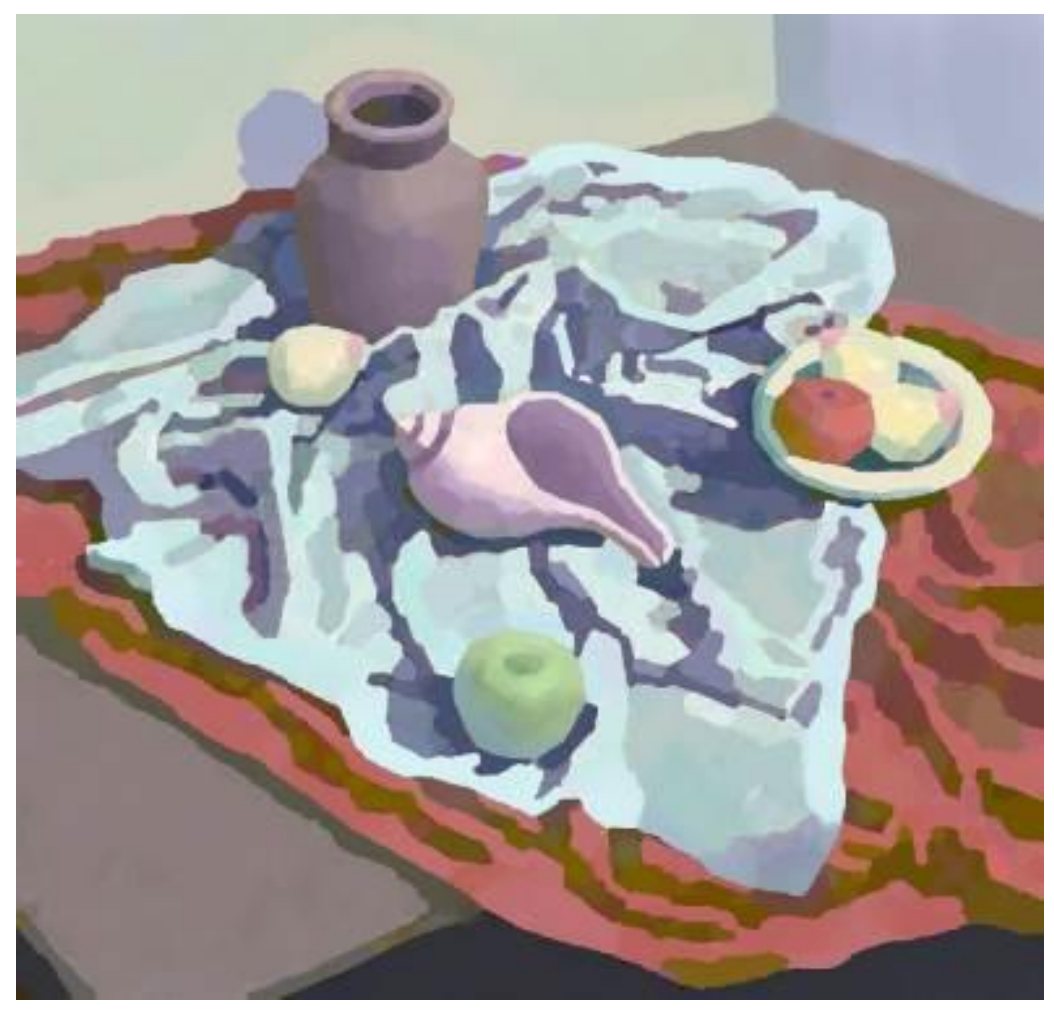

Still life,Jazz scale C major 


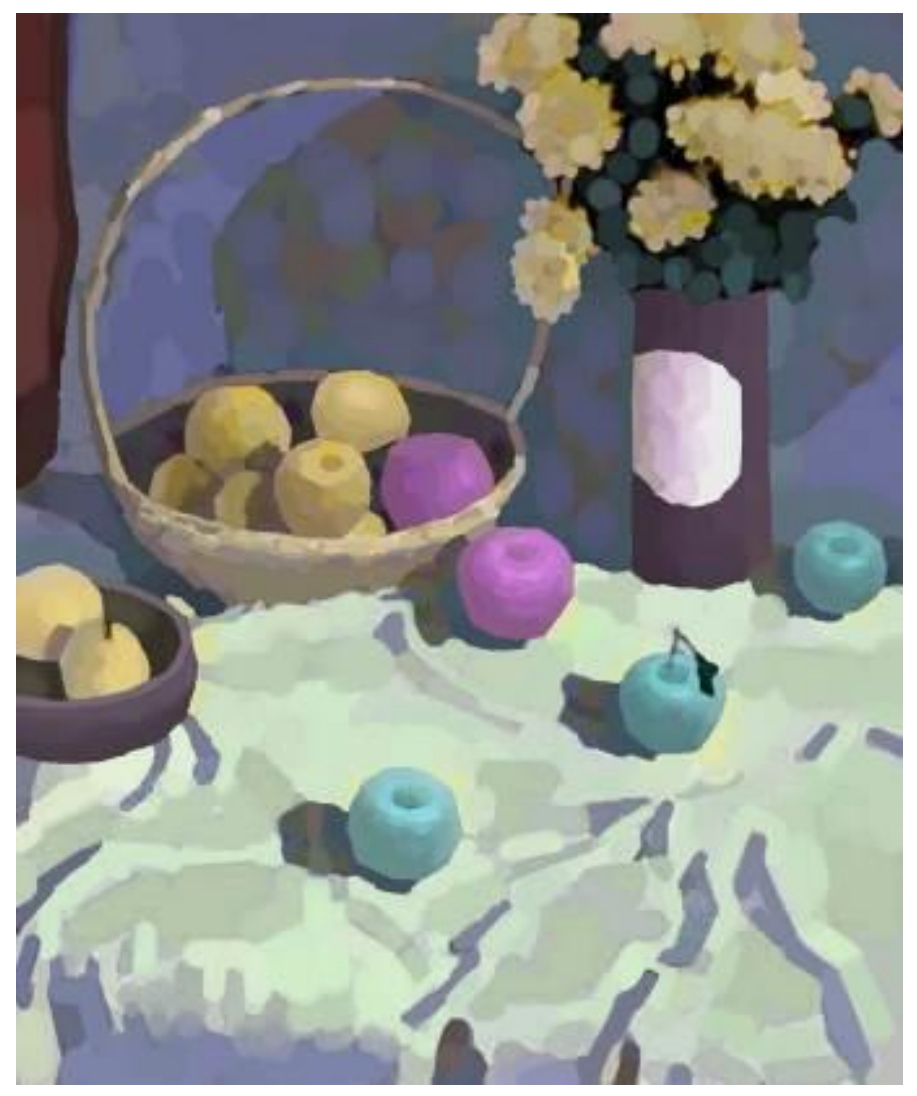

Still life,Jazz scale A major

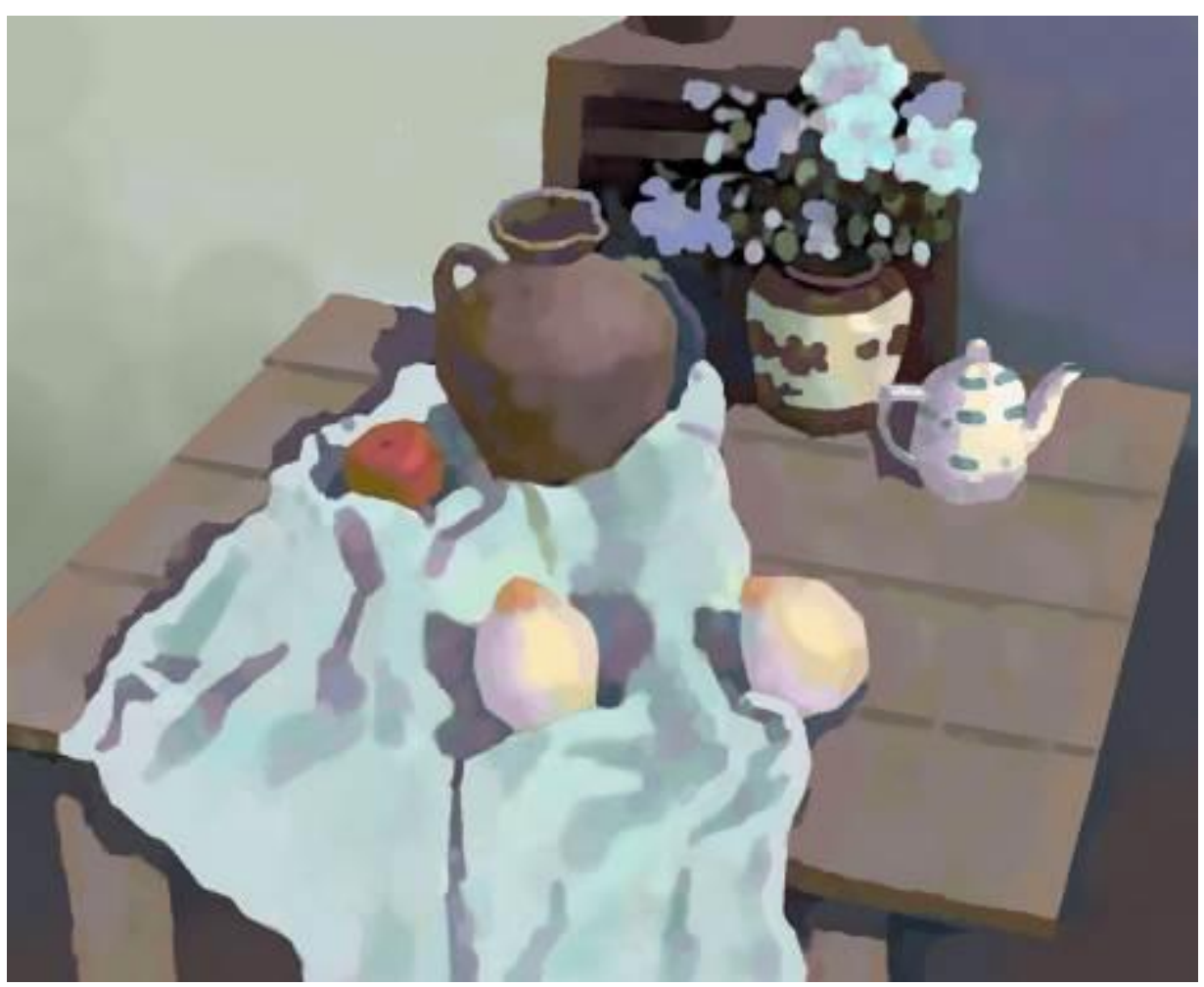

Still life,Jazz scale C major 


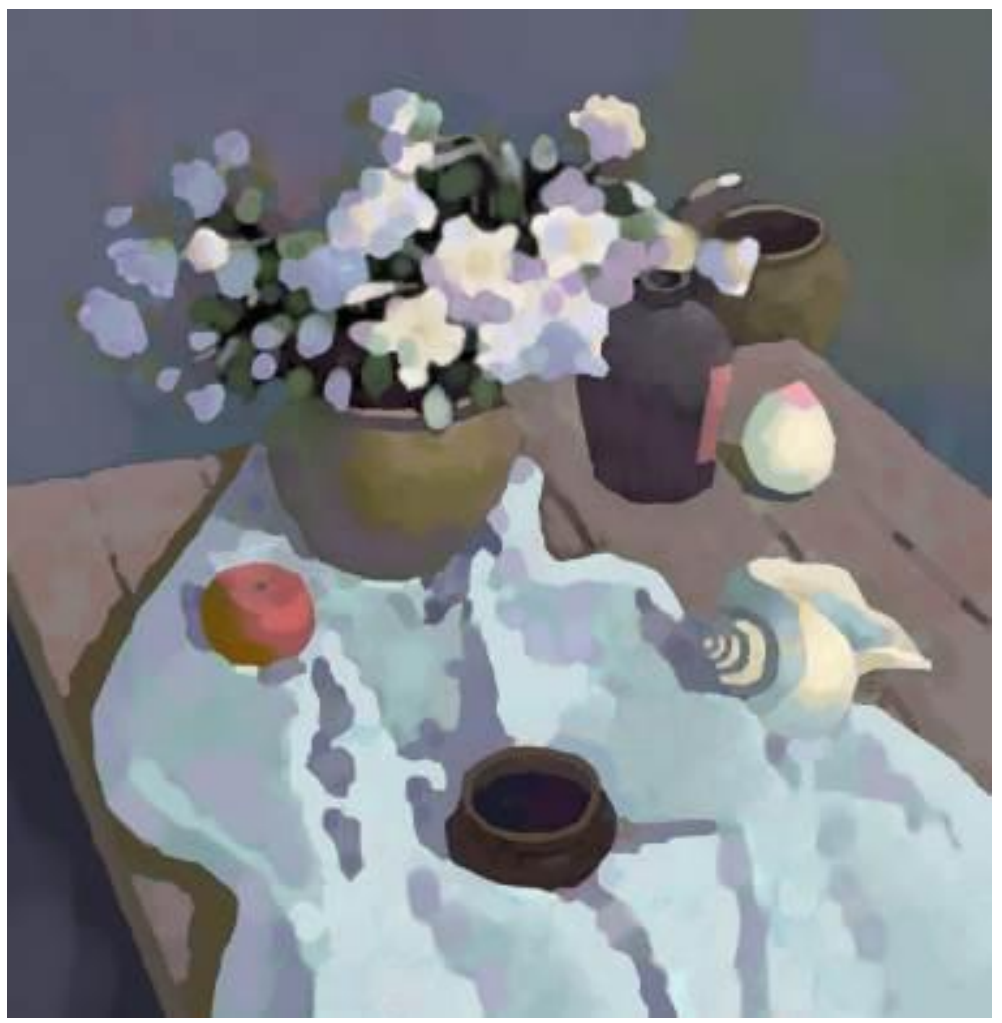

Still life,Jazz scale C major

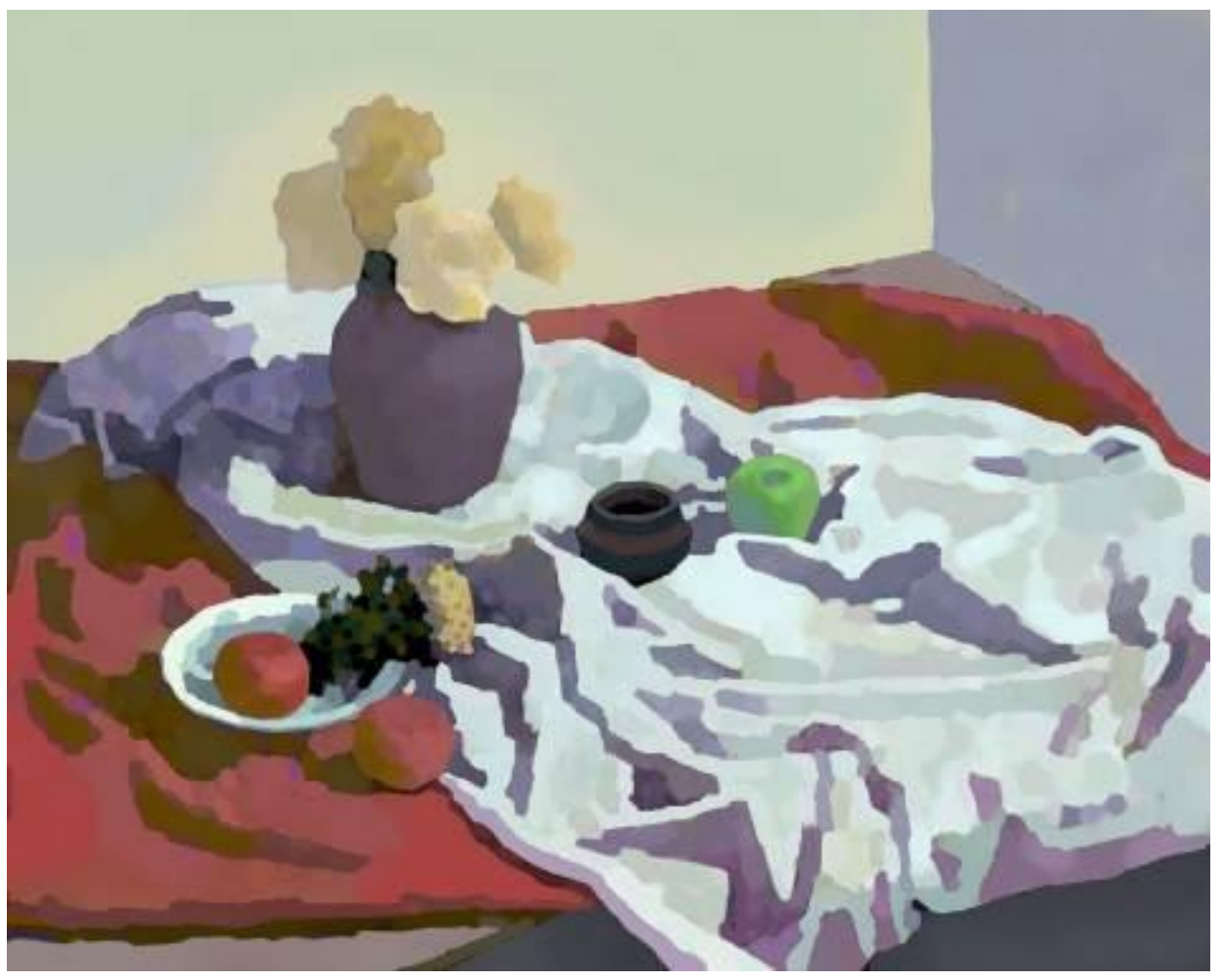

Still life,Jazz scale\#f minor 


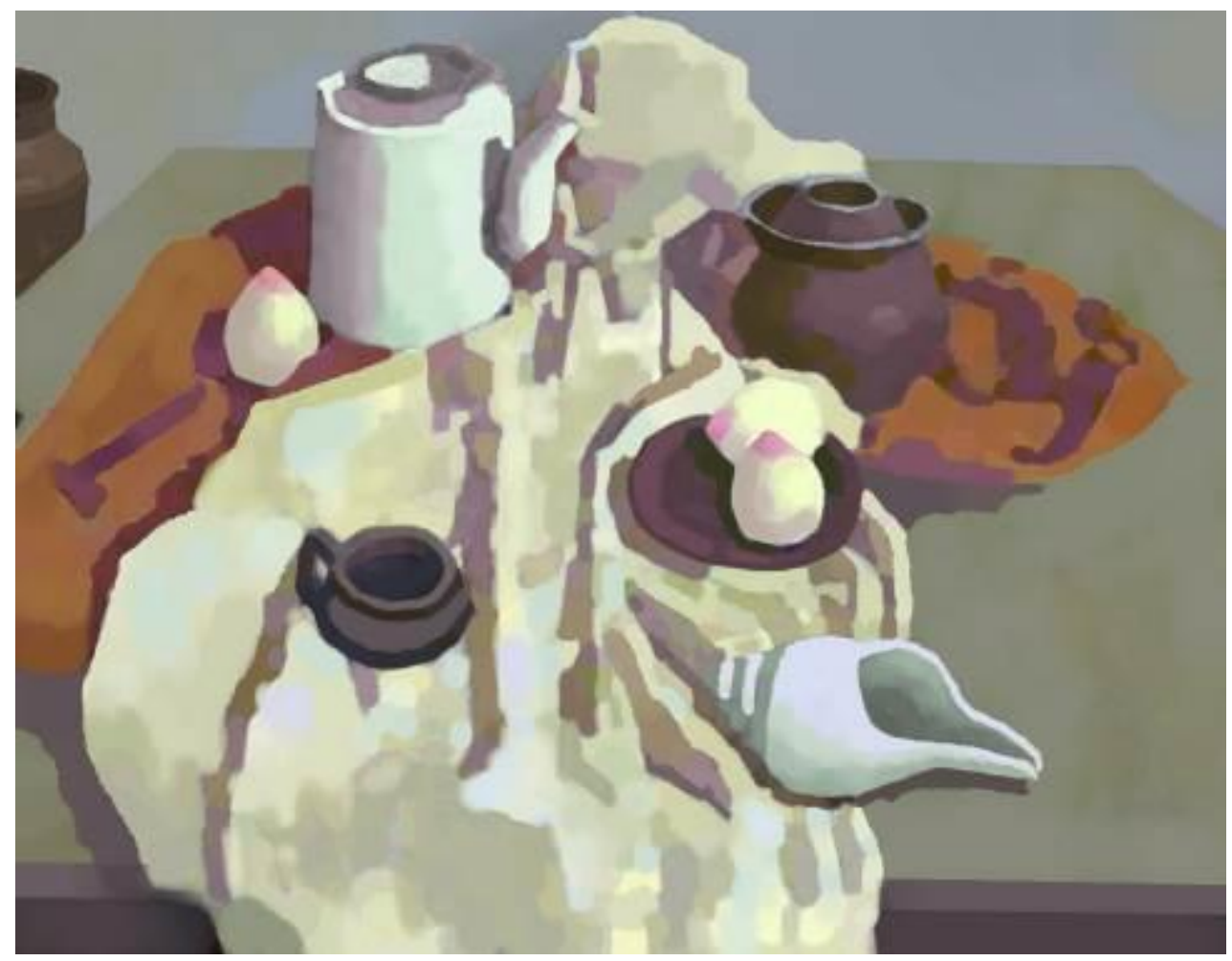

Still life,Jazz scale g minor

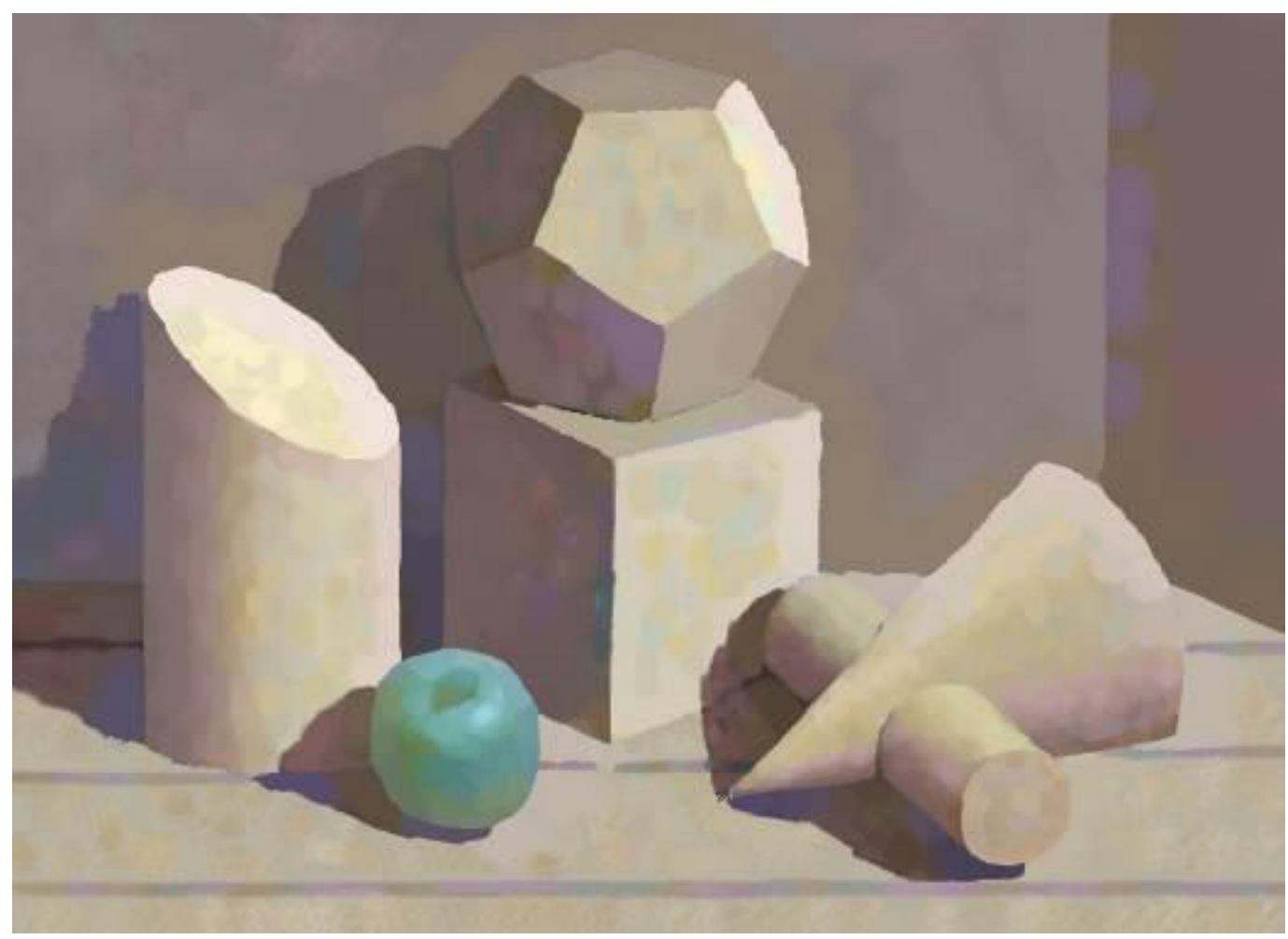

Plaster cast, jazz scale in \#f minor 


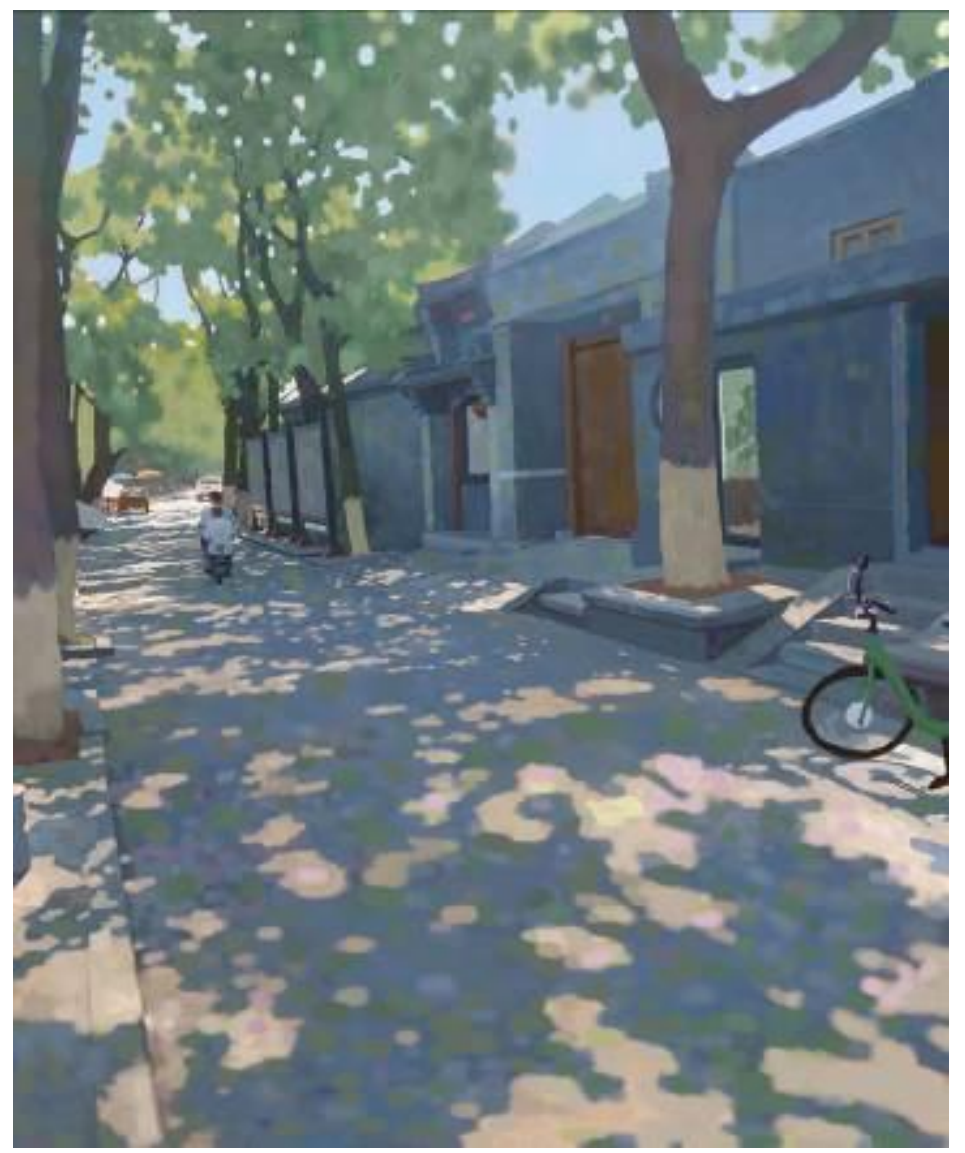

Beijing hutong, jazz scale $b$ minor

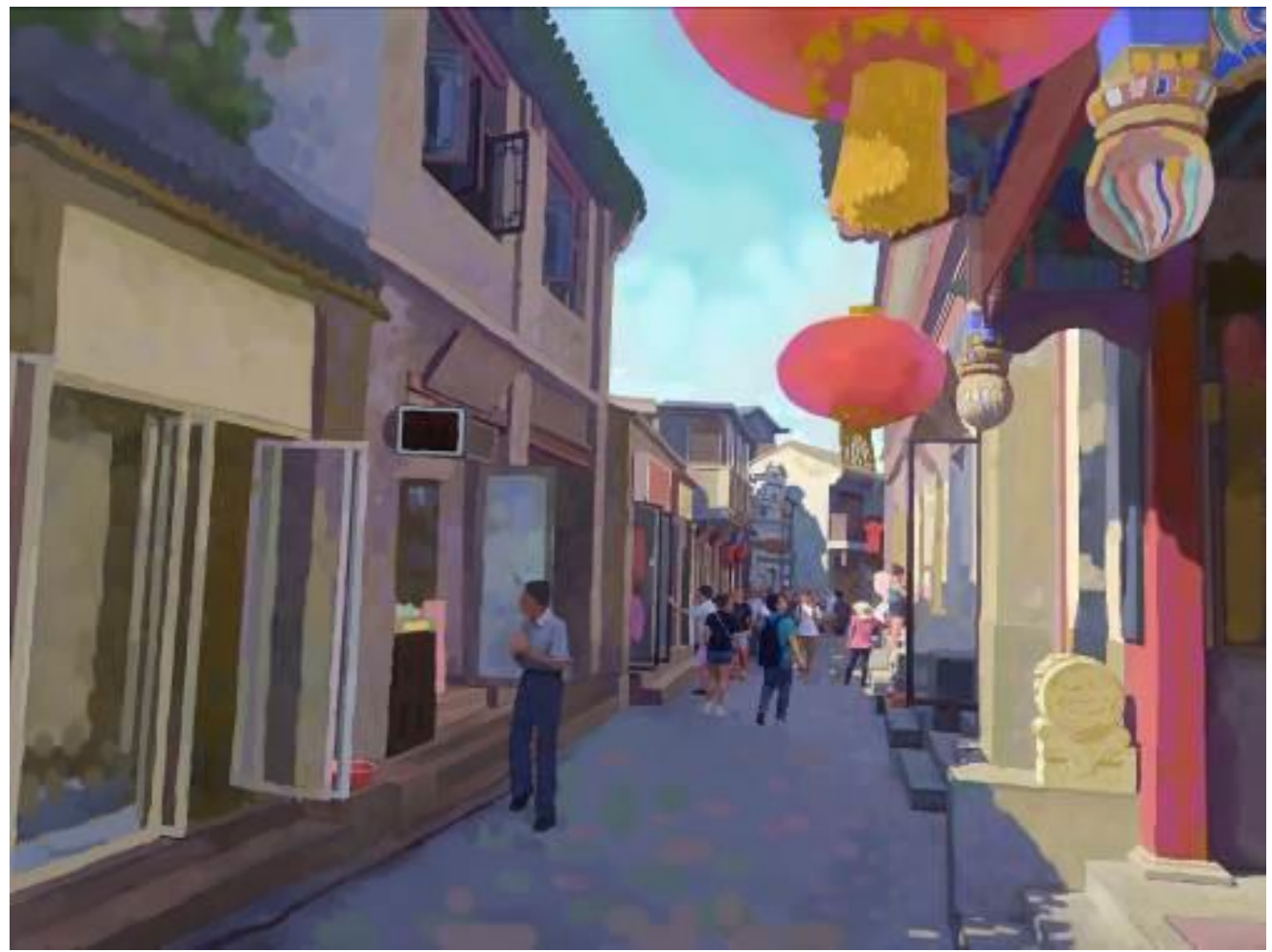

Beijing hutong, jazz scale $\mathrm{C}$ major 


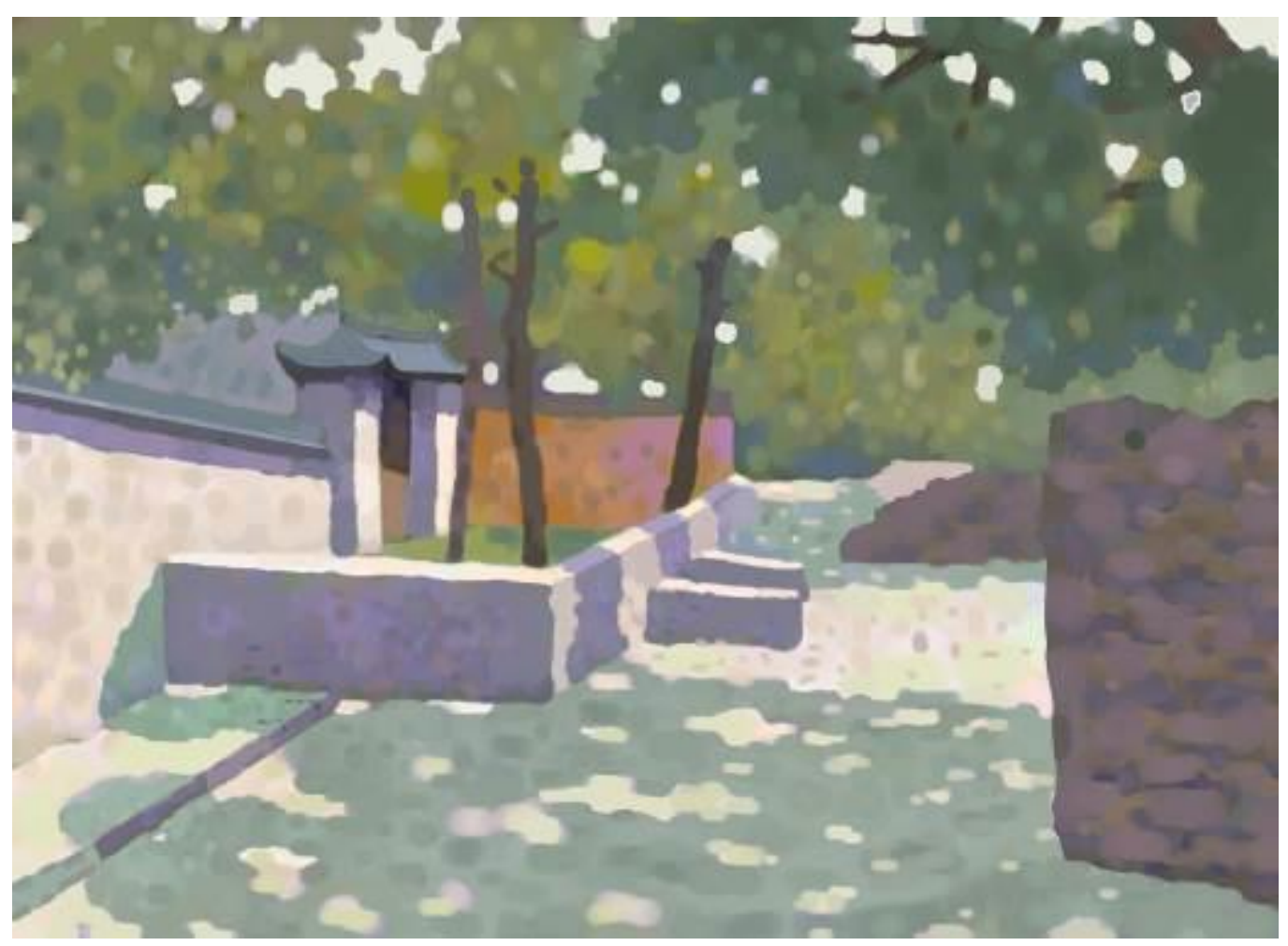

The home of cao xueqin jazz scale A major

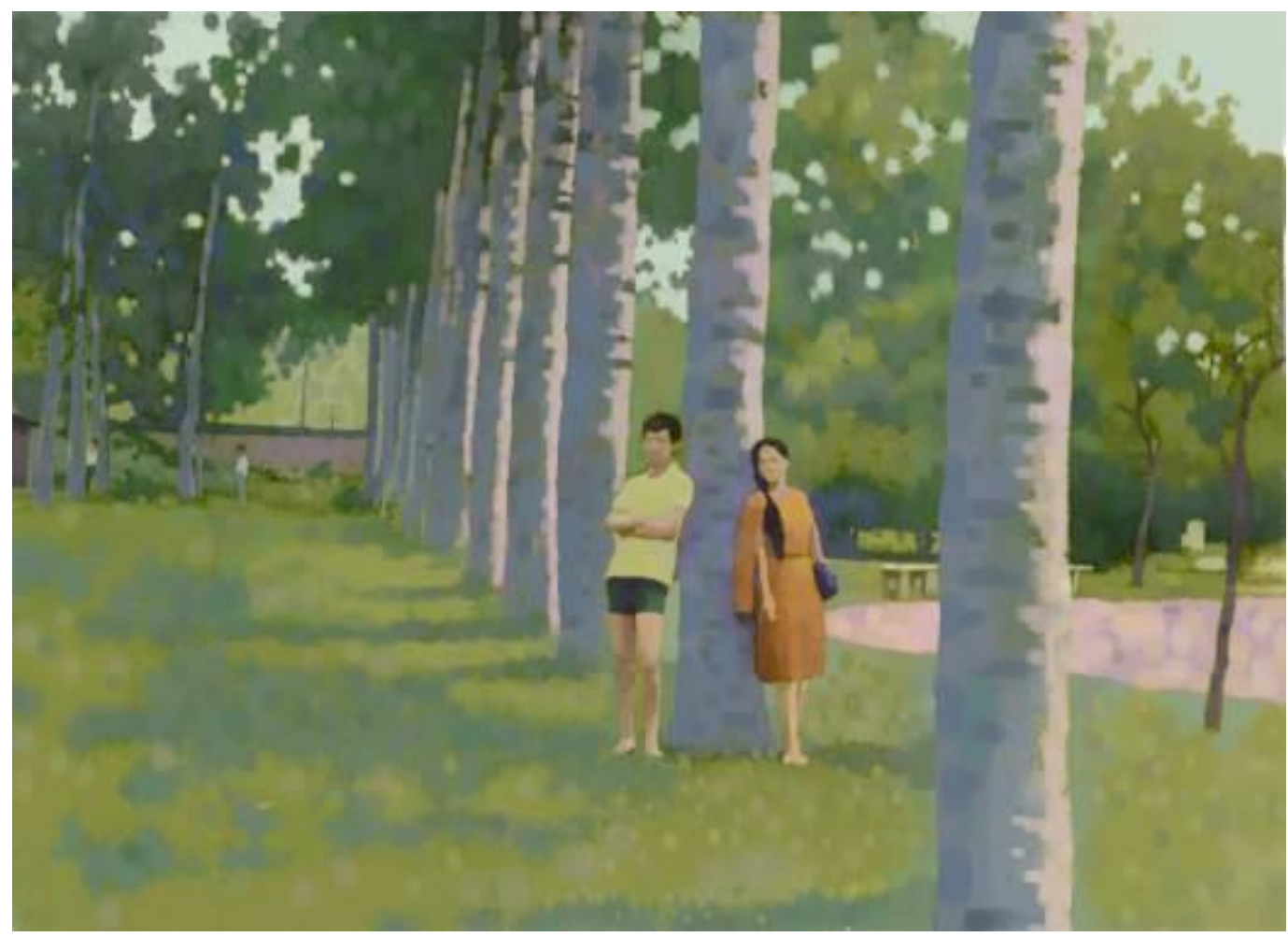

Poplar forest in the sun, jazz scale in A major 


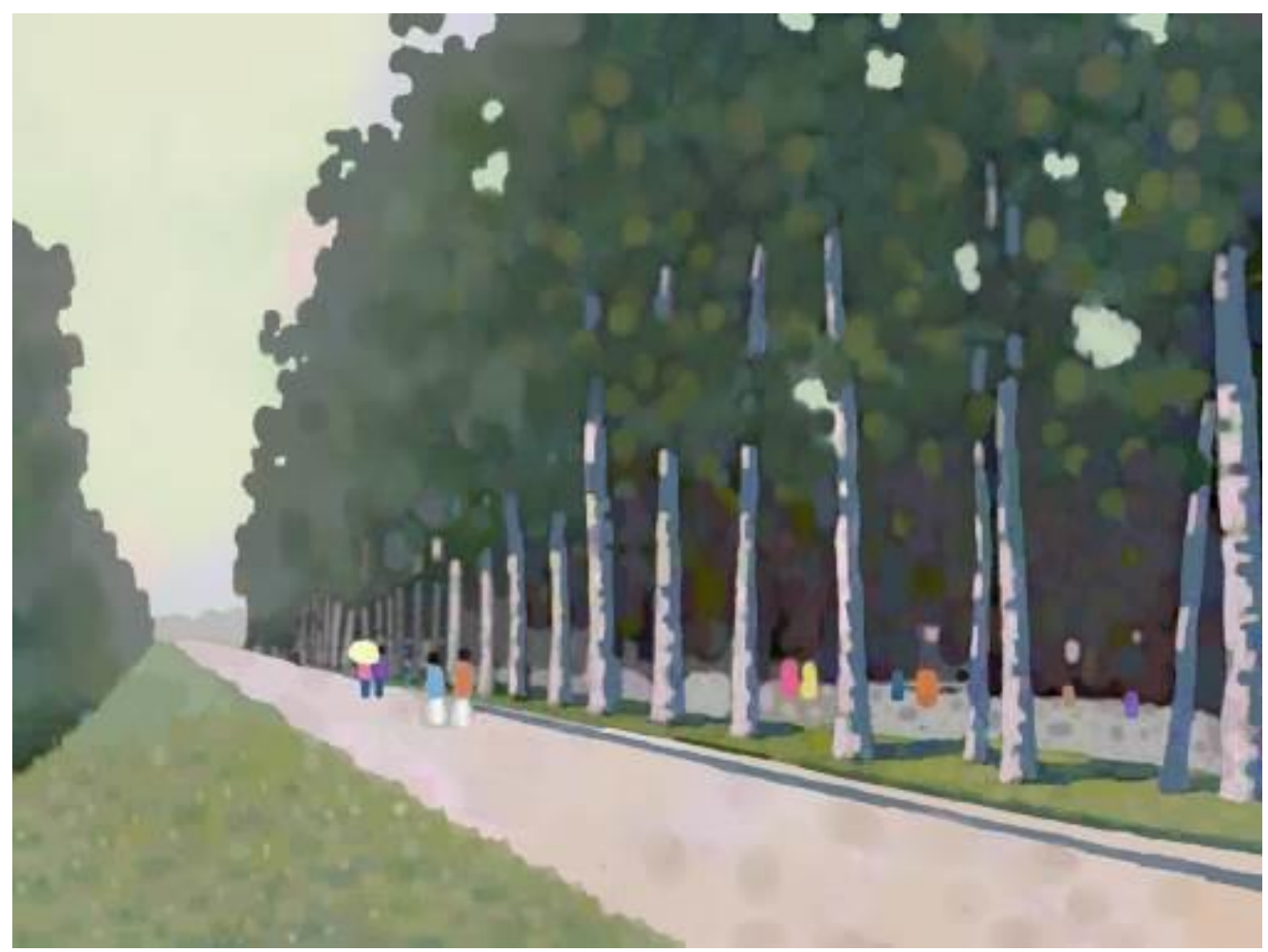

Aspen, jazz scale A major

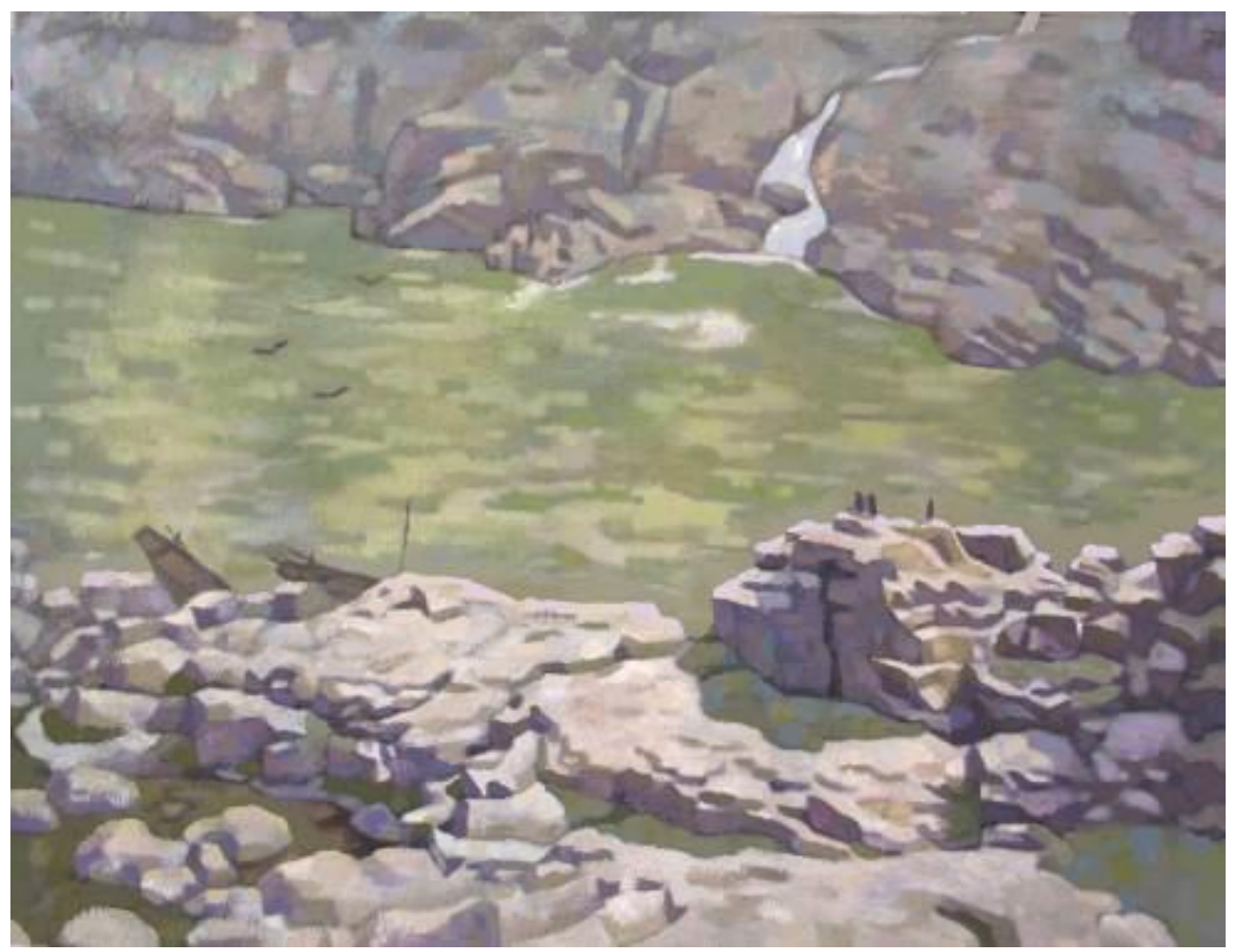

Jinsha river valley, jazz scale g minor 


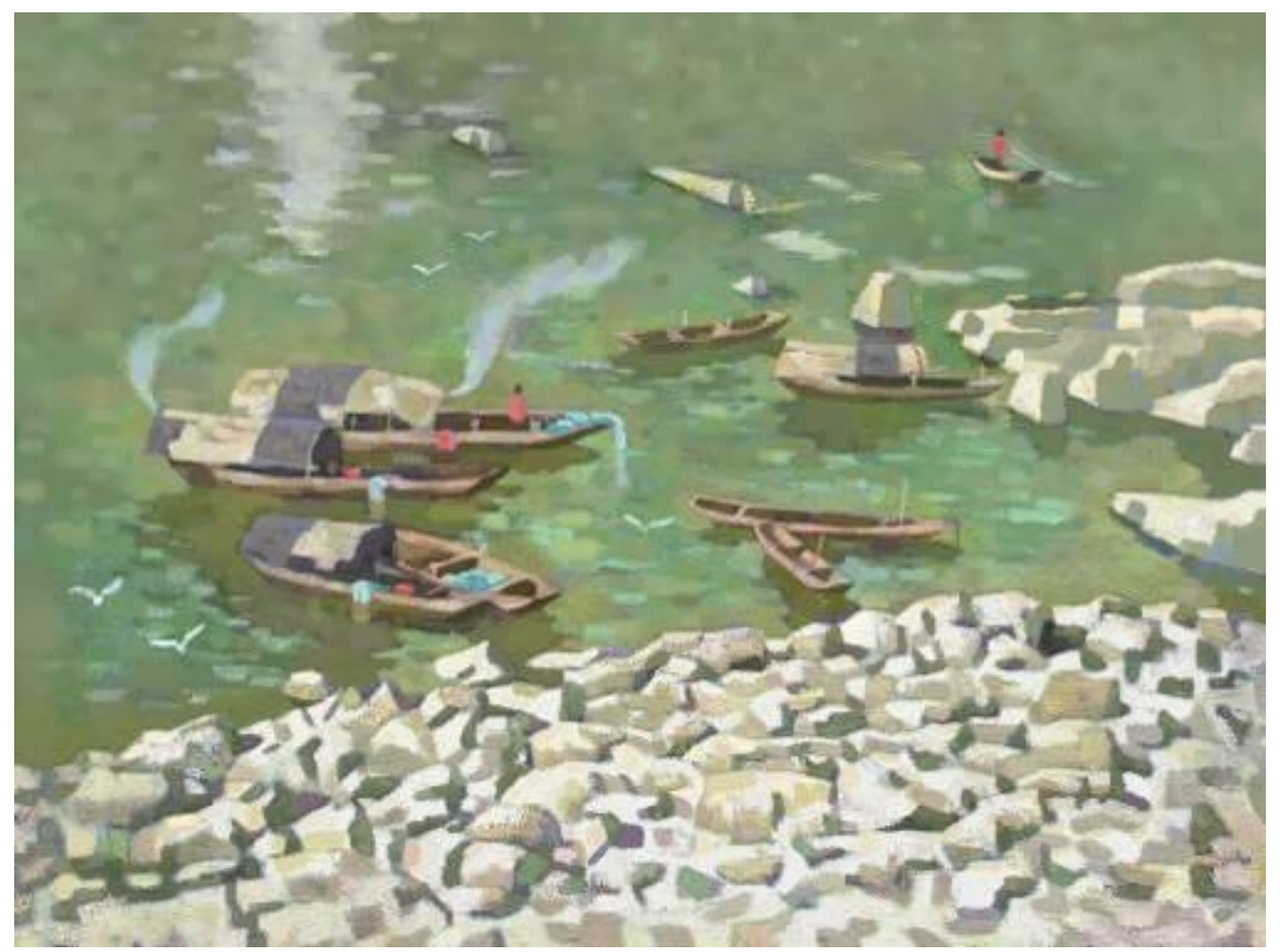

Riverside, jazz scale bA major

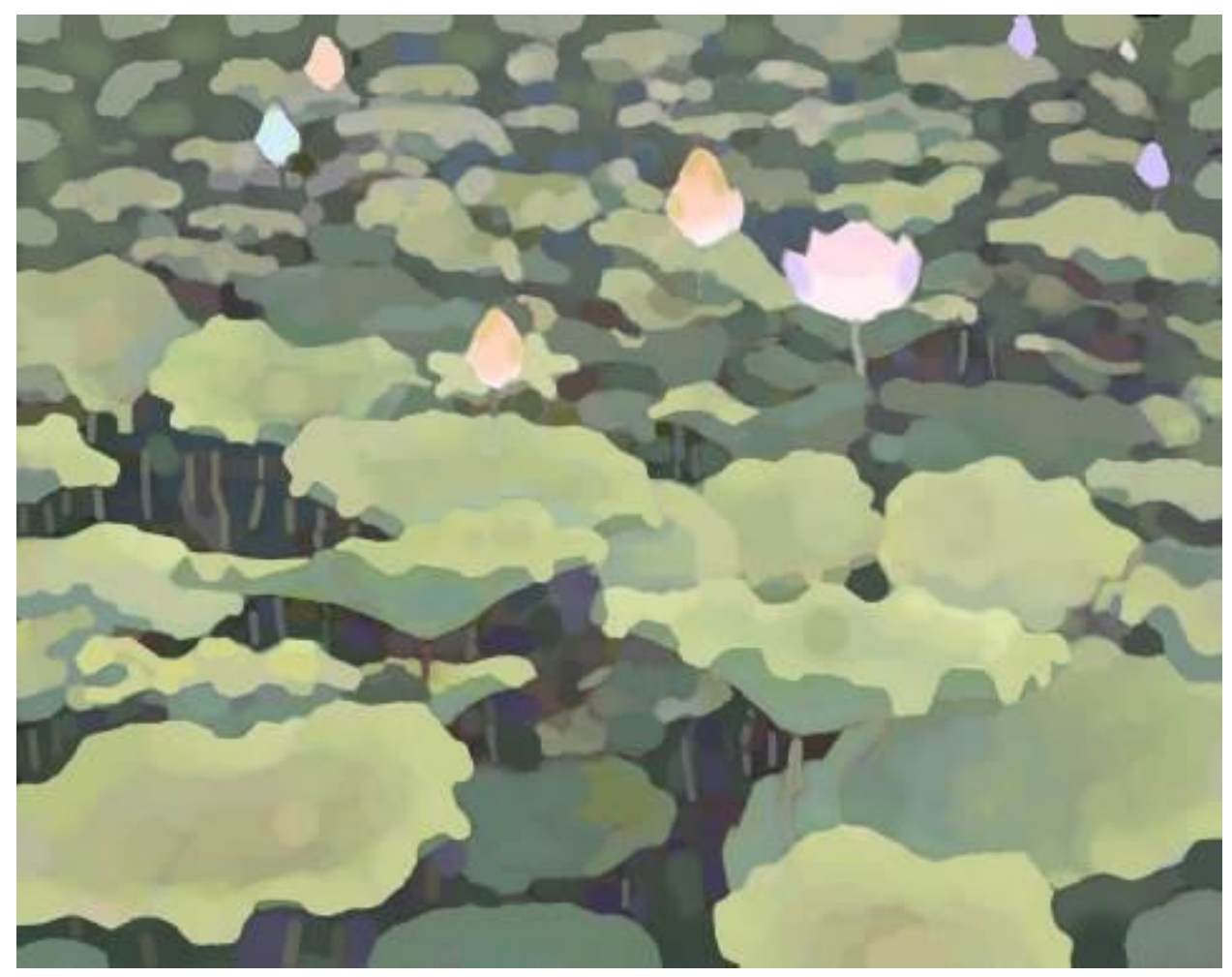

Dutch, jazz scale A major 


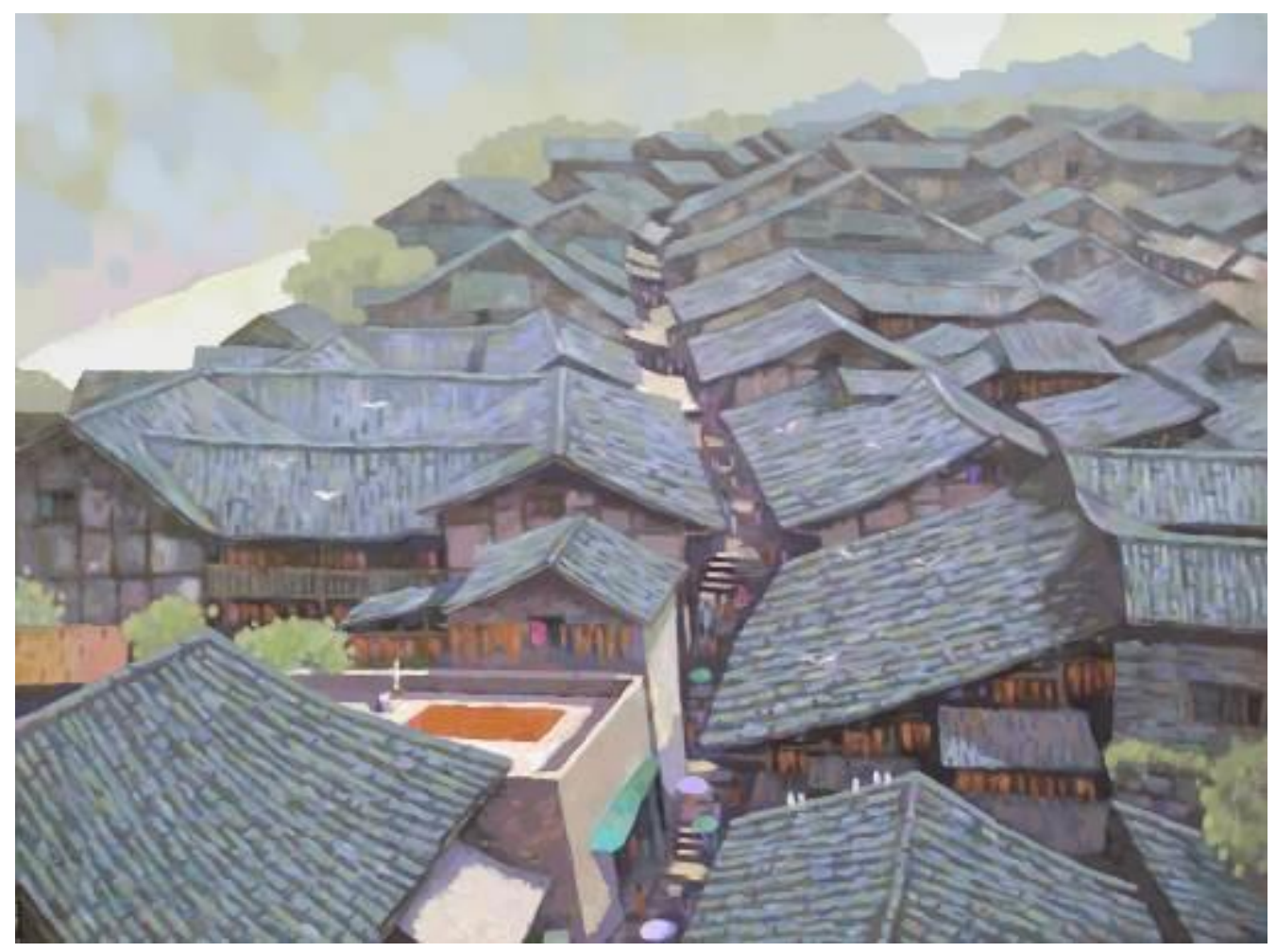

Town, jazz scale b minor

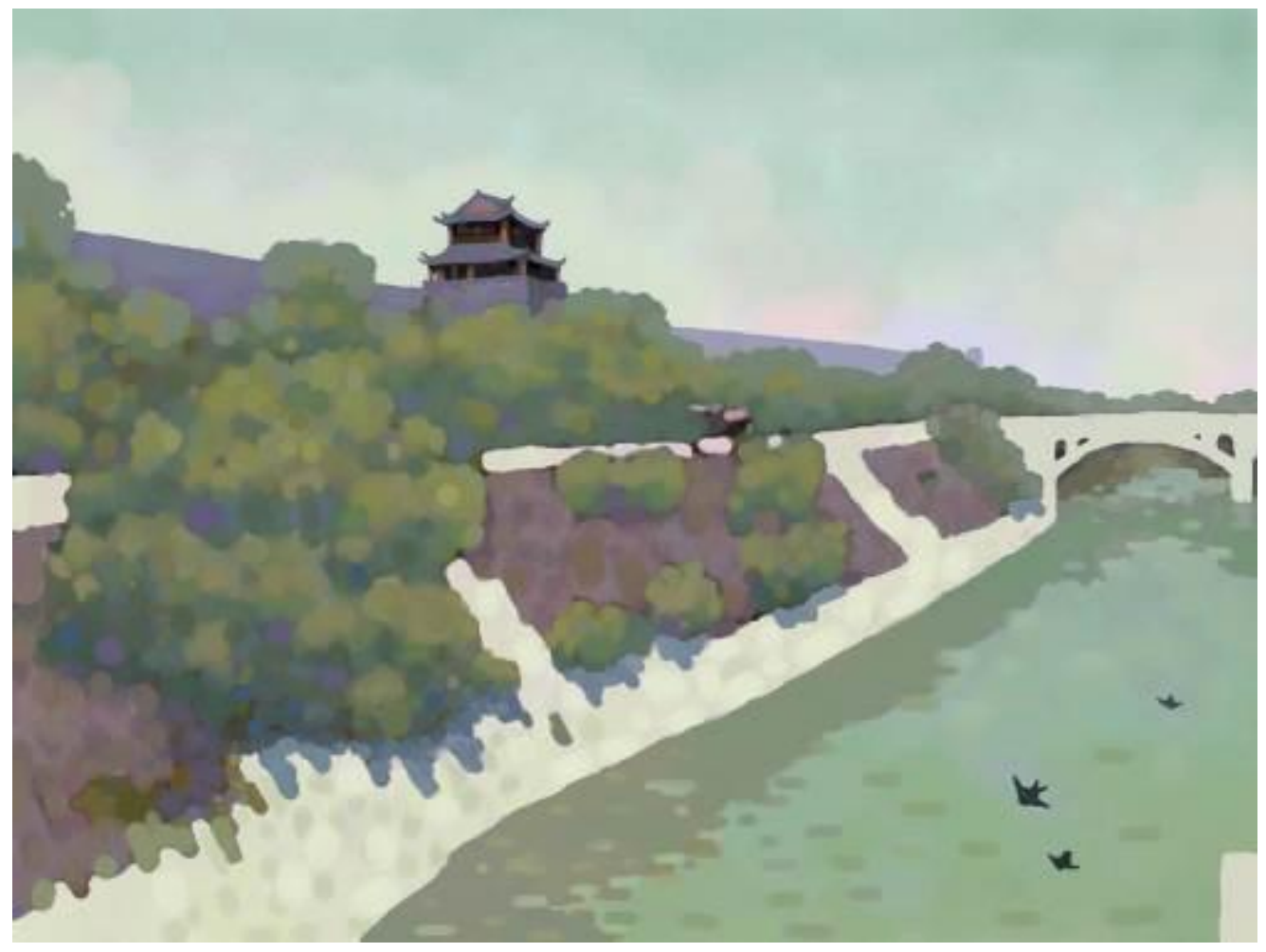

$X i$ 'an moat, jazz scale in A major 


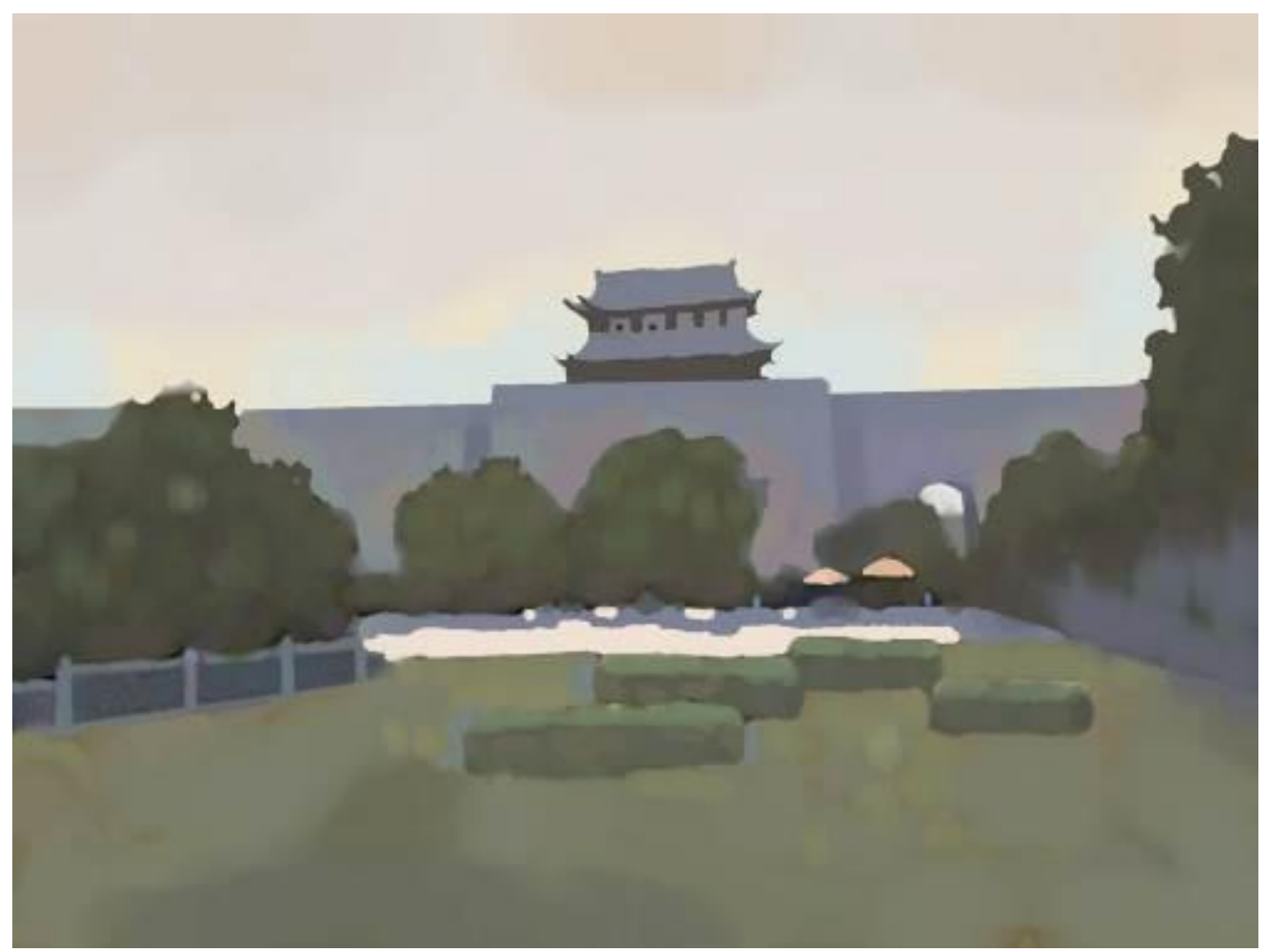

Town, jazz scale b minor

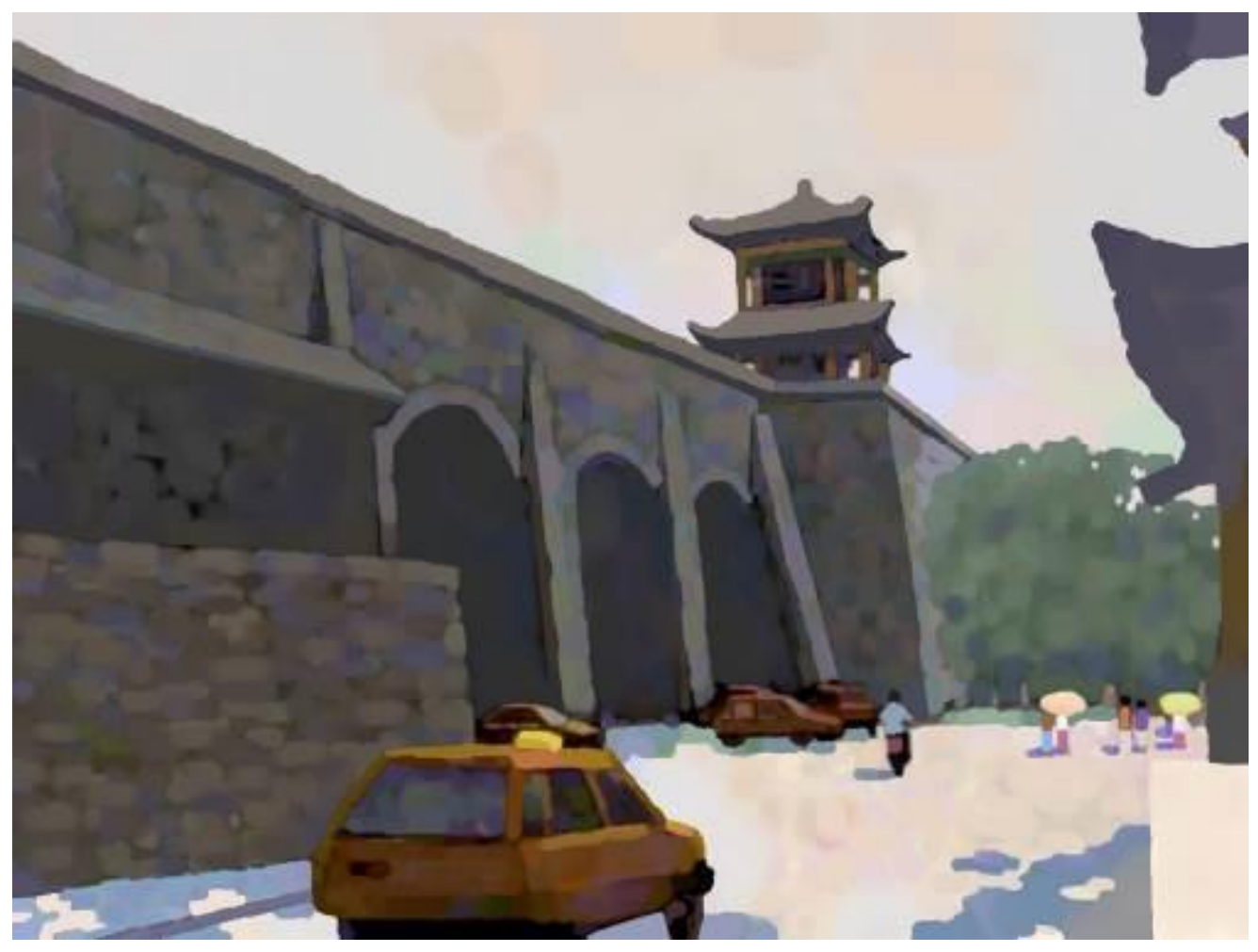

$\mathrm{Xi}$ 'an moat, jazz scale in $\mathrm{F}$ major 


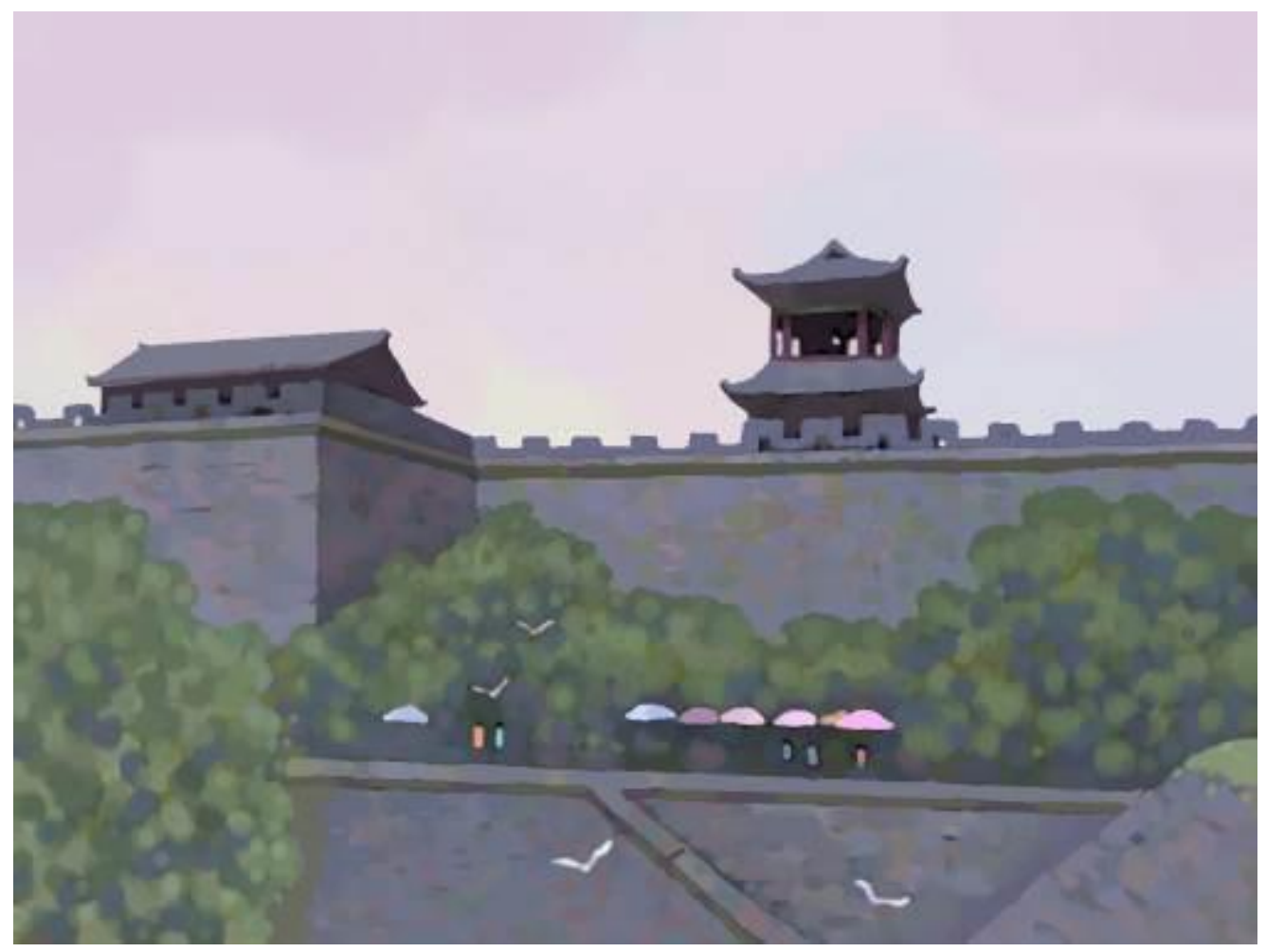

Jazz scale bA major

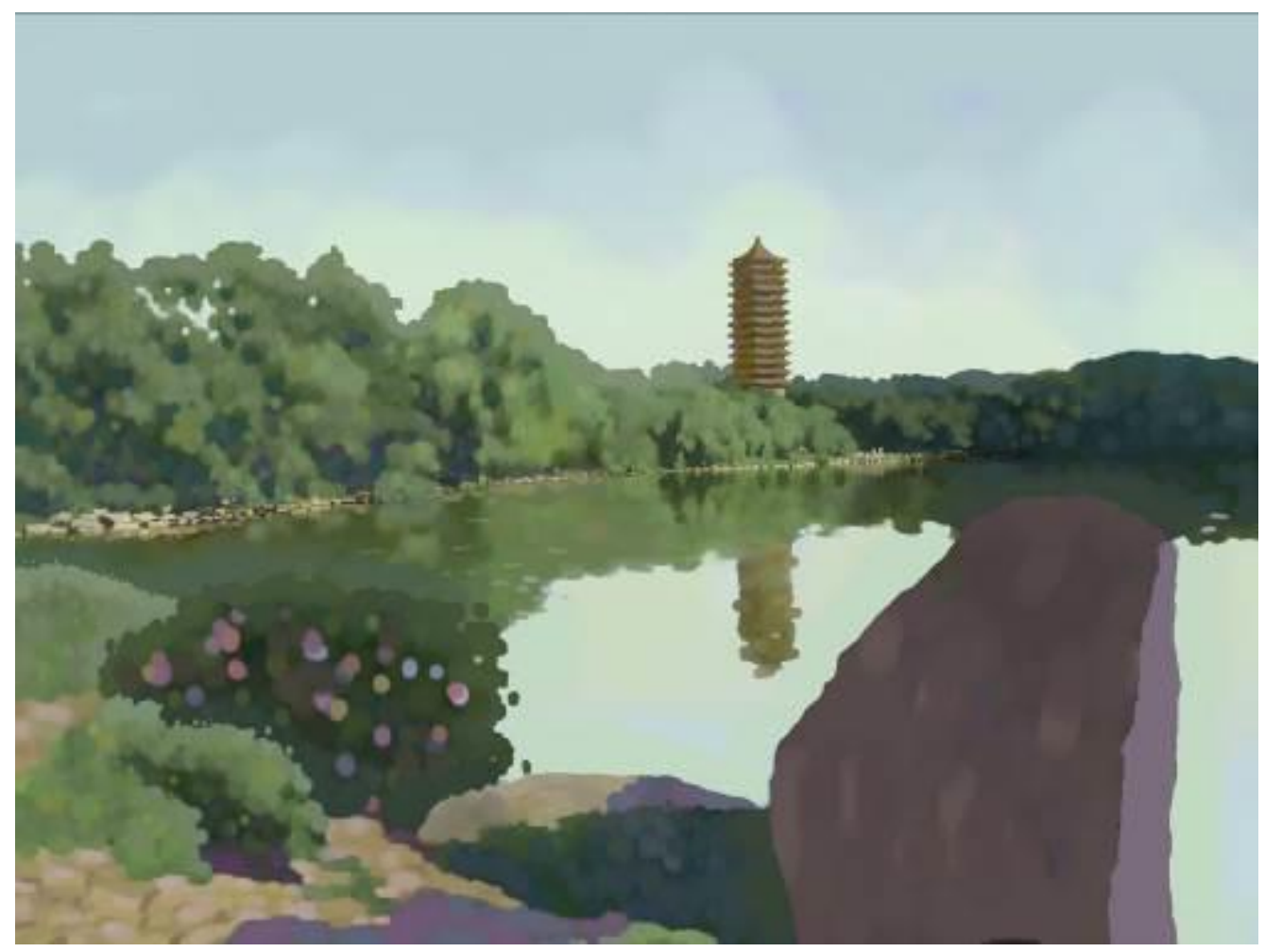

Lake, jazz scale in bB minor 


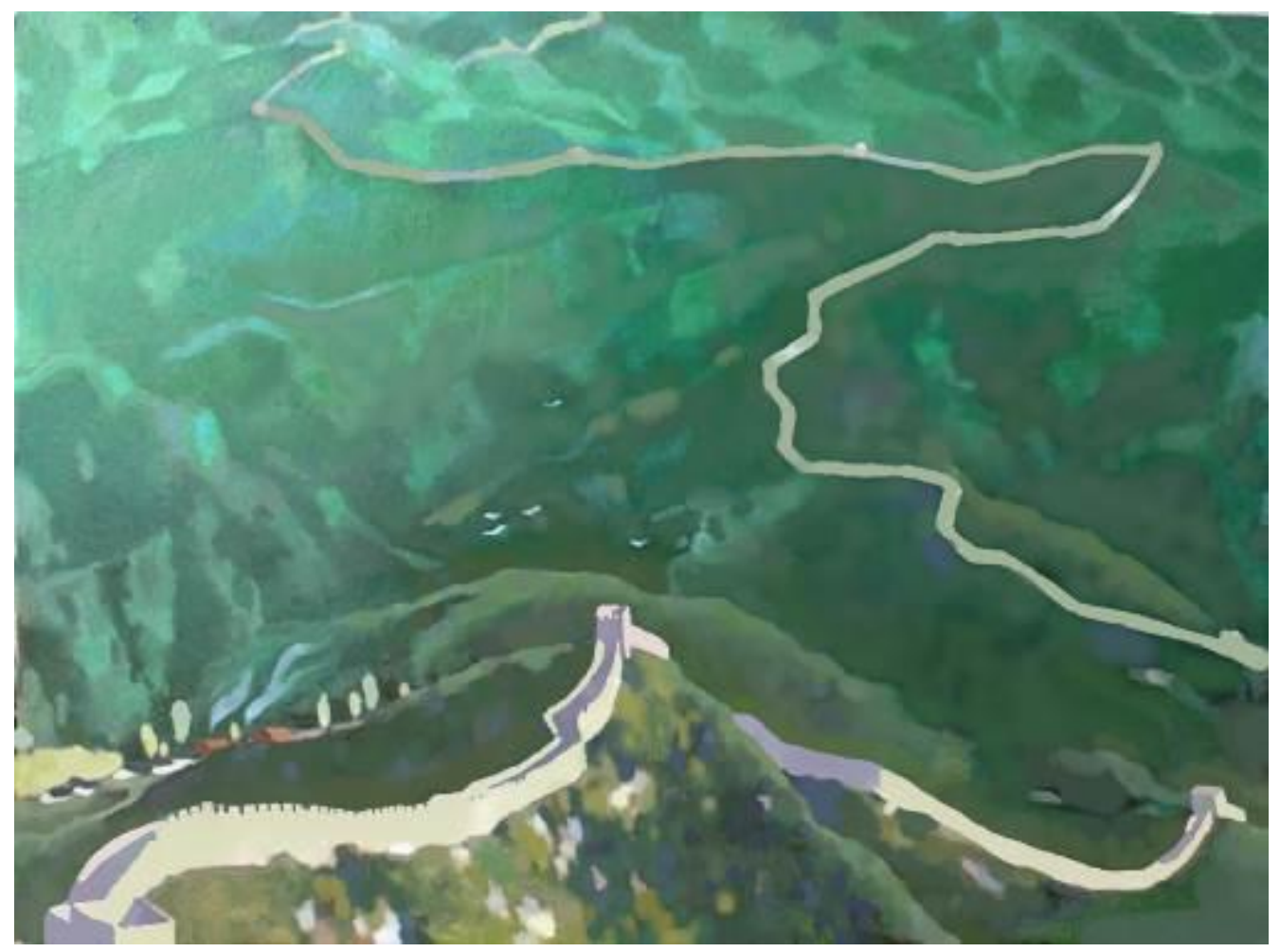

Great Wall, jazz scale in A major

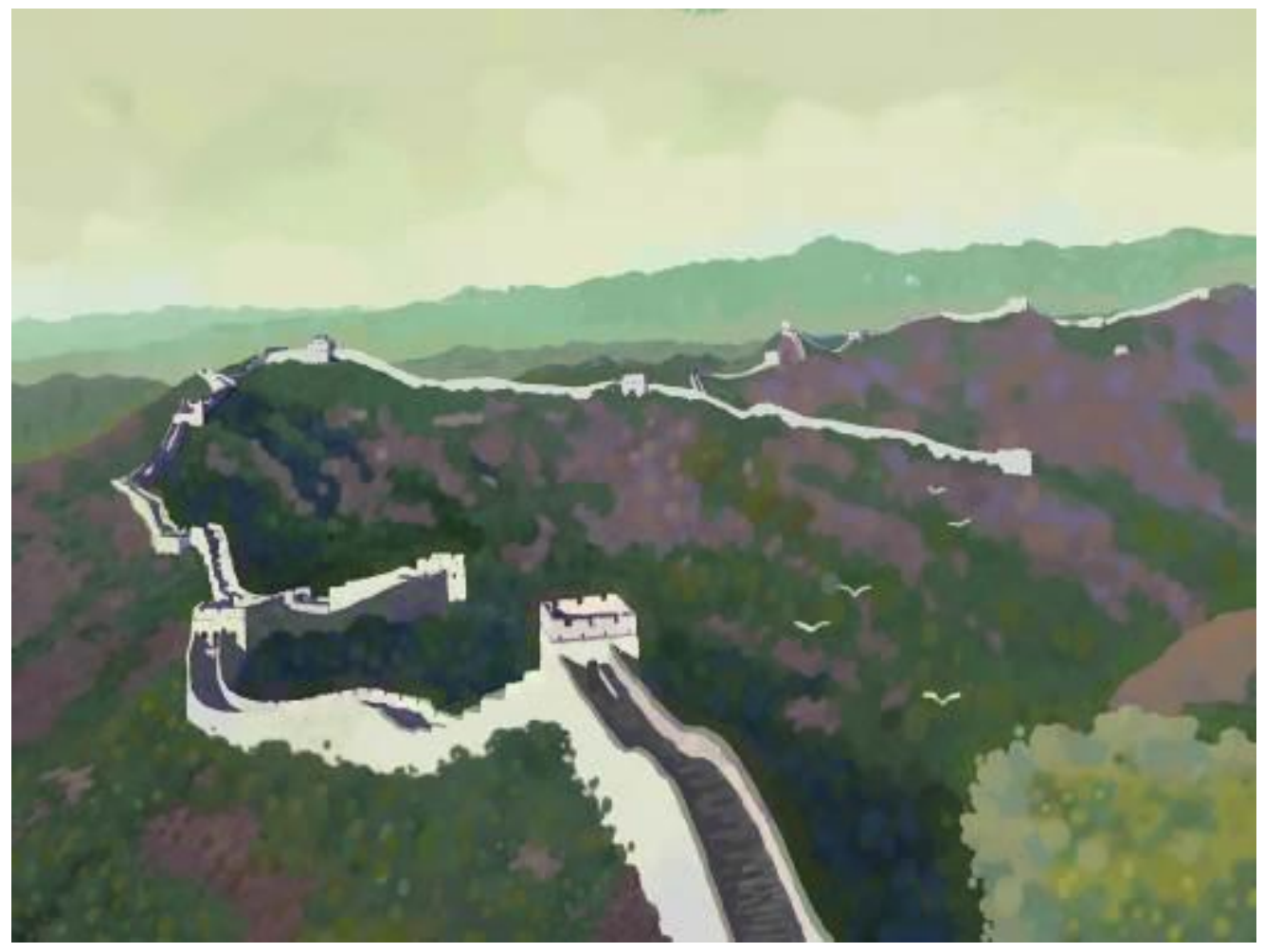

Great Wall, jazz scale in A major 


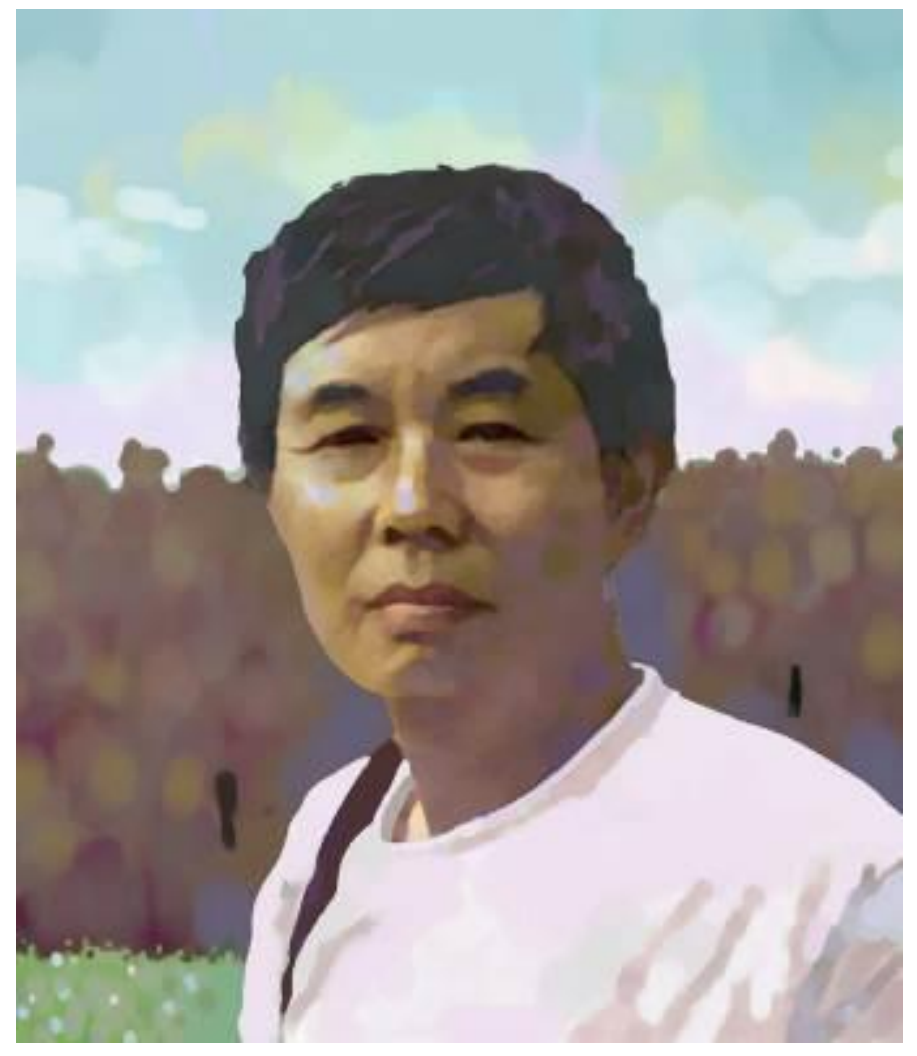

Self-portrait, jazz scale \#F minor

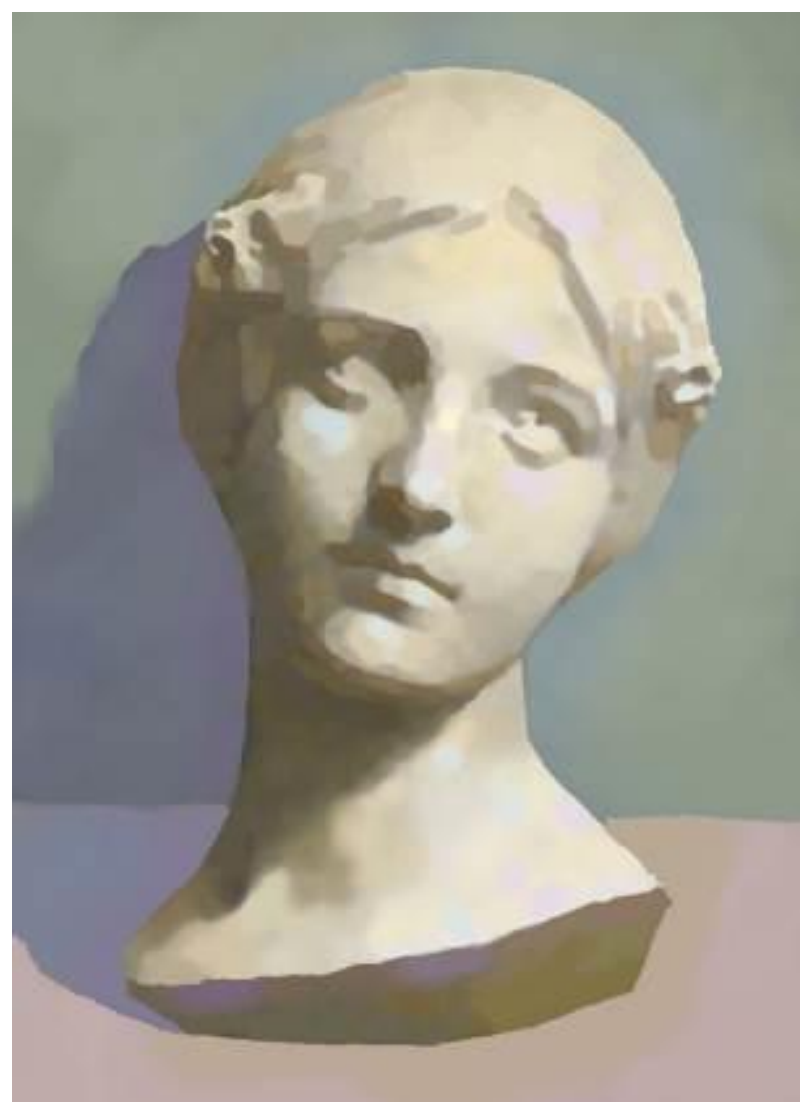

Plaster, jazz scale \#F minor 


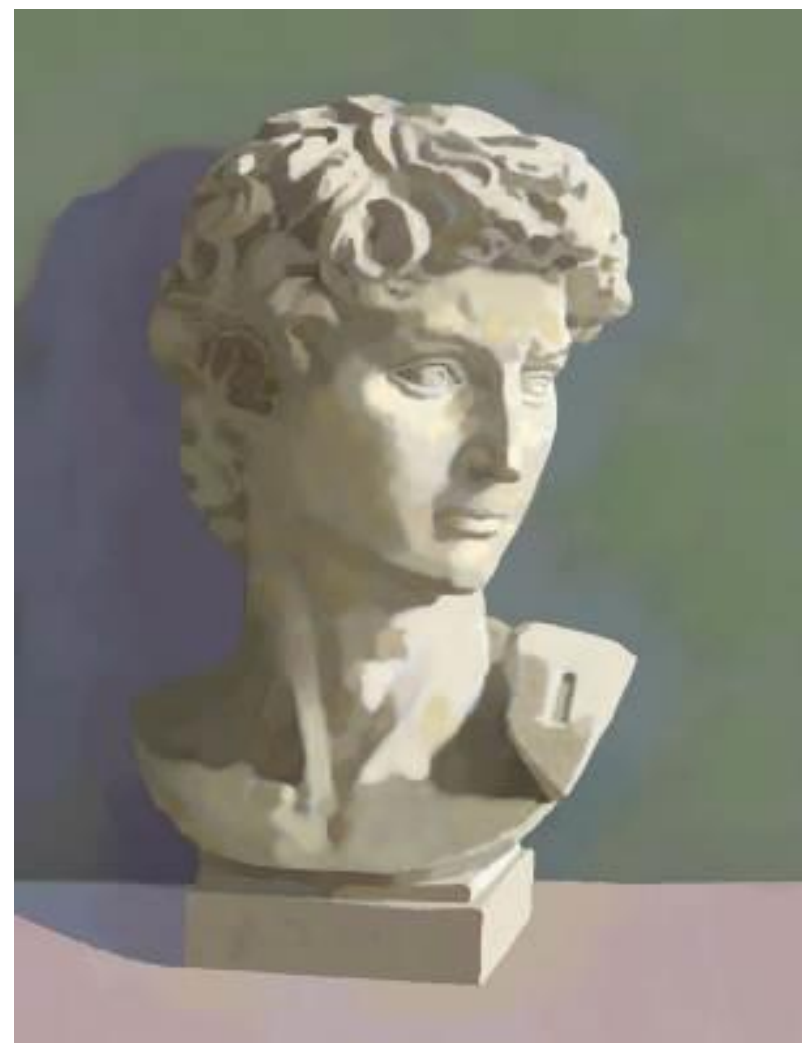

Plaster, jazz scale \#F minor

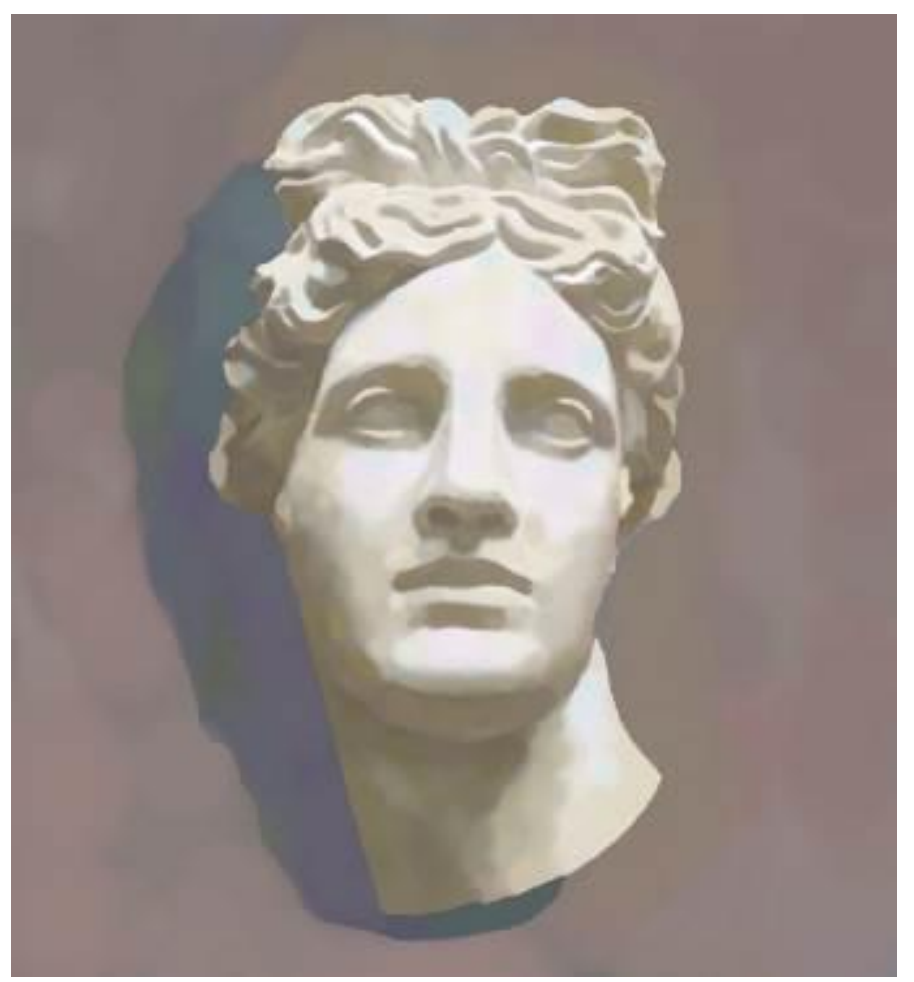

Plaster, jazz scale \#F minor 
4、Jazz Scale-Atonal

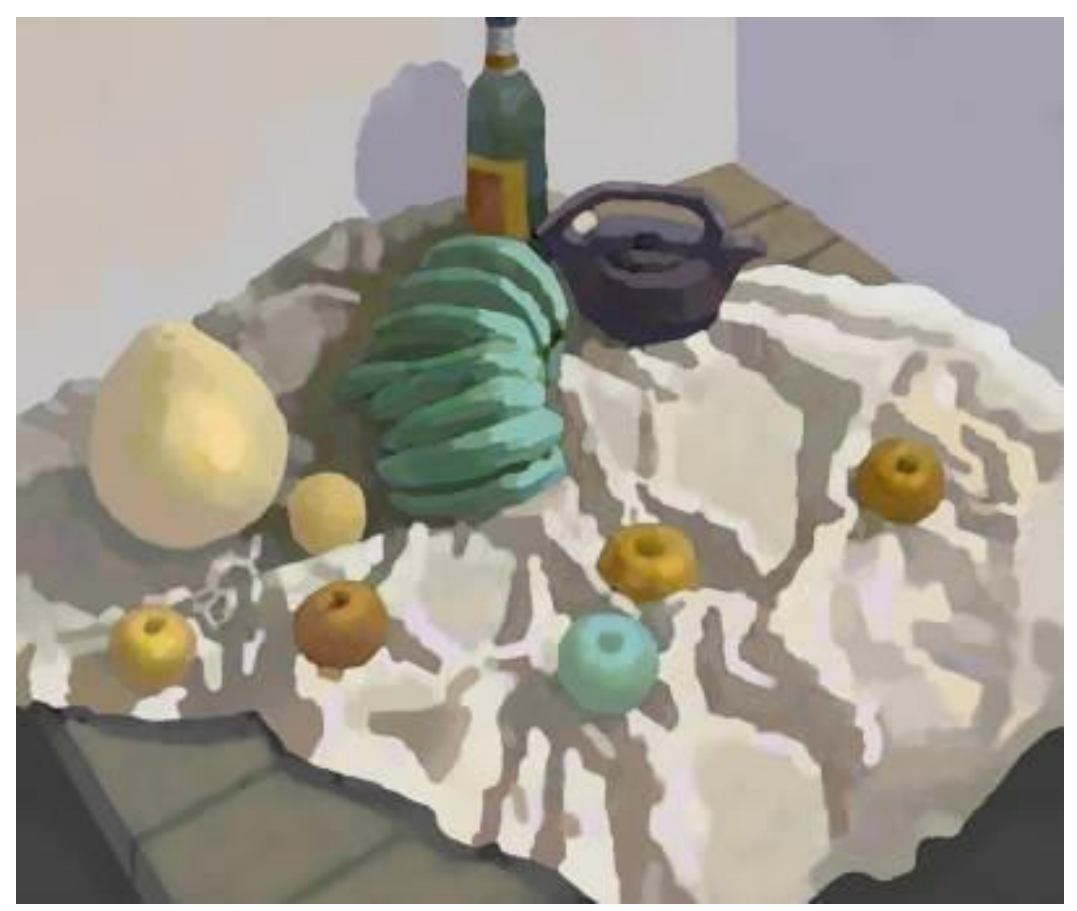

Still life, jazz scale-Atonal

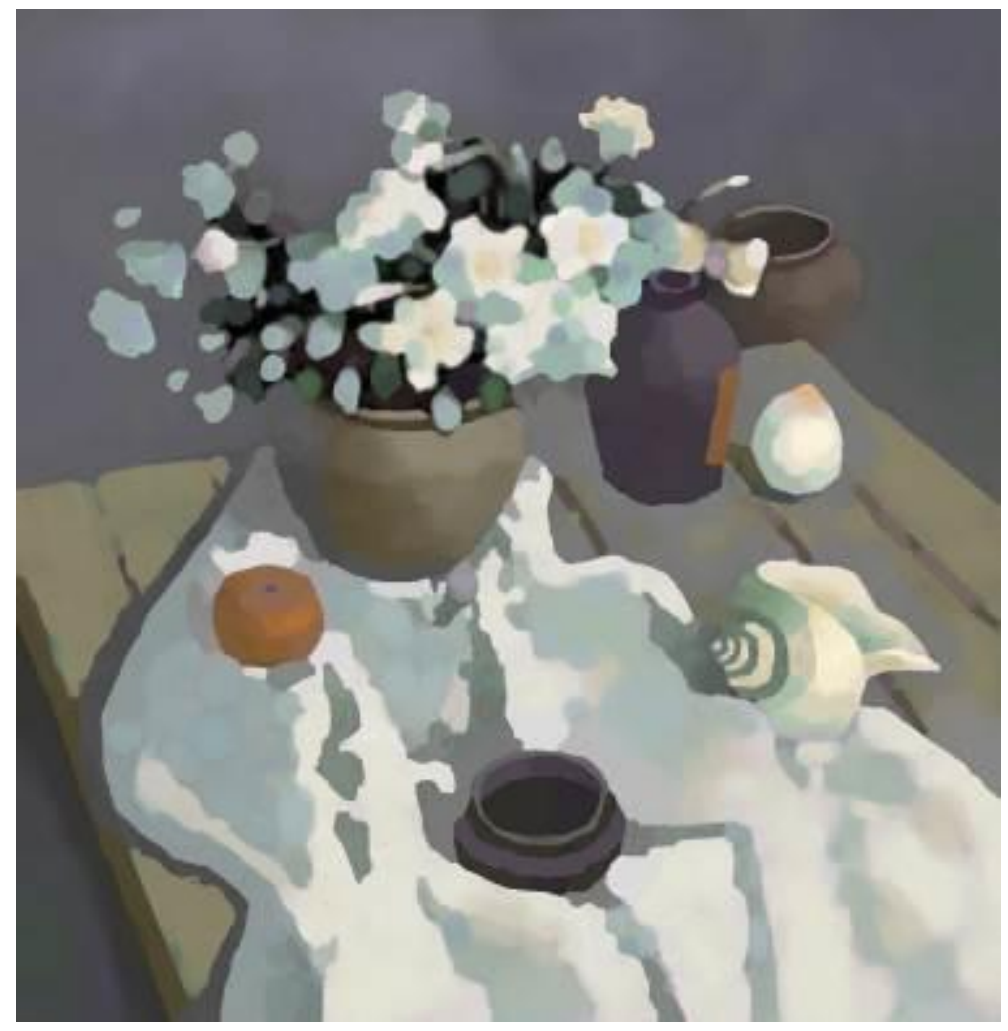

Still life, jazz scale-Atonal 


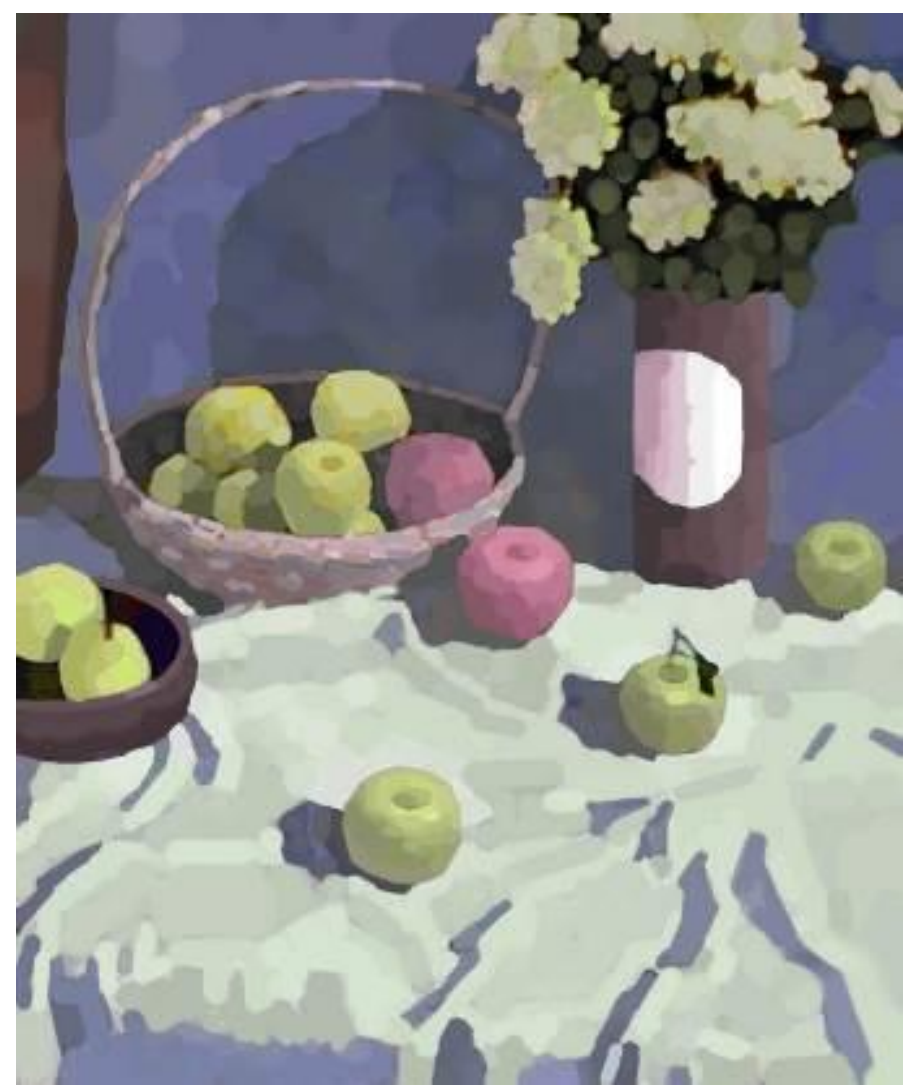

Still life, jazz scale-Atonal

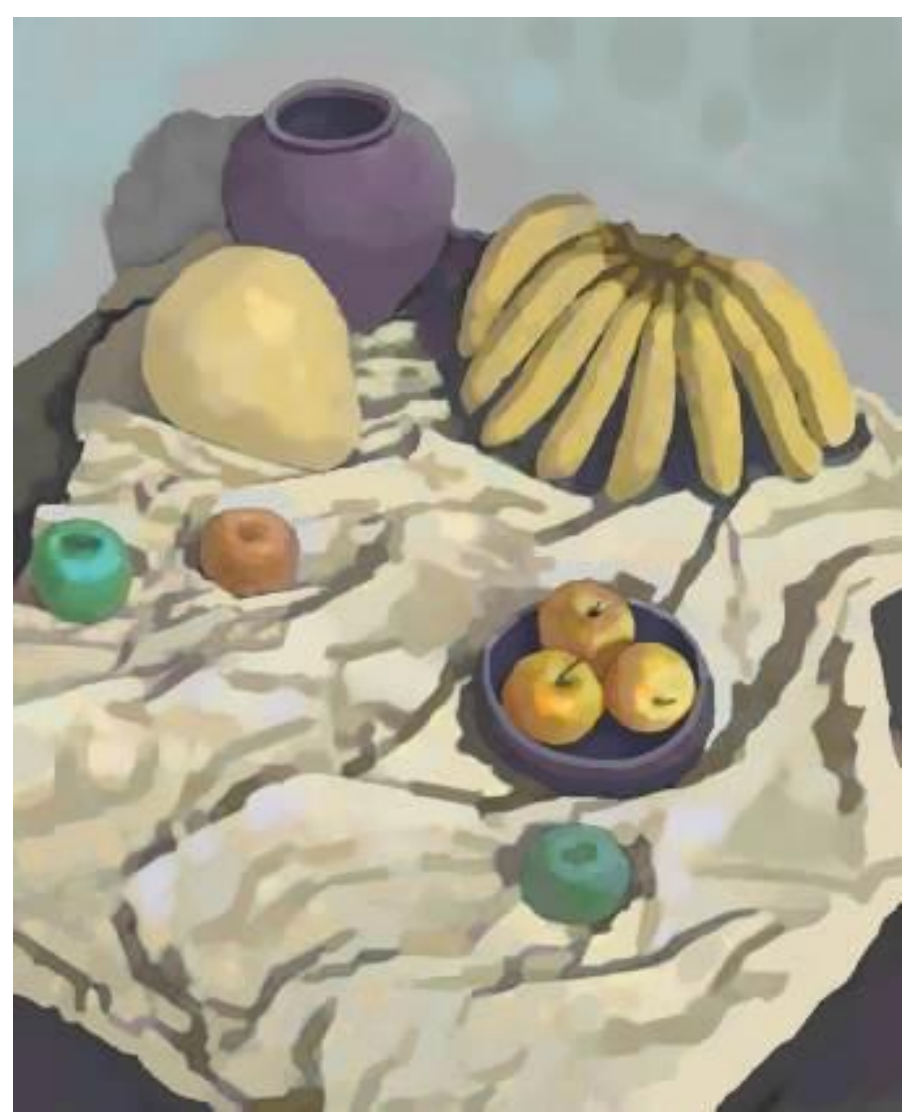

Still life, jazz scale-Atonal 


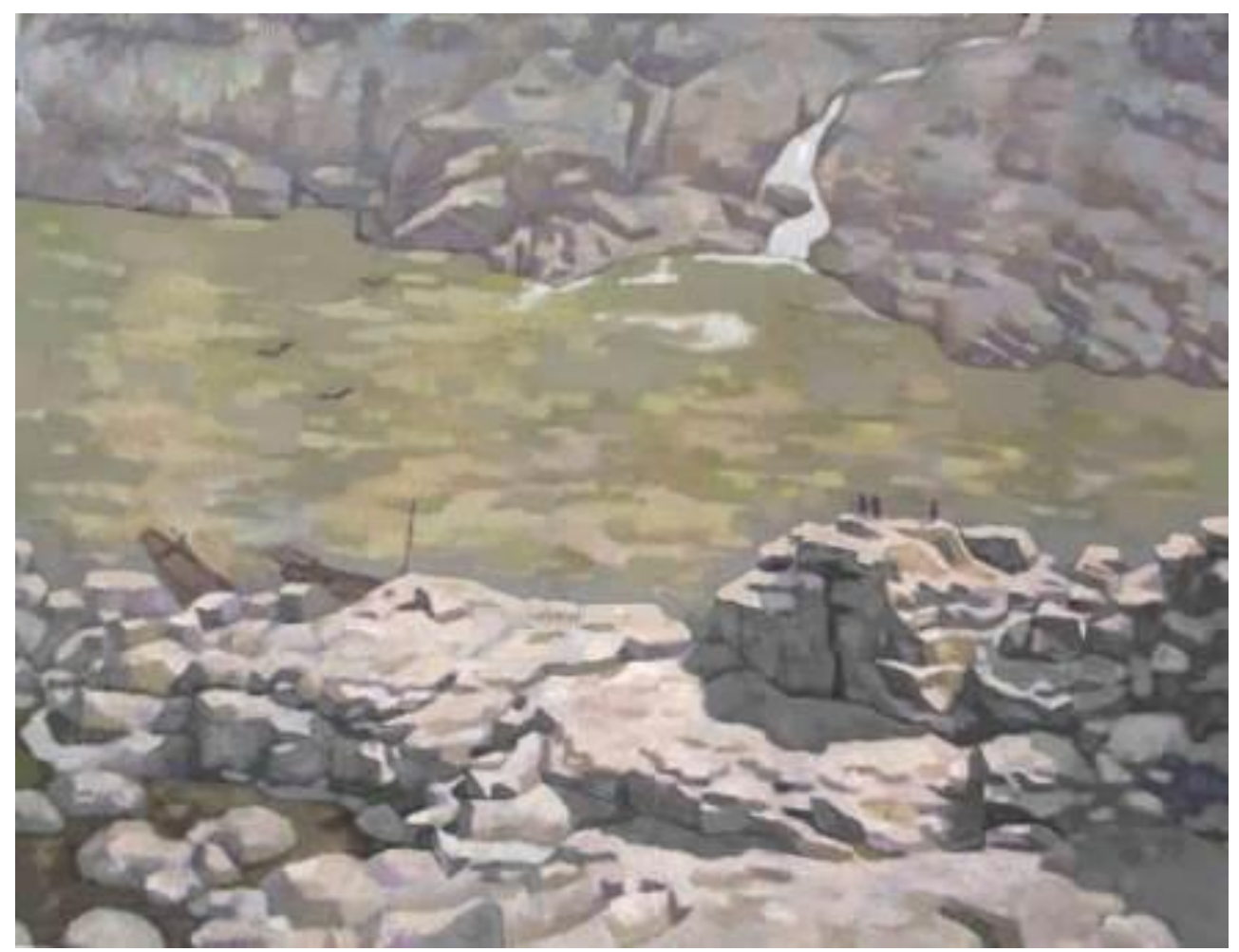

Jinsha river canyon, jazz scale-Atonal

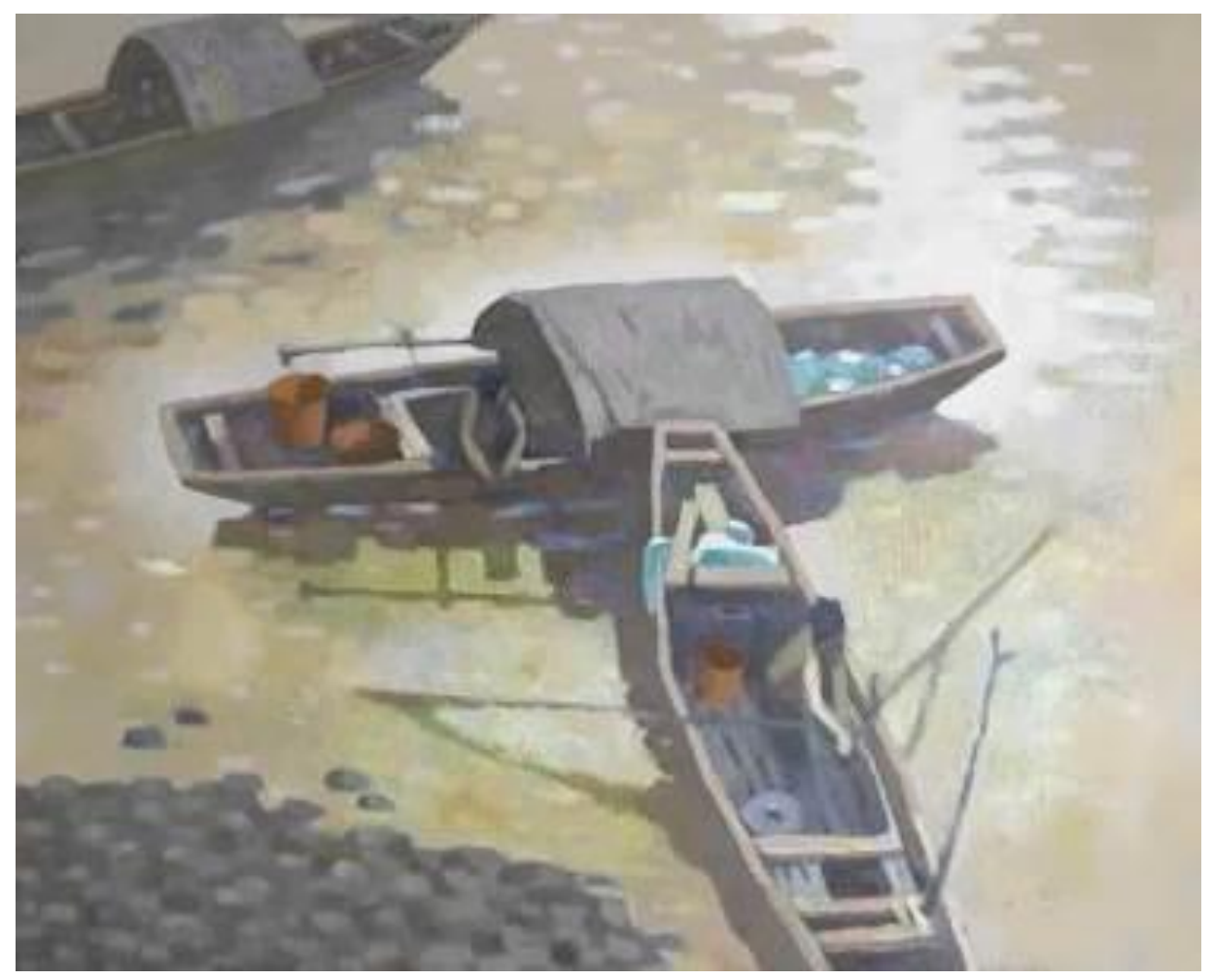

Fishing boat jazz scale-Atonal 


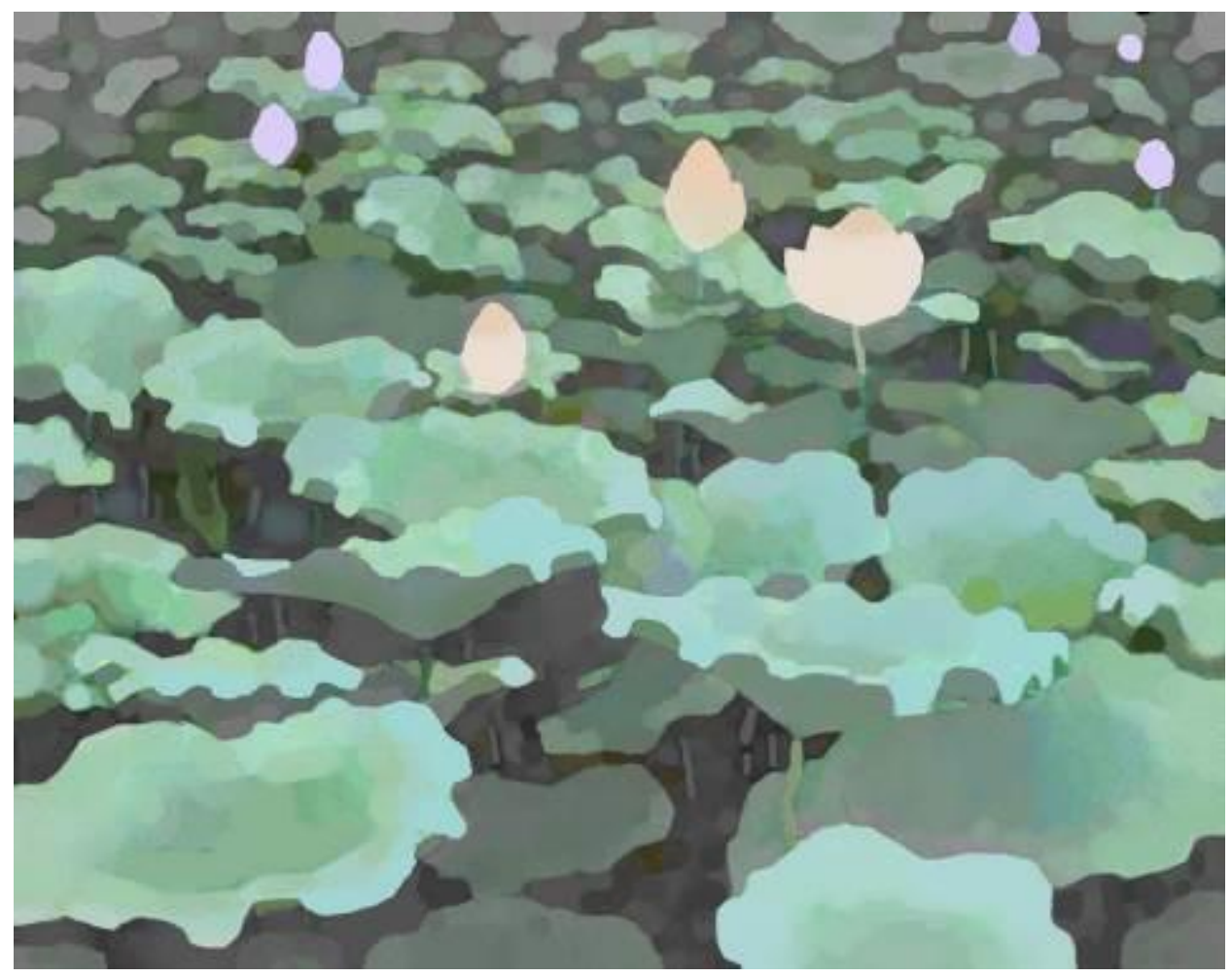

Green lotus, jazz scale-Atonal

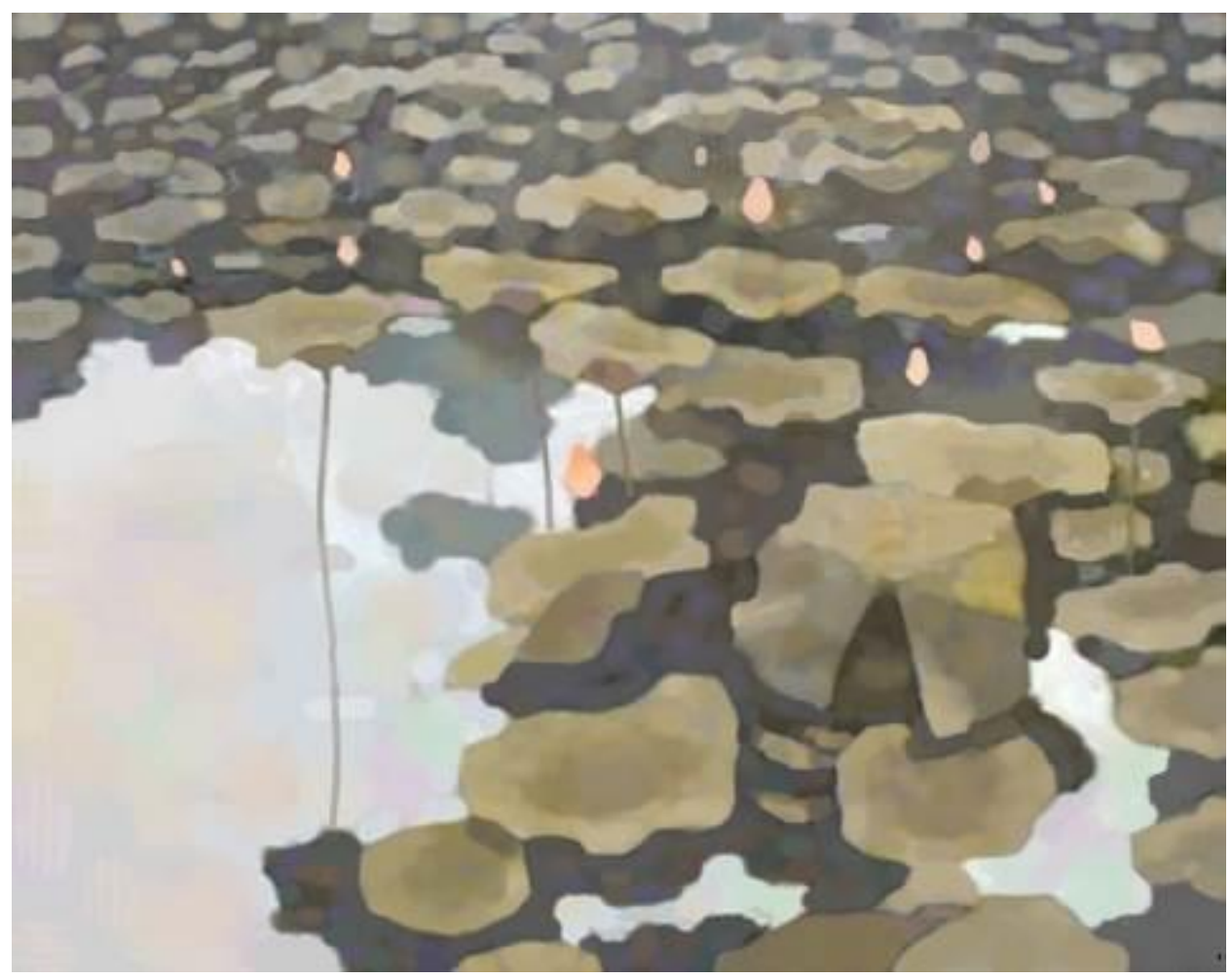

Lotus, jazz scale-Atonal 


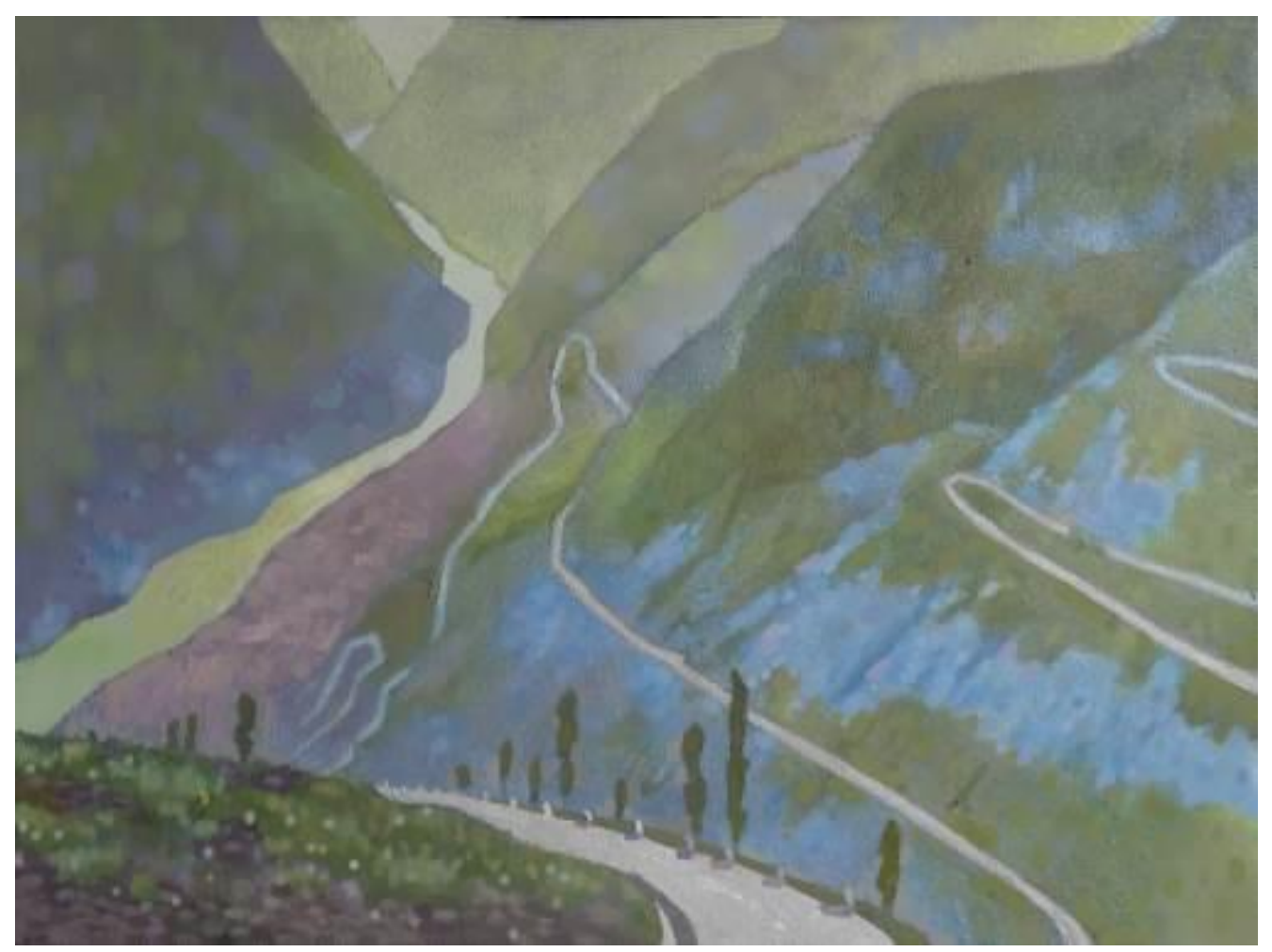

Jinsha river canyon,Atonal jazz scale-Atonal

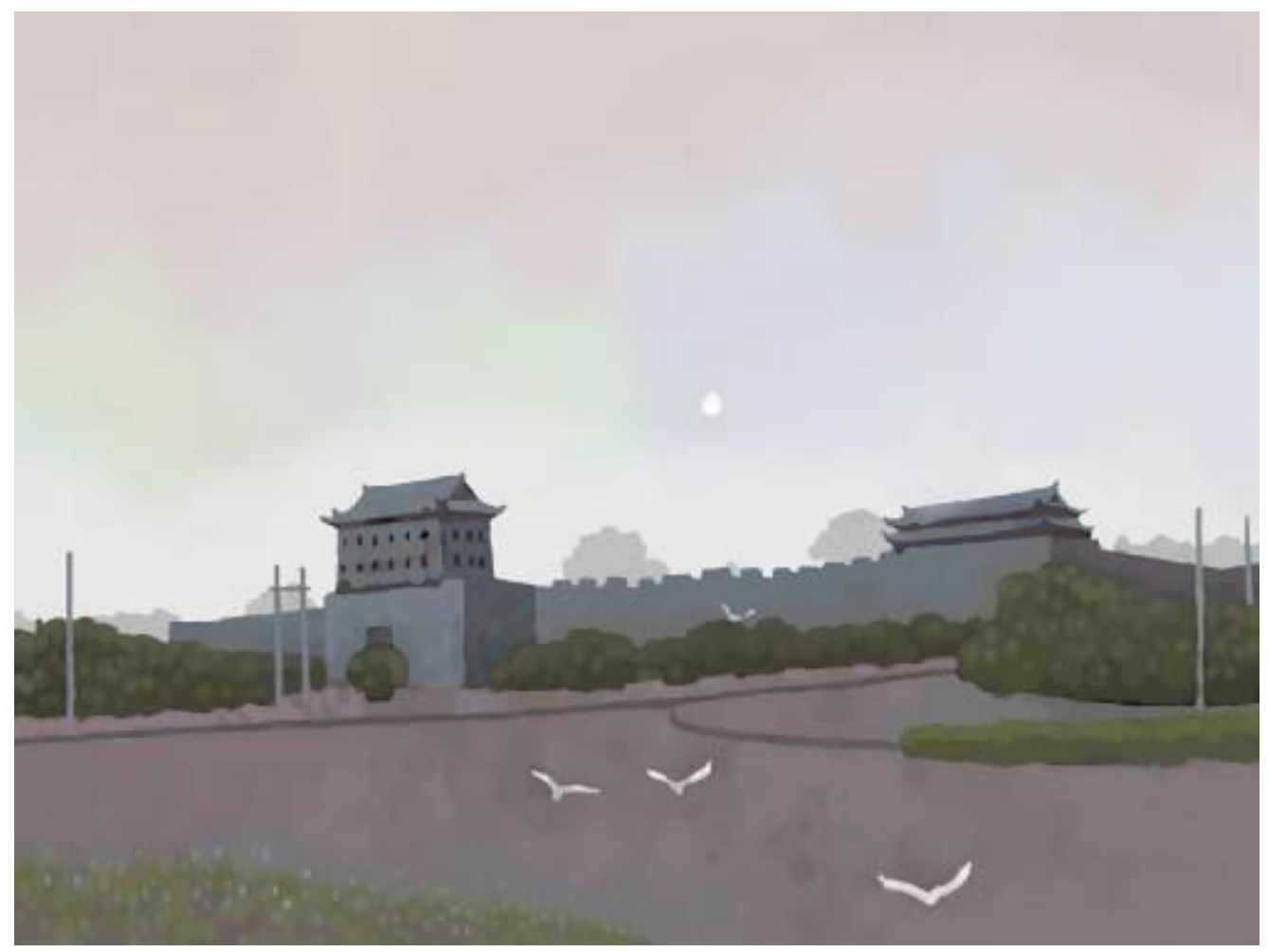

Landscape Atonal jazz scale-Atonal 


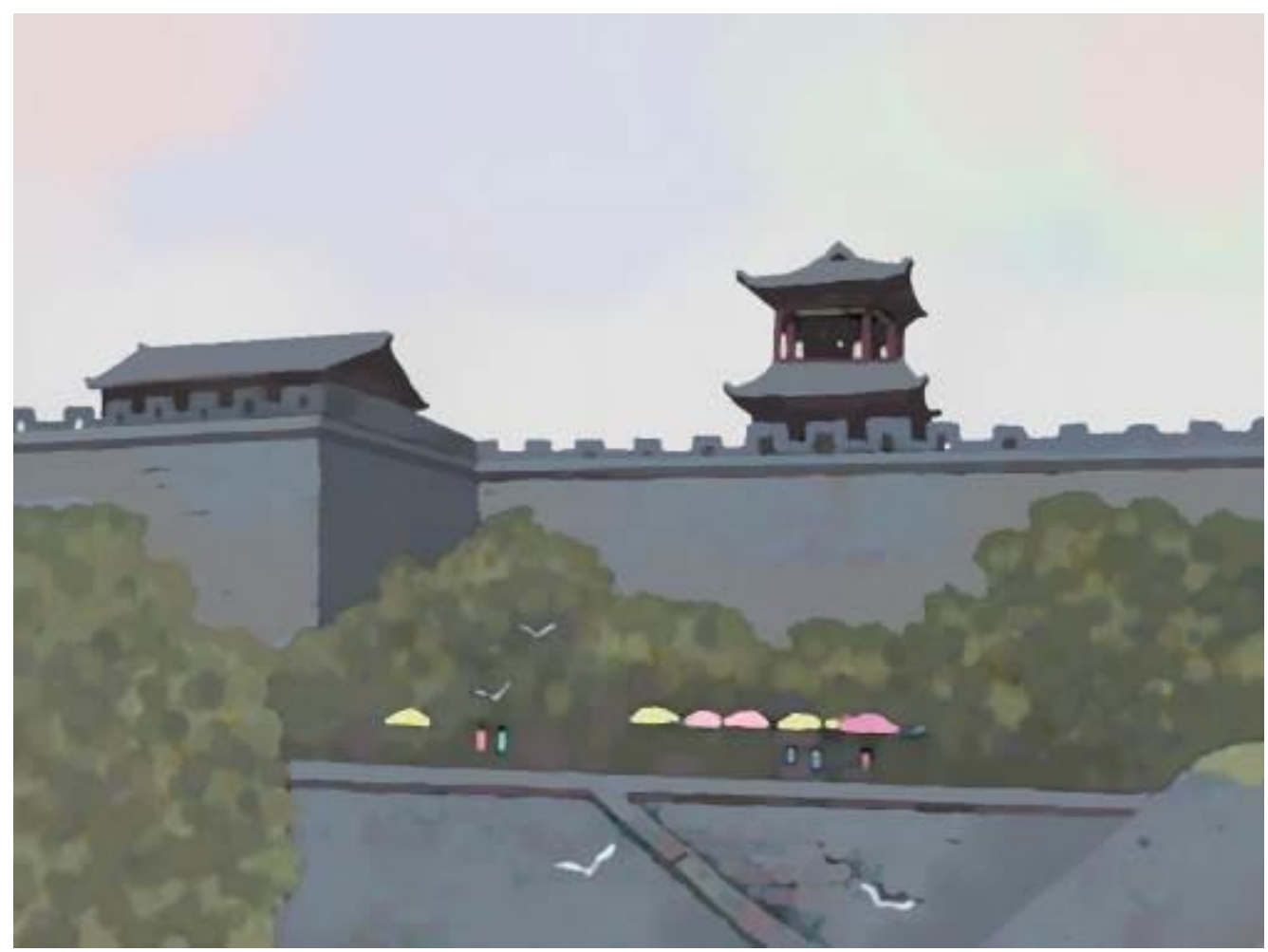

Landscape Atonal jazz scale-Atonal

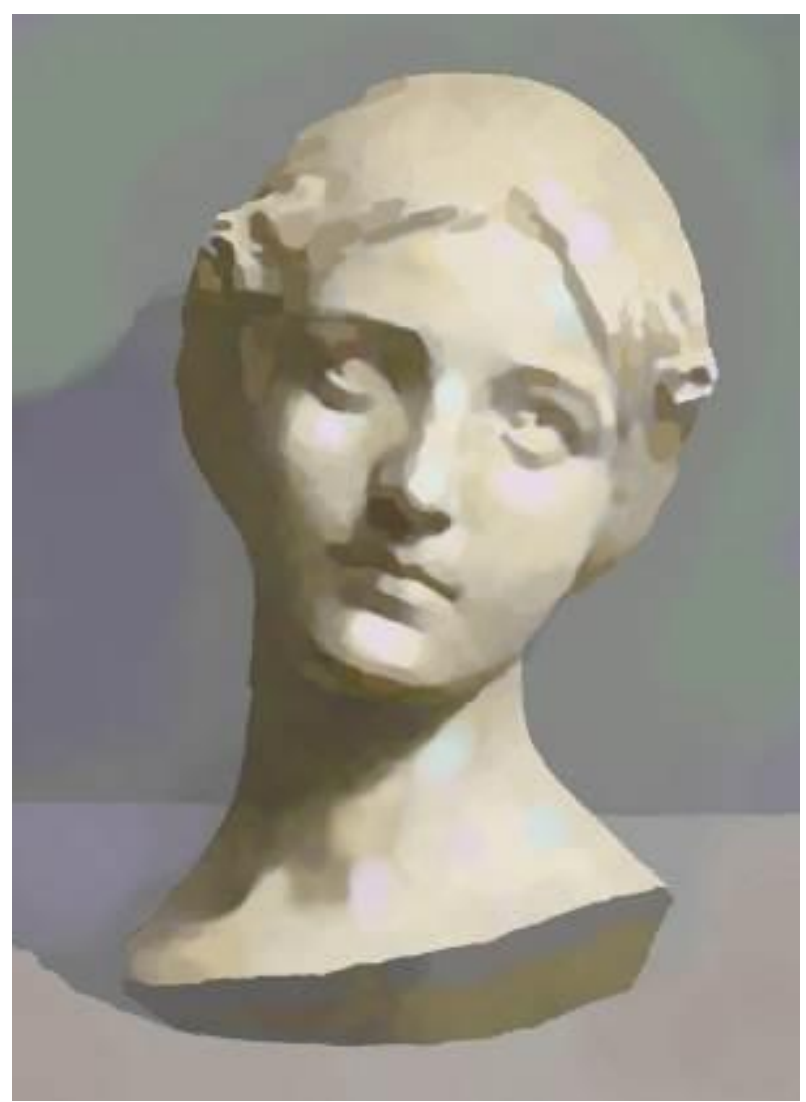

Gypsum graphics, jazz scale-Atonal 


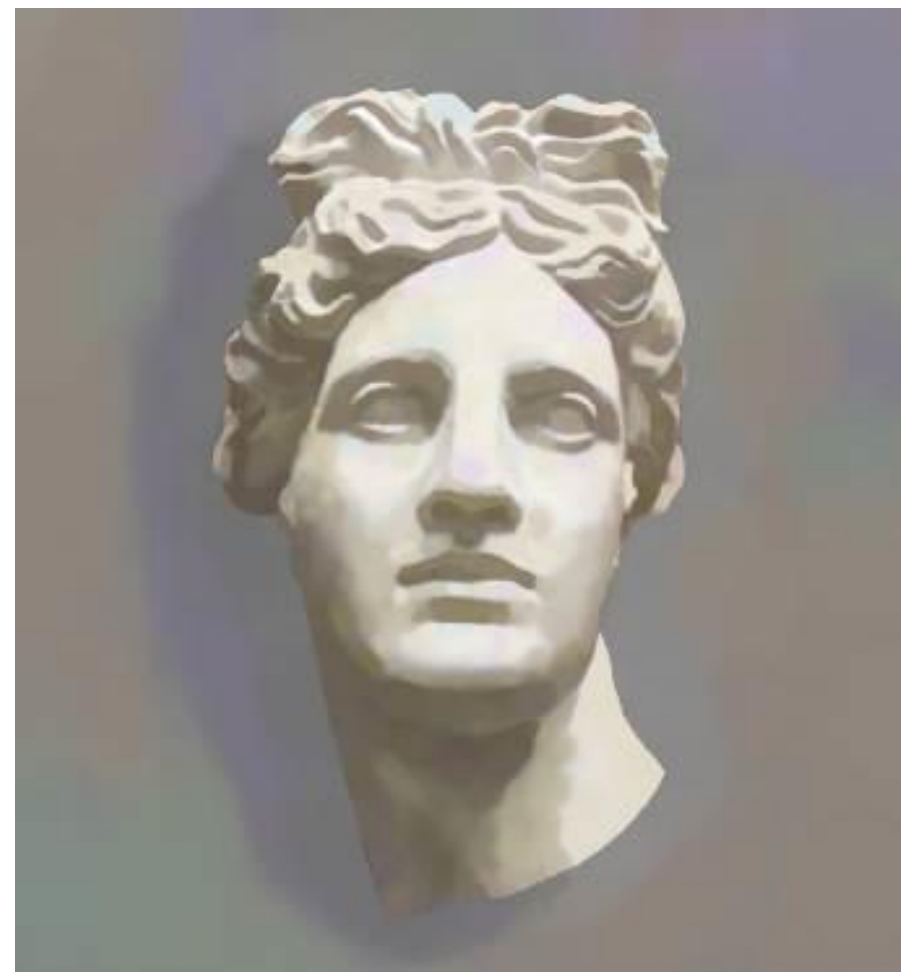

Gypsum graphics , jazz scale-Atonal

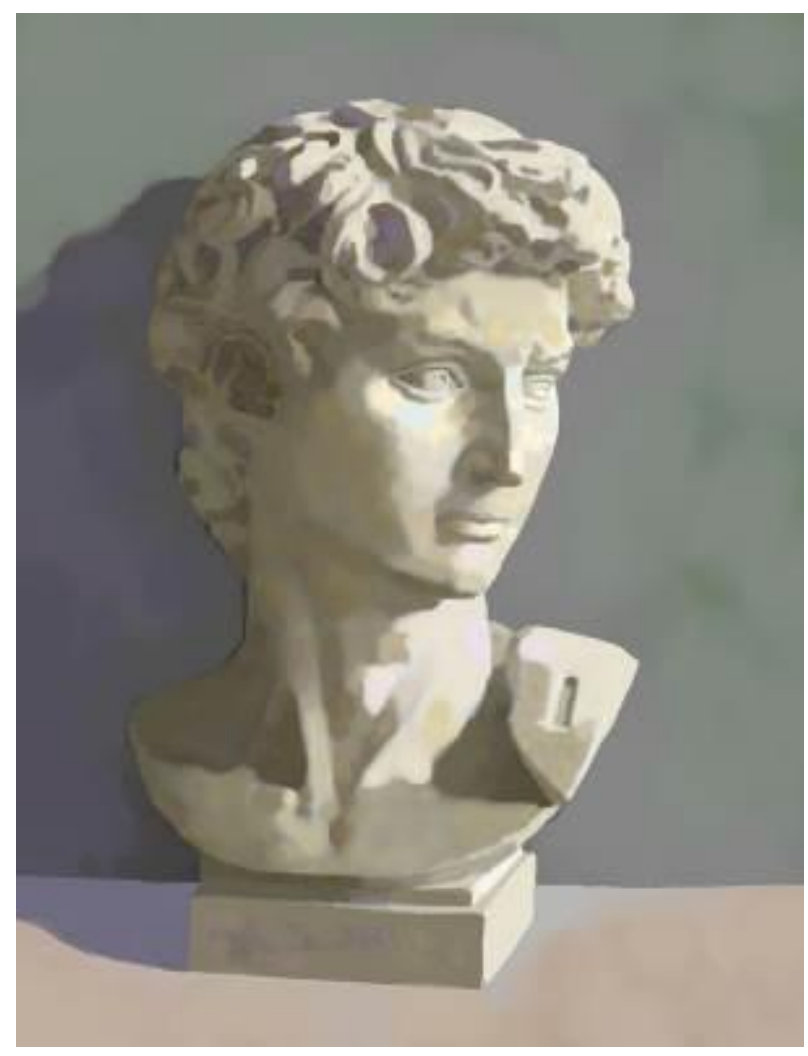

Gypsum graphics , jazz scale-Atonal 


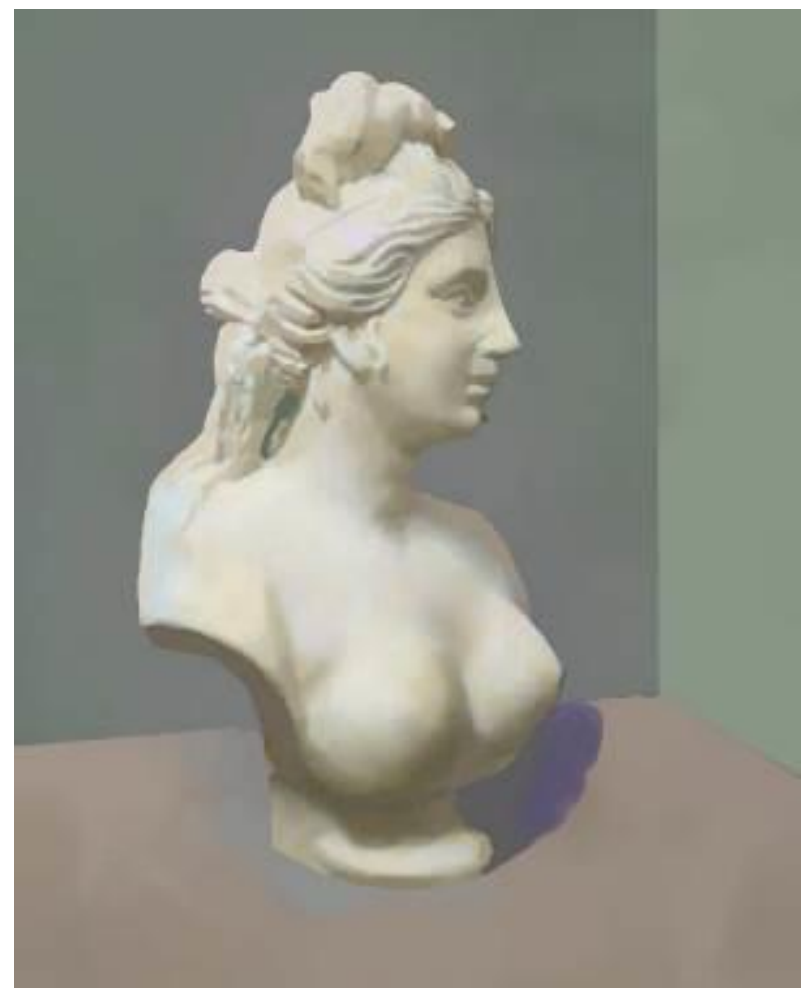

Gypsum graphics, jazz scale-Atonal

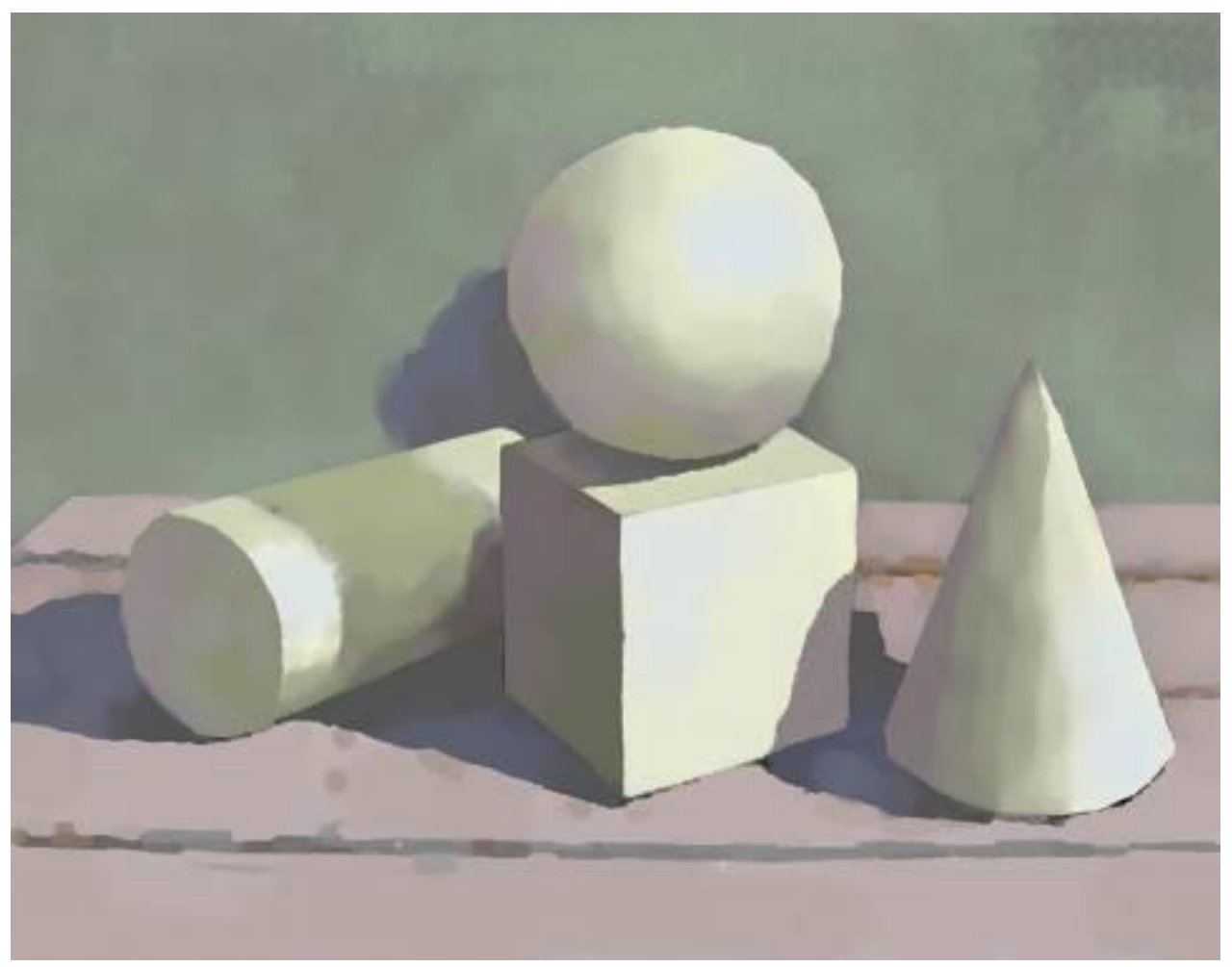

Gypsum graphics, jazz scale-Atonal 


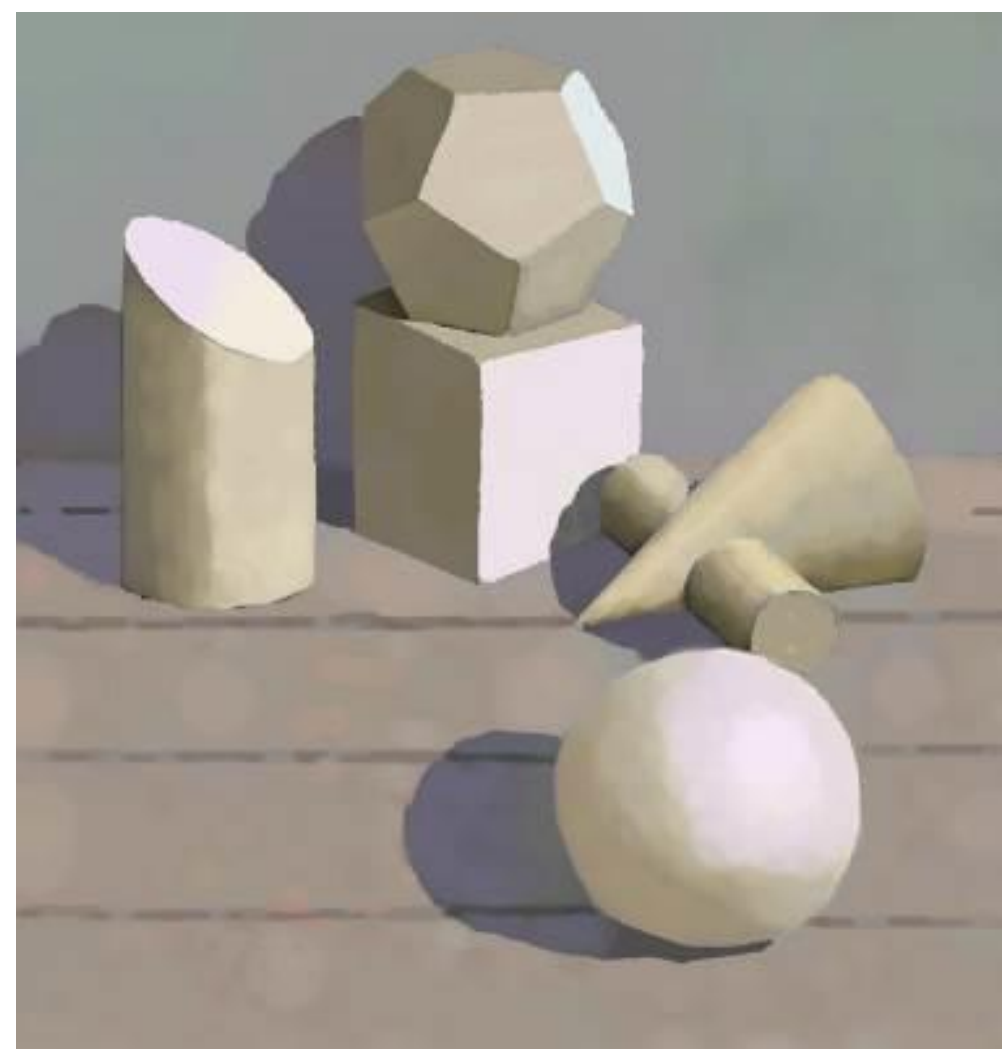

Gypsum graphics, jazz scale-Atonal

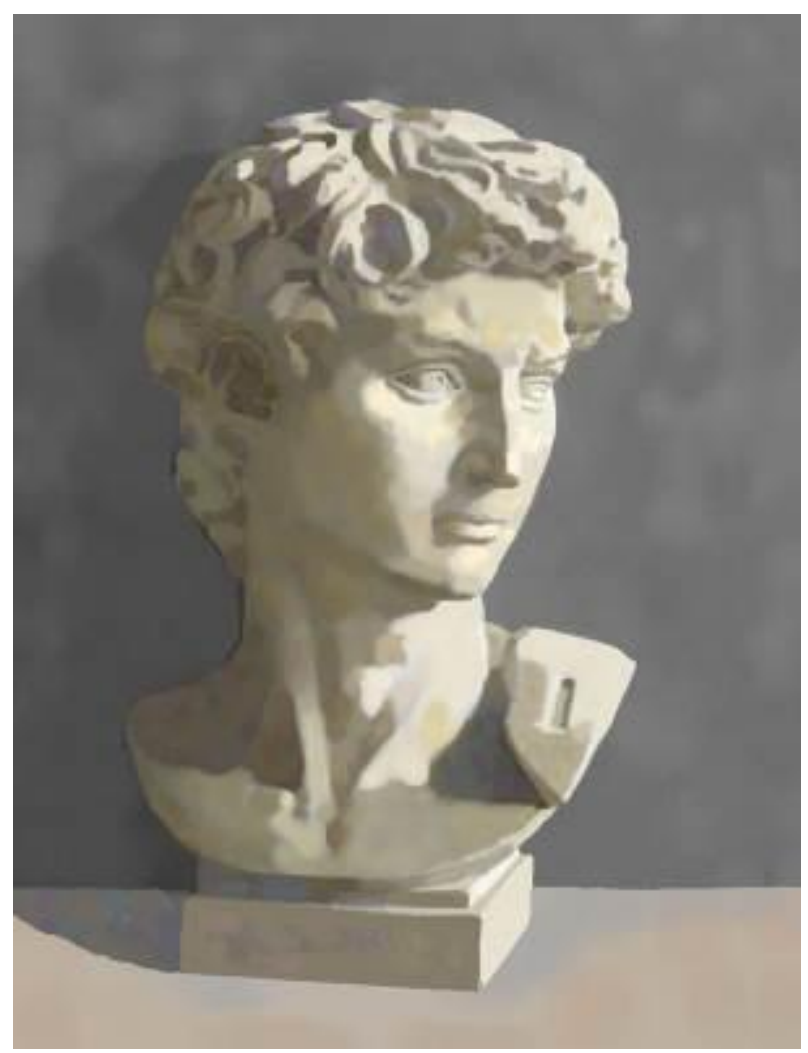

Gypsum graphics, jazz scale-Atonal 


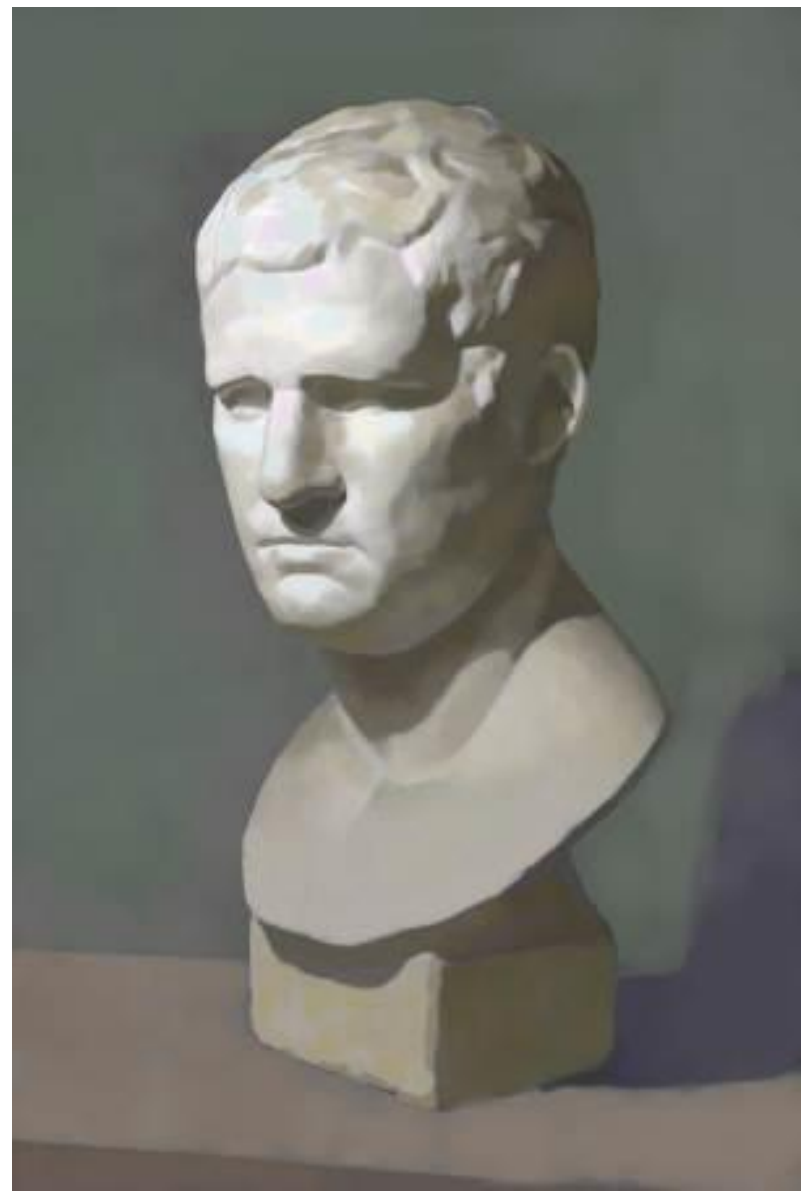

Gypsum graphics, jazz scale-Atonal 


\section{5、Next-related key group}

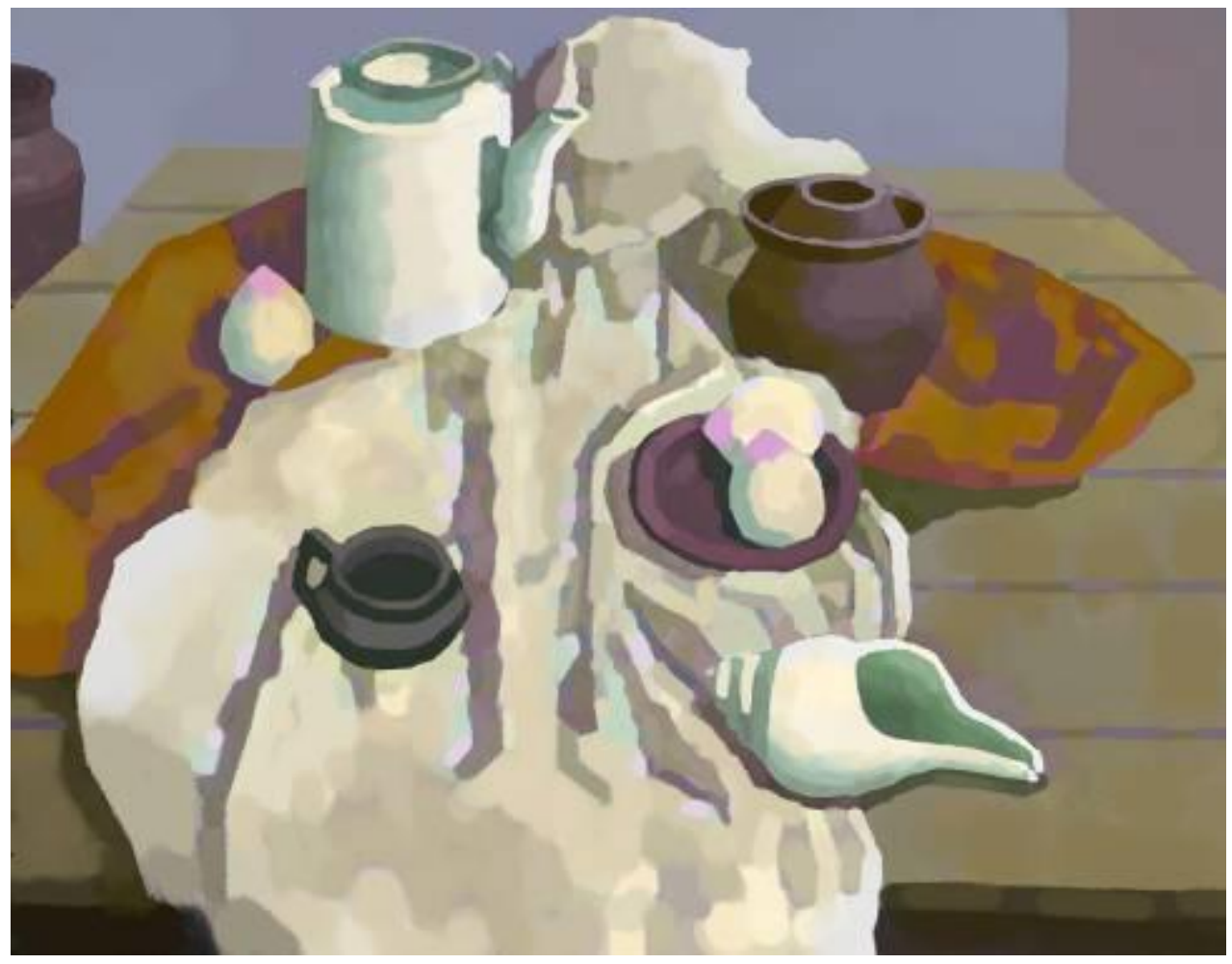

Still life, diationic scale, bE minor,A major

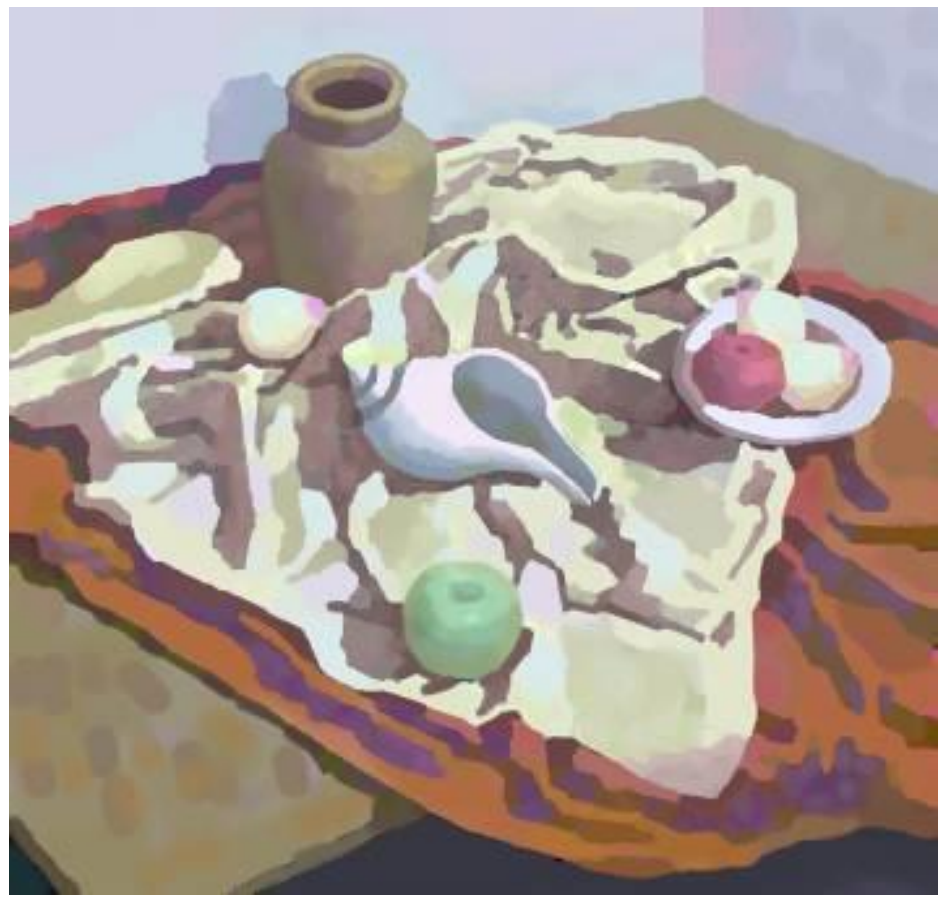

C major,\#F minor dominant key, Subdominant 


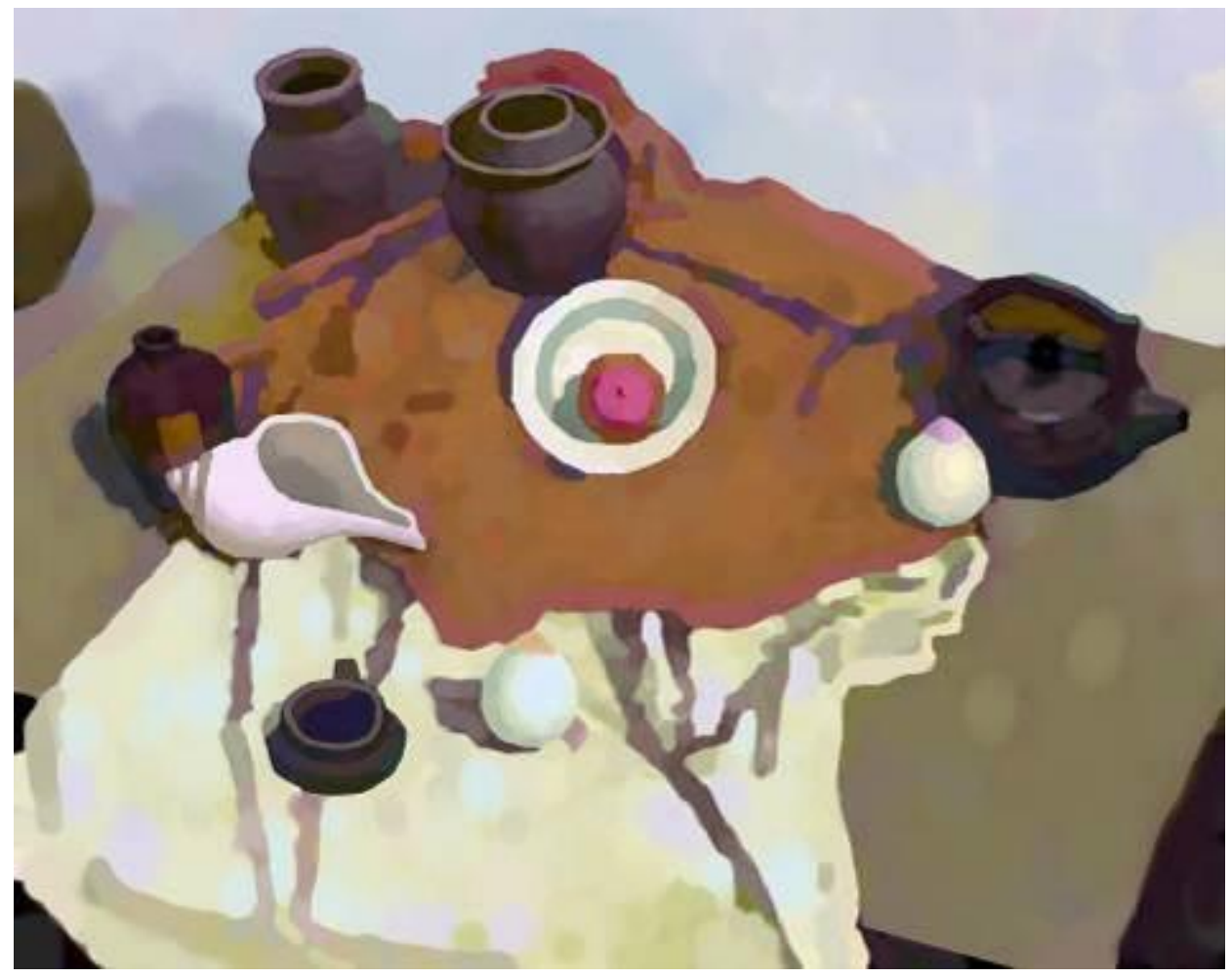

C major,\#F minor dominant key, Subdominant

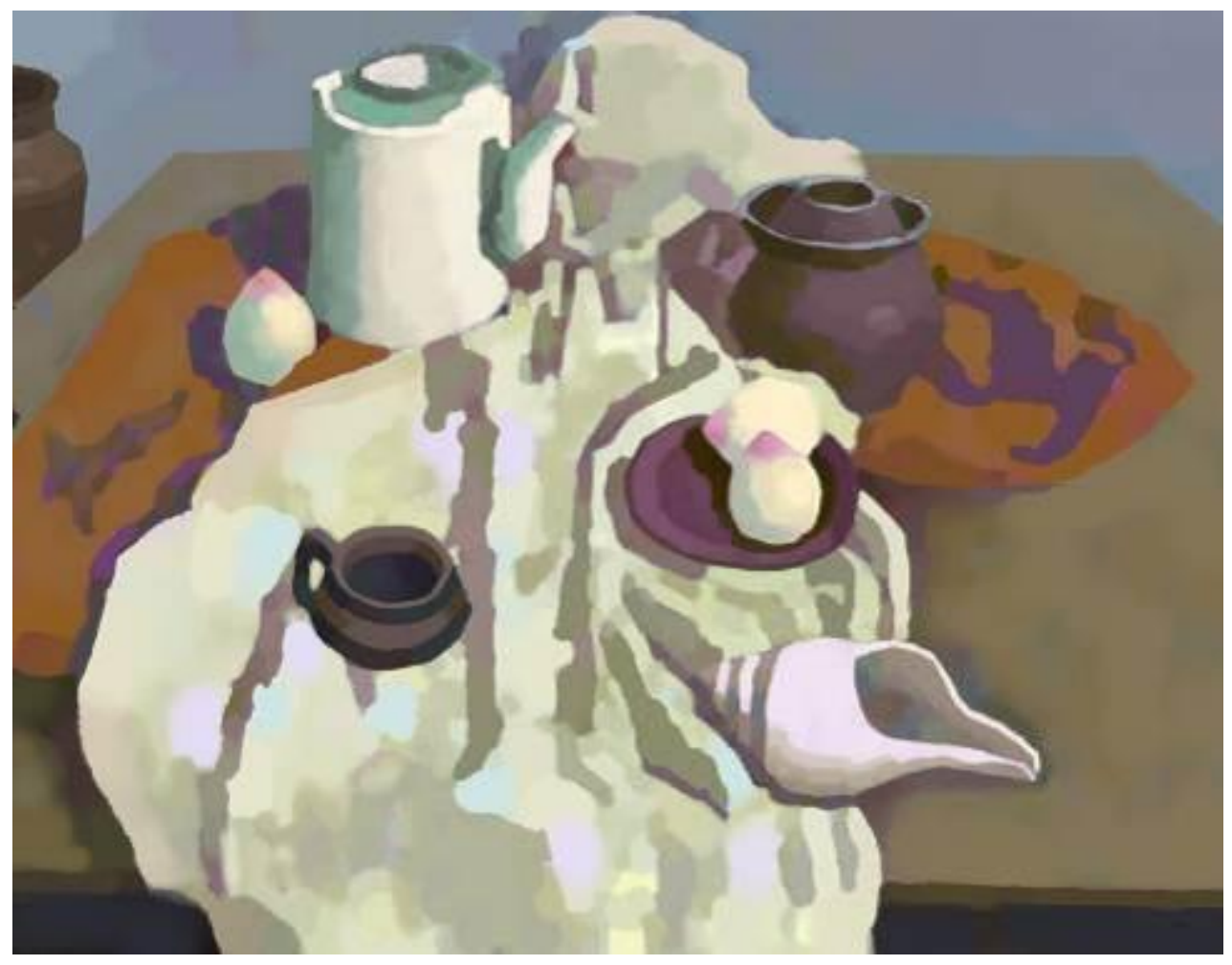

C major,\#F minor dominant key, Subdominant 


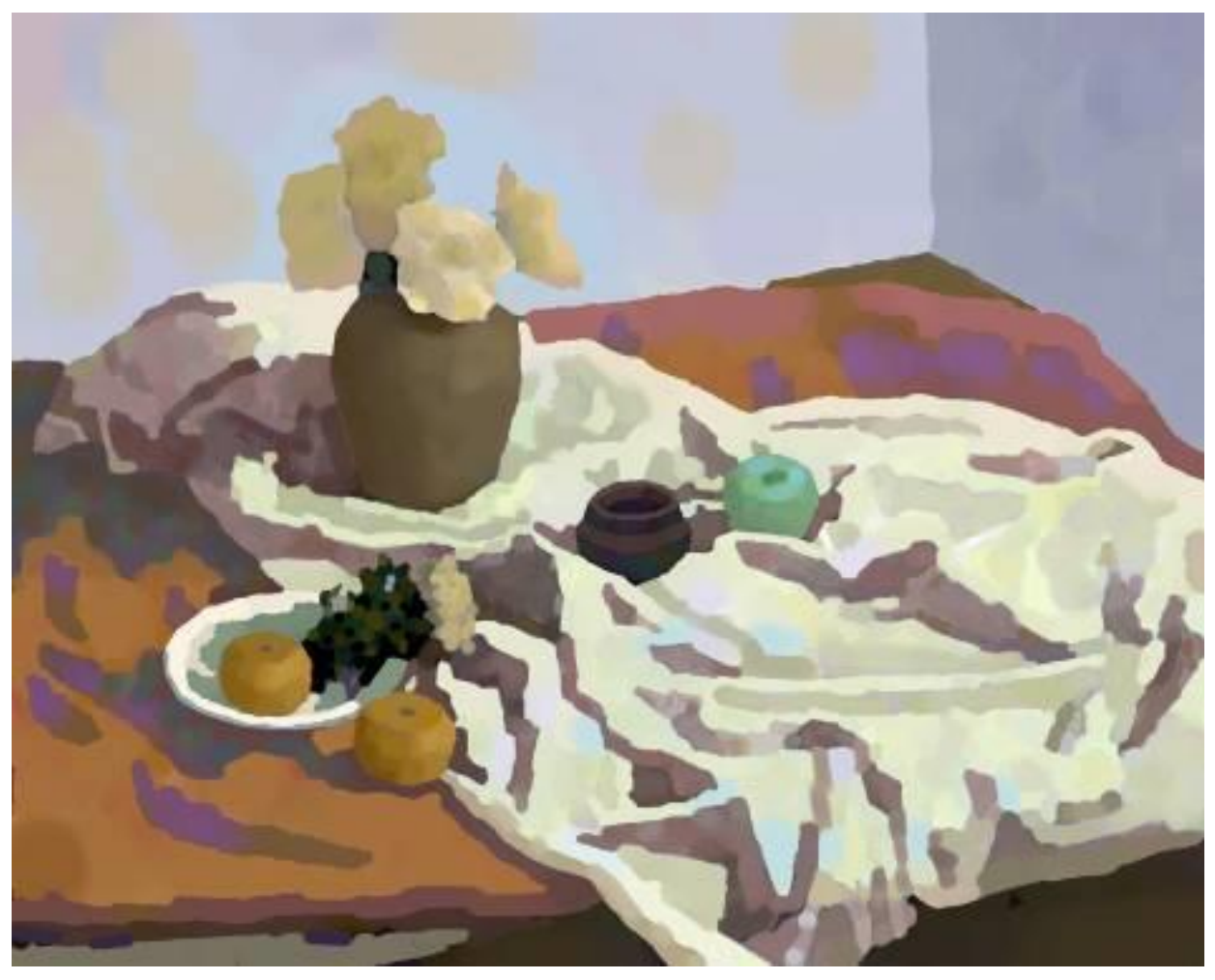

C major,\#F minor dominant key, Subdominant 


\section{6、Parallel Key Groups}

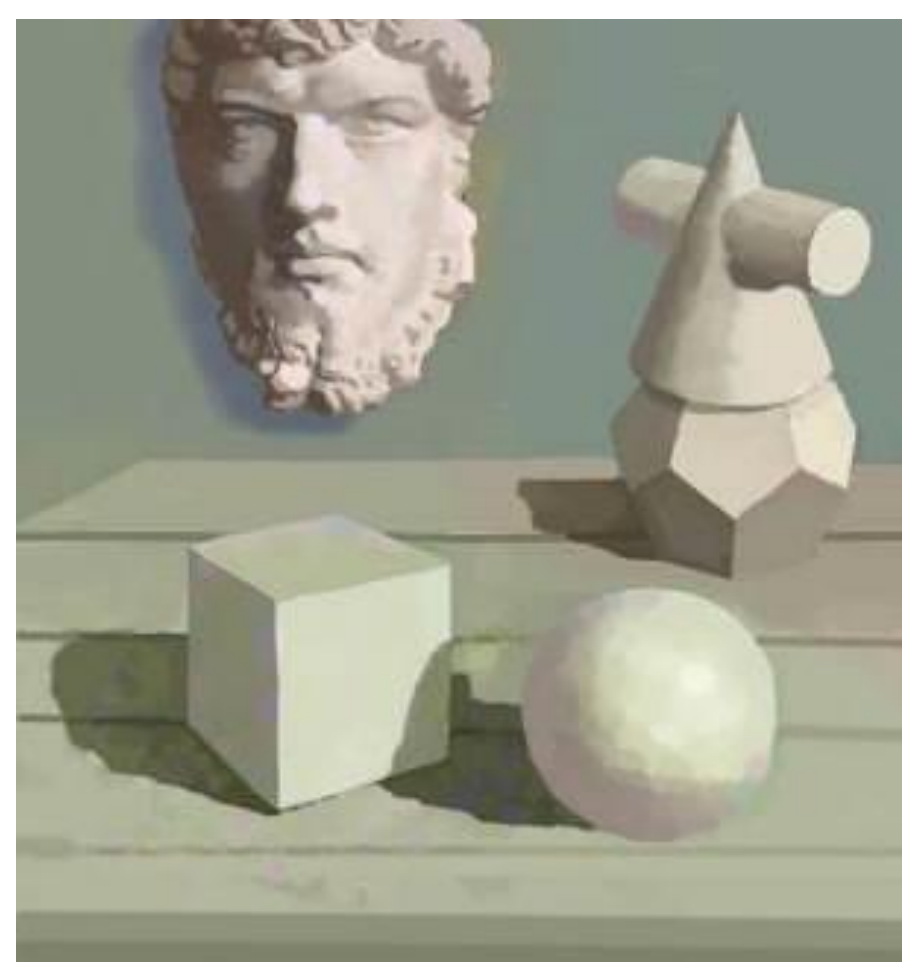

Plaster model,parallel key

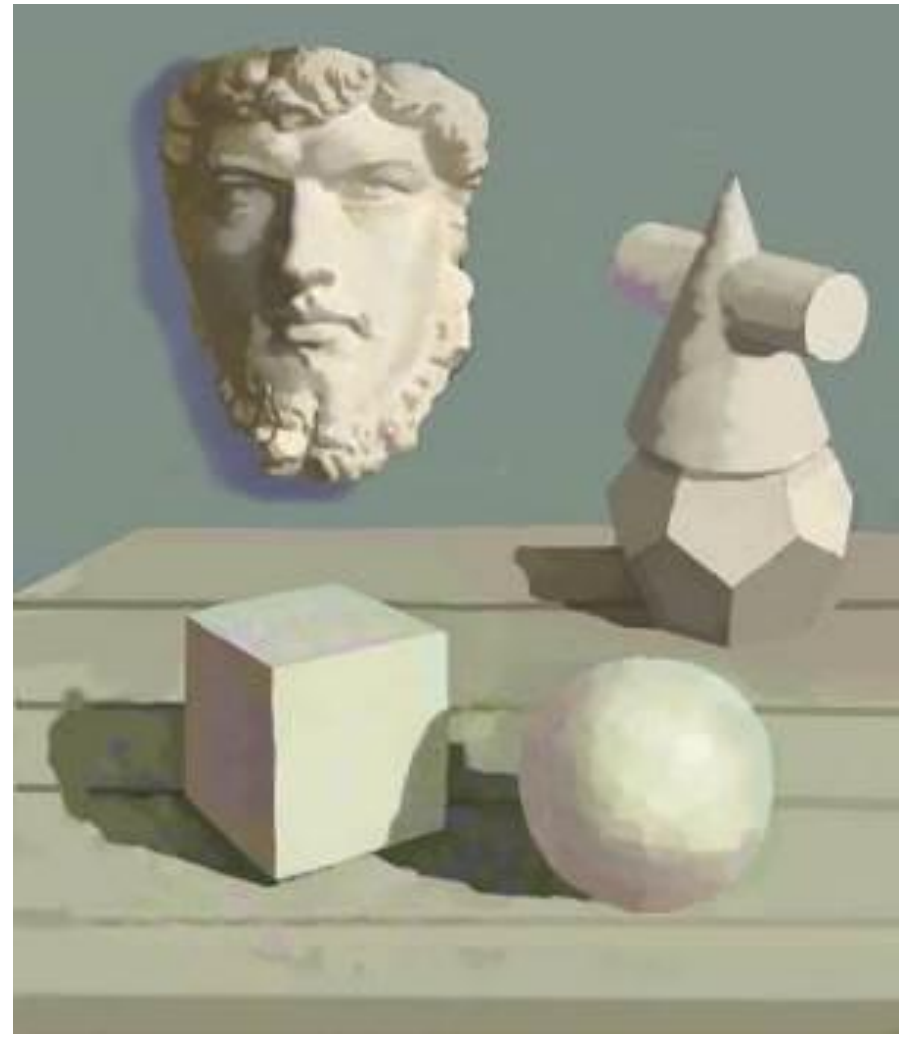

Plaster model,G-H parallel key group 


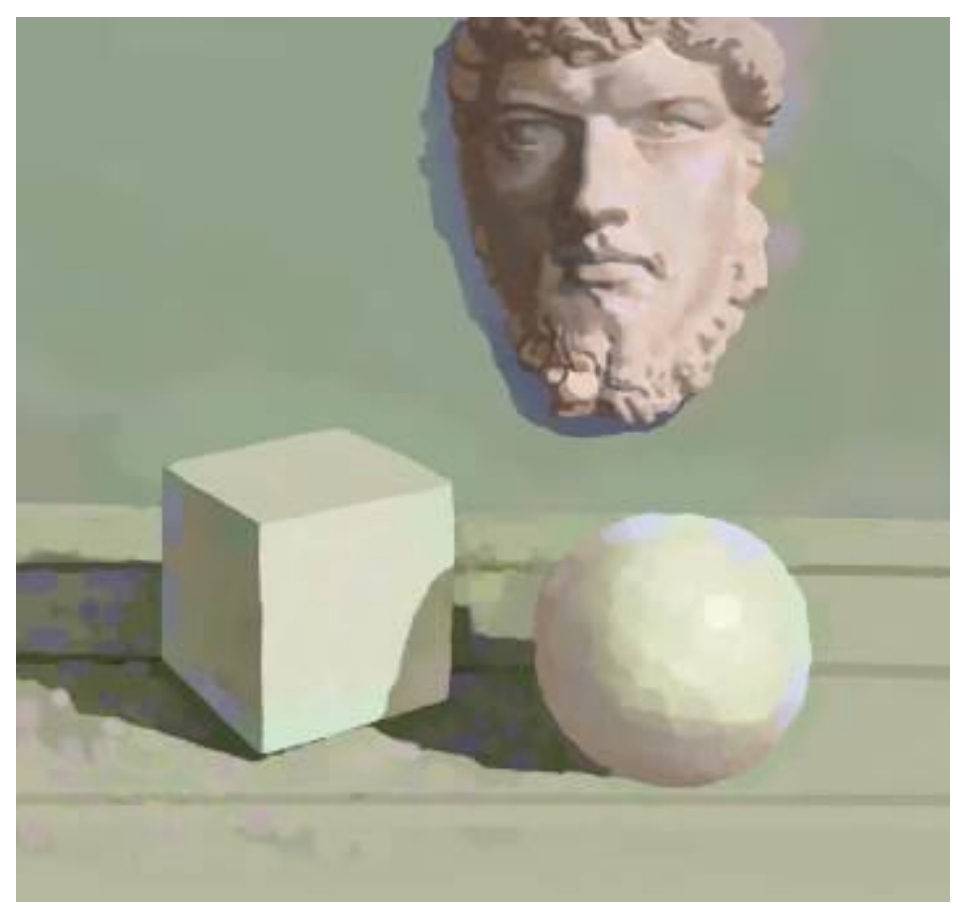

Plaster model,G-D parallel key group

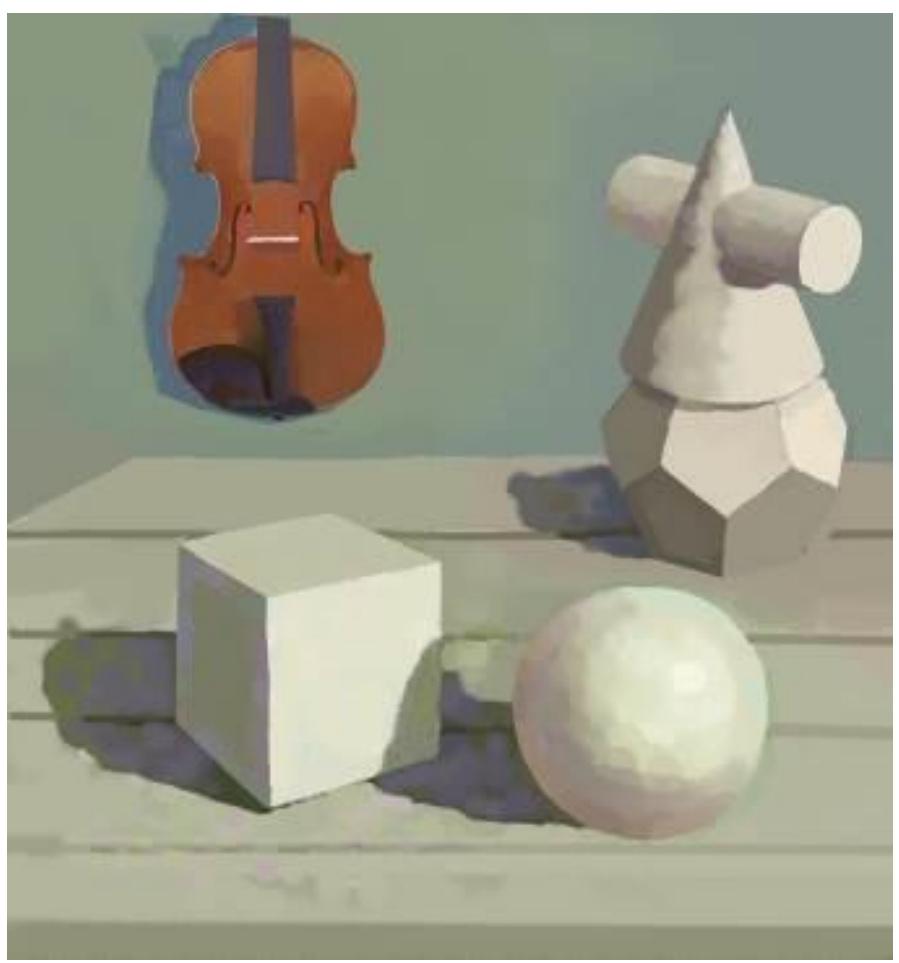

Plaster model,G-H-D parallel key group 


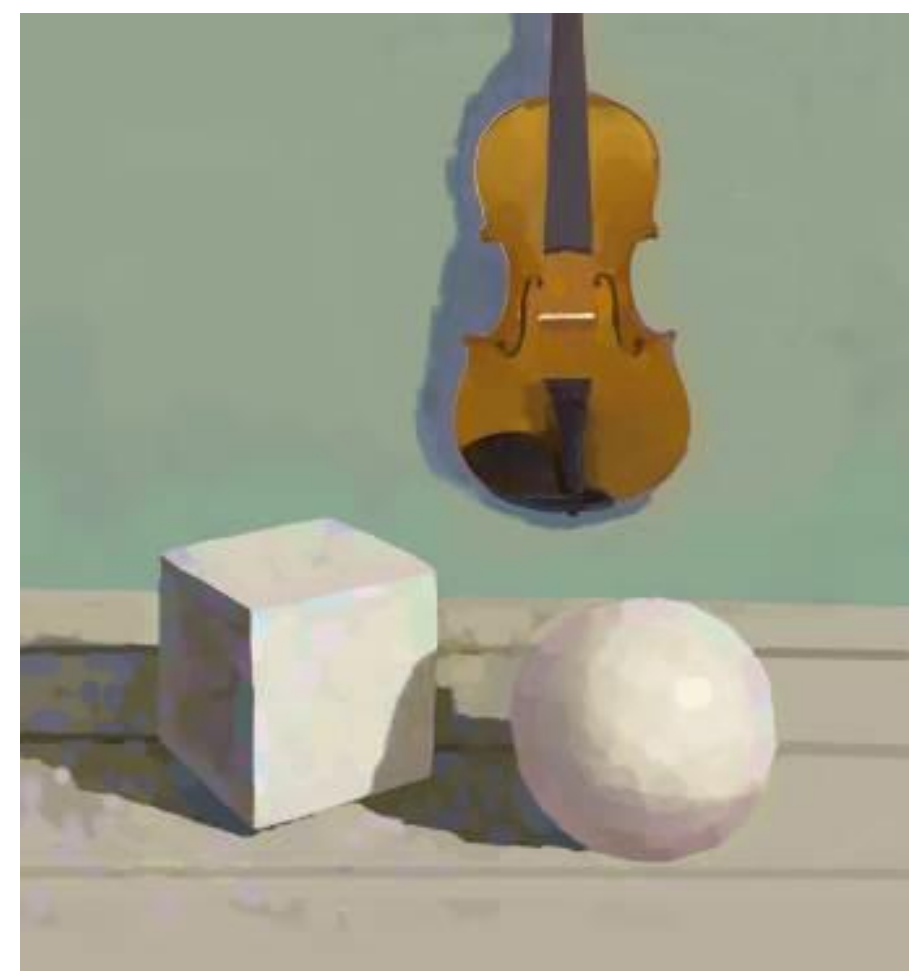

Plaster model,G-D parallel key group

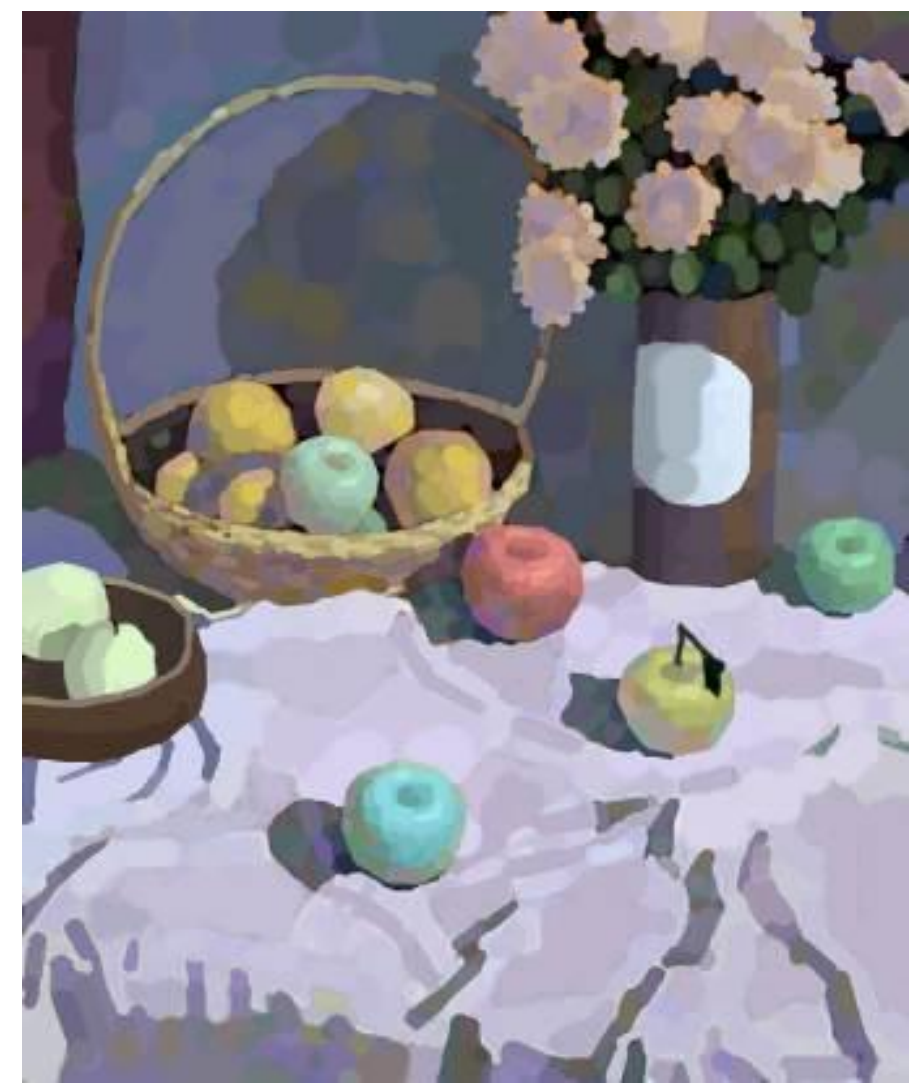

Still life,G-H-D parallel key group 


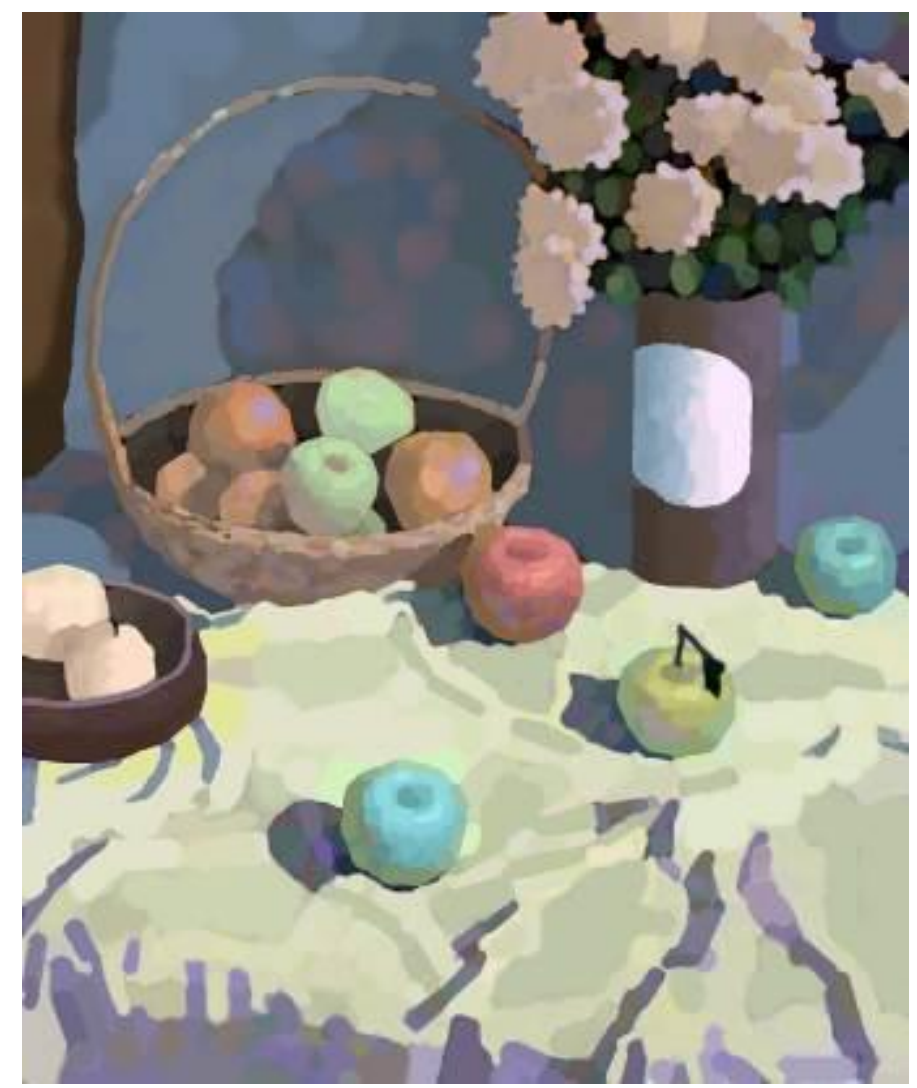

Still life,G-D parallel key group

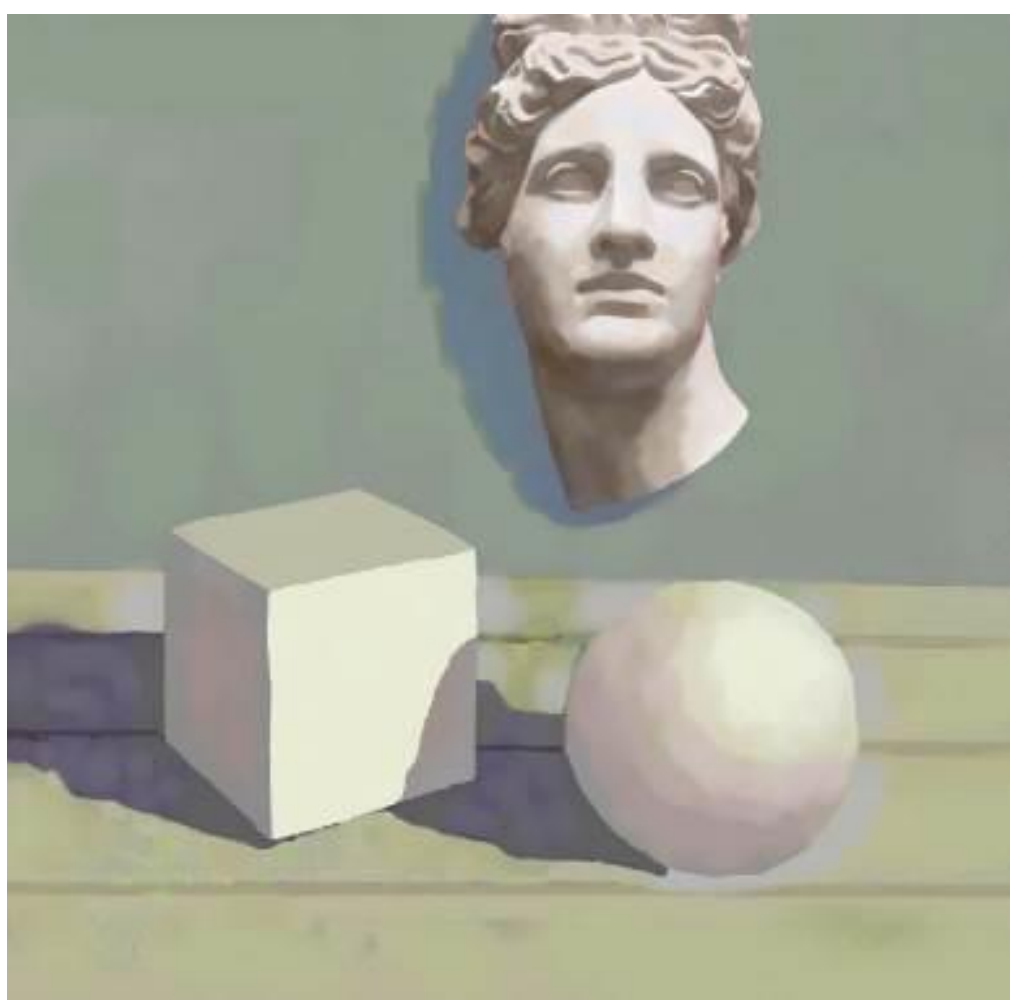

Plaster model,G-D parallel key group 


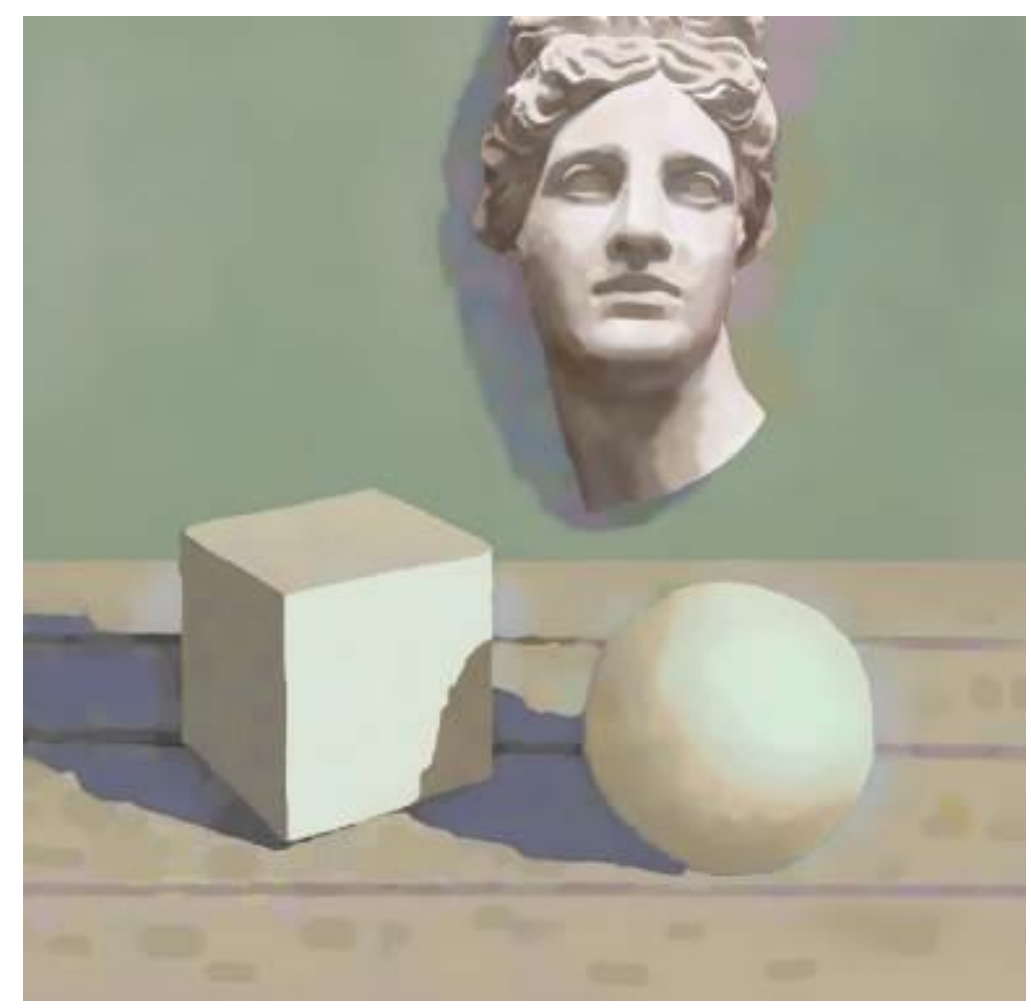

Plaster model,G-D parallel key group 


\section{References}

Chord space-time, Li Xiaohong,24th World Congress of Philosophy Beijing 13-20 August 2018

Spiritual chords, Li Xiaohong,24th World Congress of Philosophy Beijing 13-20 August 2018

Chord language: chord space-time and chord painting,Li Xiaohong,ISBN:9781370273348

Chord language - chord painting Legend, Li Xiaohong,ISBN: 9781370273348

\section{Chromatics}

Garau, Augusto (1993). Color Harmonies. University of Chicago press. p. 7. ISBN 0226281965.

Dahlhaus, Carl. Gjerdingen, Robert O. trans. (1990). Studies in the Origin of Harmonic Tonality, p. 141. Princeton University Press. ISBN 0-691-09135-8.

Wyszecki, Günther; Stiles, W.S. Color Science: Concepts and Methods, Quantitative Data and Formulae 2nd ed. New York, NY: Wiley Series in Pure and Applied Optics. 1982. ISBN 978-0-471-02106-3.

R. W. G. Hunt. The Reproduction of Colour 6th ed. Chichester, England: Wiley-IS\&T Series in Imaging Science and Technology. 2004: 11-12. ISBN 978-0-470-02425-6.

色彩艺术、作者：约翰内斯.伊顿，译者：杜定宇，世界图书北京出版公司，1999 年 06 月。

\section{Chord-Harmonics}

Walker, James and Don, Gary (2013). Mathematics and Music, p. 147. CRC. ISBN 9781439867099.

Nettles, Barrie \& Graf, Richard (1997). The Chord Scale Theory and Jazz Harmony. Advance Music, ISBN 3-89221-056-X

Van der Merwe, Peter (1989). Origins of the Popular Style: The Antecedents of Twentieth-Century Popular Music. Oxford: Clarendon Press. ISBN 0-19-316121-4.

Mazzola, Guerino; Daniel Muzzulini (1990). Geometrie der Töne: Elemente der mathematischen Musiktheorie. Birkhäuser. ISBN 978-3-7643-2353-0. Retrieved 26 February 2012

Dunbar, Brian (2010). Practical Music Theory: A Guide to Music as Art, Language, and Life. Rochester, Minn., USA: Factum Musicae. ISBN 978-0578062471. 
Jones, George T. (1994). HarperCollins College Outline Music Theory. ISBN 0-06-467168-2.

和声学 (Harmony)、作者: [美]瓦尔特•辟斯顿, 译者:丰陈宝、沈敦行, 人民音乐出版社 1956-11

律学基础教程、作者: 阎林红, 中央音乐学院出版社 ISBN：9787810964654

\section{Meridian,Science of channels and collaterals}

中医基础理论（TCM Basic Sciences）、作者 张安玲，徐胤聪，同济大学出版社 2009-7-1

经络腧穴学, 沈雪勇编著, 中国中医药出版社 2008 年 1 月 1 日, ISBN: 9787801564412

经络学(规划教材)、作者:李鼎, 上海科学技术出版社、1995 年 06 月

黄帝内经、作者: 佚名, 中医古籍出版社, 2003-11.

\section{Physics}

Greene,Brian.The Elegant Universe, W.W.Norton and Co.New York,NY.c1999 ISBN 0-375-70811-1.

加来道雄. 《超越时空》. 上海世纪出版集团. 2009. ISBN 978-7-5428-4804-8.

Kragh, Helge. Quantum Generations: A History of Physics in the Twentieth Century Reprint. Princeton University Press. 2002. ISBN 978-0691095523.

Werner Heisenberg. Physics and Philosophy: The Revolution in Modern Science. Prometheus Books. 1999. ISBN 978-1-57392-694-2.

Calter, Paul. "Pythagoras \& Music of the Spheres". Geometry in Art \& Architecture. Dartmouth College. Retrieved November 26, 2011.

Plant, David. "Johannes Kepler \& the Music of the Spheres". Skyscript.co.uk. Retrieved November 26, 2011. 


\section{Afterword}

This book is an experimental atlas of the book Chord Language - Chord Time and Space and Chord Painting, providing an intuitive example of the need to learn chord language and chord painting. The combination of the two books can better understand and master the concept of chord language while gaining intuitive and sensory experience.

Chord painting comes from an internal observation (self-observation) visual experiment, which is a long-term observation and correction process. We will continue to supplement and update the illustration as the experiment progresses.

Publications In The Chord Language Series:

和弦语言：和弦时空与和弦绘画 https://www.smashwords.com/books/view/667328

和弦语言：和弦绘画图例 https://www.smashwords.com/books/view/824548

Chord Language-Chord Painting Legend https://www.smashwords.com/books/view/951300

Chord Language: Chord Space-Time And Chord Painting https://www.smashwords.com/books/view/955364

ORCID: https://orcid.org/0000-0001-6461-1239 